\title{
Epigenetic Regulation of Gene Expression in Physiological and Pathological Brain Processes
}

\author{
JOHANNES GRÄFF, DOHOON KIM, MATTHEW M. DOBBIN, AND LI-HUEI TSAI
}

Picower Institute for Learning and Memory, Department of Brain and Cognitive Sciences, Massachusetts Institute of Technology (MIT); Stanley Center for Psychiatric Research, Broad Institute of MIT and Harvard

University; and Howard Hughes Medical Institute, MIT, Cambridge, Massachusetts

$\begin{array}{ll}\text { I. Introduction } & 604\end{array}$

II. Terminology $\quad 605$

$\begin{array}{ll}\text { A. Epigenetic modifications of the DNA } & 605\end{array}$

B. Epigenetic modifications of histones $\quad 606$

$\begin{array}{ll}\text { C. Nucleosome remodeling } & 608\end{array}$

III. Physiological Functions of Epigenetic Regulation in the Cns 608

A. Development of the nervous system and cellular differentiation 608

B. Synaptic plasticity $\quad 612$

C. Learning and memory $\quad 615$

$\begin{array}{ll}\text { D. Neuroprotection } & 619\end{array}$

IV. Pathological Epigenetic Regulation I: Developmental Disorders 620

A. Rubinstein-Taybi syndrome $\quad 620$

B. Rett syndrome $\quad 622$

C. Fragile x syndrome $\quad 622$

D. Other developmental disorders 623

V. Pathological Epigenetic Regulation II: Psychiatric Disorders 624

$\begin{array}{ll}\text { A. Addiction } & 624\end{array}$

$\begin{array}{lr}\text { B. Depression } & 627\end{array}$

$\begin{array}{lr}\text { C. Schizophrenia } & 628\end{array}$

$\begin{array}{ll}\text { D. Vulnerability to stress } & 629\end{array}$

VI. Pathological Epigenetic Regulation III: Neurodegenerative Disorders 632

A. Huntington's disease

B. Alzheimer's disease $\quad 633$

C. Parkinson's disease $\quad 634$

D. Other neurodegenerative diseases

VII. Pathological Epigenetic Regulation IV: Other Brain Disorders 635

A. Glioma $\quad 635$

$\begin{array}{ll}\text { B. Stroke/Ischemia } & 637\end{array}$

$\begin{array}{ll}\text { C. The aging brain } & 637\end{array}$

VIII. Synopsis and Outlook 637

$\begin{array}{ll}\text { A. Clinical considerations } & 638\end{array}$

$\begin{array}{ll}\text { B. Future directions } & 638\end{array}$

Gräff J, Kim D, Dobbin MM, Tsai L-H. Epigenetic Regulation of Gene Expression in Physiological and Pathological Brain Processes. Physiol Rev 91: 603-649, 2011; doi:10.1152/physrev.00012.2010.—Over the past decade, it has become increasingly obvious that epigenetic mechanisms are an integral part of a multitude of brain functions that range from the development of the nervous system over basic neuronal functions to higher order cognitive processes. At the same time, a substantial body of evidence has surfaced indicating that several neurodevelopmental, neurodegenerative, and neuropsychiatric disorders are in part caused by aberrant epigenetic modifications. Because of their inherent plasticity, such pathological epigenetic modifications are readily amenable to pharmacological interventions and have thus raised justified hopes that the epigenetic machinery provides a powerful new platform for therapeutic approaches against these diseases. In this review, we give a detailed overview of the implication of epigenetic mechanisms in both physiological and pathological brain processes and summarize the state-of-the-art of "epigenetic medicine" where applicable. Despite, or because of, these new and exciting findings, it is becoming apparent that the epigenetic machinery in the brain is highly complex and intertwined, which underscores the need for more refined studies to disentangle brain-region and cell-type specific epigenetic codes in a given environmental 
condition. Clearly, the brain contains an epigenetic "hotspot" with a unique potential to not only better understand its most complex functions, but also to treat its most vicious diseases.

\section{INTRODUCTION}

During the first decade after the completion of the Human Genome Project, much of molecular biology's focus has been shifted from the raw sequence of genes to their regulation over time and in response to intra- and extracellular stimuli. Much like a book on a shelf, genes do not exert effects by their mere presence; rather, the pages of the book, i.e., the chromatin, need to be opened first so that the words, i.e., the genes, can be read and interpreted accordingly. The "epigenetic" regulation of gene expression precisely refers to this process. The term epigenetics derives from the greek prefix epi, which literally means "on" or "above," and thus defines what is occurring on the physical support of the genes, the chromatin.

The developmental biologist Conrad Hal Waddington (1905-1975) coined the term epigenetics in 1940, and defined it as "...the interactions of genes with their environment which bring the phenotype into being" (351). By this explanation, he had already described the first of two important characteristics of epigenetic processes, which is their plasticity. In 1942, Waddington extended his original definition stating "... it is possible that an adap- tive response can be fixed without waiting for the occurrence of a mutation..." (350), and thereby framed the second important aspect of epigenetic processes, which is their potential heritability and, thus, long-term stability. Owing to this Janus-faced property, epigenetic mechanisms provide an organism with the molecular means to promptly react to environmental contingencies with stable alterations in gene expression.

The brain is arguably one of the most complex tissues, in part because it enables its bearer to readily sense, and enduringly remember, its environment. With our current knowledge of neuroscience, it therefore seems obvious that epigenetic mechanisms must operate during the development of the central nervous system (CNS), in synaptic plasticity and during learning and memory. However, when Francis Crick (1916-2004) in 1984 proposed that "memory might be coded in alterations to particular stretches of chromosomal DNA" (67), the echo in the scientific community was rather modest (Fig. 1). It took another 20 years until histone acetylation, a common form of epigenetic modification, was for the first time shown to be dynamically altered during memory formation (187). Since then, however, the number of studies addressing epigenetic mechanisms in the CNS has

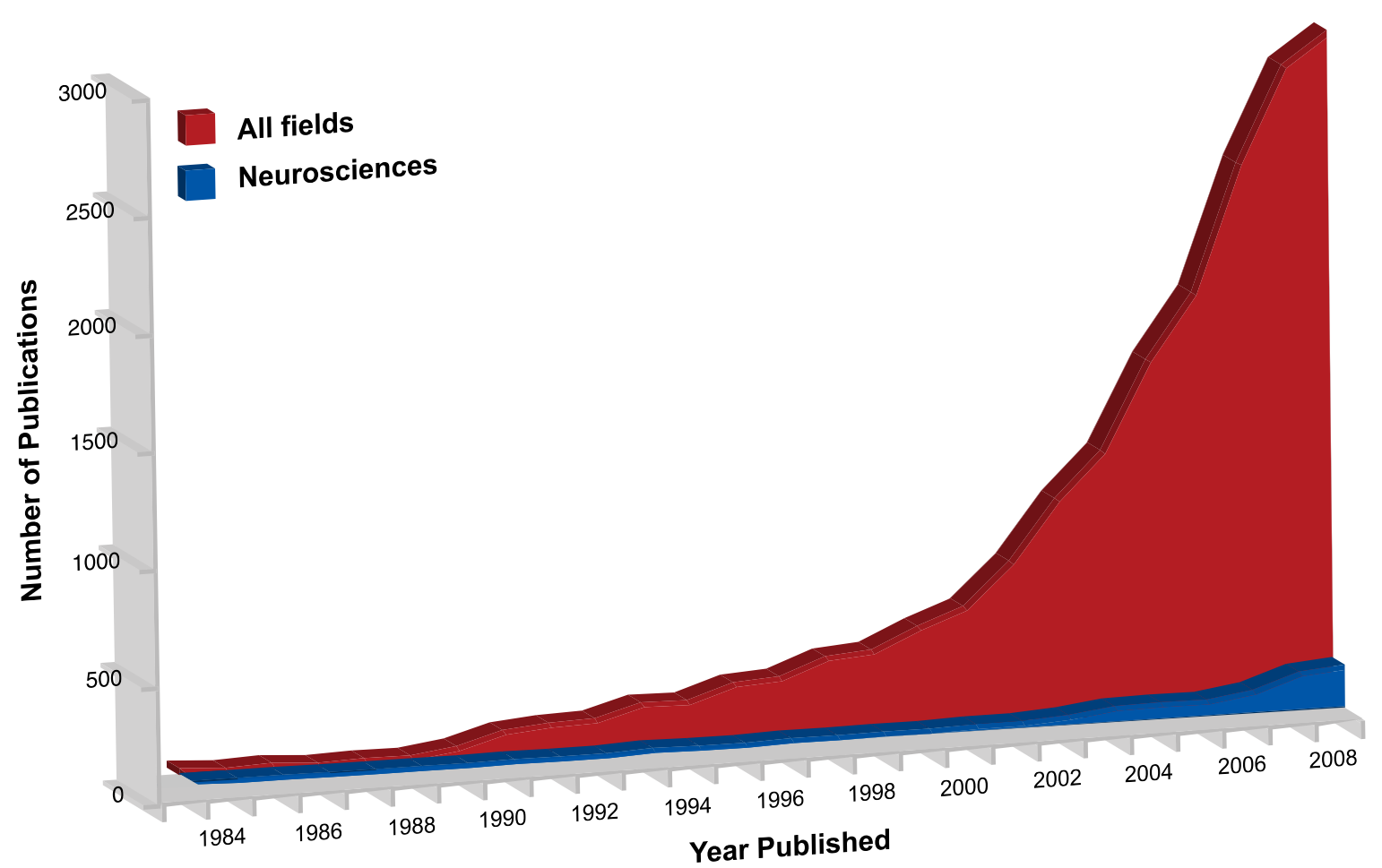

FIG. 1. Development of the number of citations including the term epigenetic. Shown is the number of citations per year that include the term epigenetic in all research fields combined, and in the field of neurosciences. Citation numbers were retrieved from PubMed (http://www.ncbi.nlm.nih.gov/sites/entrez). 
steadily increased (Fig. 1), and with them the awareness that, not only do epigenetic mechanisms play pivotal roles in normal CNS functions, but their dysregulation also underlies a variety of CNS diseases. In this review, we give a detailed account of the implication of epigenetic mechanisms in physiological CNS functions, and outline the current knowledge of aberrant epigenetic programs in neurodevelopmental, psychiatric, and neurodegenerative disorders. Because aberrant epigenetic programs are potentially reversible, we also review the state-of-the-art of approaches to counteract epigenetic dysfunction in CNS disorders. Finally, we discuss where the study of epigenetics in the CNS might lead in the future.

\section{TERMINOLOGY}

Epigenetics is most commonly defined as "the study of mitotically and/or meiotically heritable changes in gene function that cannot be explained by changes in DNA sequence" (295). This definition, however, is not particularly well suited for the nervous system in which there is an overall absence of mitosis. We therefore propose a more recent definition of epigenetics for the purpose of this review, which reads epigenetics as "the structural adaptation of chromosomal regions so as to register, signal, or perpetuate altered activity states" (27). In this definition, the three major levels of epigenetic changes are embodied (Fig. 2): 1) chemical modifications at the level of the nucleotides, which include DNA methylation and RNA interference (RNAi); 2) modifications at the level of histones that encompass posttranslational modifications (PTMs) of histone proteins and the incorpora- tion of histone variants; and 3) nucleosome remodeling, which refers to ATP-dependent processes that regulate the accessibility of nucleosomal DNA. We first give a brief overview of each of these modifications, and then describe their implications for CNS function in more detail in the relevant sections.

\section{A. Epigenetic Modifications of the DNA}

\section{DNA methylation}

DNA methylation refers to the covalent addition of a methyl group from the methyl donor $S$-adenosylmethionine (SAM) to a cytosine base within the DNA. This reaction is catalyzed by a family of DNA methyltransferases (DNMTs), with DNMT1 being the main enzyme in mammals (177). DNA methylation most often occurs on $\mathrm{CpG}$ dinucleotides, but several instances of non-CpG methylation have also been found in mammals (279). Most CpG dinucleotide methylation occurs outside of CpG-rich clusters, called CpG islands. DNA demethylation can be passive, when it is simply the absence of methylation maintenance, or active, via the actions of recently discovered enzymes such as DNA glycolases (372).

Traditionally, DNA methylation in the promoter region of a gene has been associated with decreased transcriptional activity (289). This is because DNA methylation can inhibit the binding or transcription factors directly by "masking the DNA" or indirectly, by recruiting methyl-CpG binding proteins (MBPs), which possess repressive chromatin-remodeling activities $(26,167)$. How-
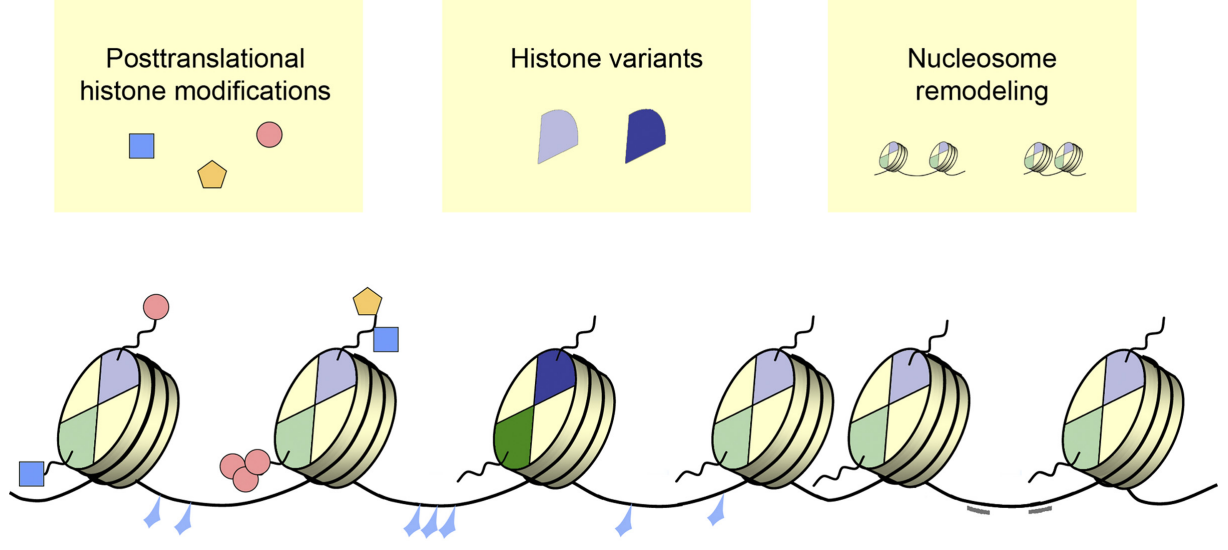

FIG. 2. Overview of possible epigenetic modifications. Inherent to all types of epigenetic modifications is the regulation of the accessibility of the chromatin structure to the transcription machinery. See text for more details. [Modified from Gräff and Mansuy (113), with permission from Elsevier.]

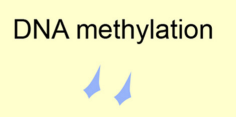

RNA interference

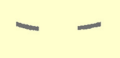


ever, as highly methylated stretches of DNA have also been found in the promoter and coding regions of actively transcribed genes, the functional impact of DNA methylation on transcriptional activity is not that clear-cut (325, 362 ).

DNA methylation is abundant on permanently silenced imprinted genes, and thus has often been viewed as a stable epigenetic modification. However, it is now clear that DNA methylation is a highly dynamic process that is fully reversible, making the aberrant DNA methylation patterns found in some cancers and in various disorders of the nervous system potentially amenable to pharmacological treatments.

\section{2. $R N A i$}

Epigenetic alterations of the DNA can also be produced by double-stranded RNA (dsRNA) and protein components of the RNAi machinery. Here, it is thought that small RNAs produced by cleavage of dsRNA serve as sequence-specific facilitators to guide other enzymes of the epigenetic machinery into place (222). Thus, when members of the RNAi machinery such as the genes piwi and homeless in Drosophila melanogaster are mutated, centromeric heterochromatin formation is inhibited. Likewise, in the fission yeast Schizosaccharomyces pombe, deletions of genes involved in the RNAi machinery, such as argonaute, result in reduced heterochromatin formation, which is accompanied by reduced histone methylation on lysine (K) 9 on histone $(\mathrm{H}) 3$, a marker of transcriptional repression (181). In mammals, additionally, short-interfering RNAs (siRNAs) were shown to induce DNA methylation alongside H3 methylation, resulting in decreased levels of gene expression (222). Noncoding RNAs, therefore, have a conserved epigenetic role in gene repression both at the transcriptional and posttranscriptional level.

\section{B. Epigenetic Modifications of Histones}

\section{Posttranslational histone modifications}

Histones are basic proteins that regulate the compaction of the chromatin. Histones consist of a globular histone core and a loosely structured $\mathrm{NH}_{2}$-terminal histone tail, which protrudes out of the tight histone-DNA assembly termed the nucleosome. A nucleosome consists of an octamer of the four core histones H2A, H2B, H3, and H4 in duplicates, around which 147 base pairs of DNA are wrapped to form the 10-nm-thick primary structure of the chromatin (Fig. 3A). Nucleosomes are linked together by the linker histone $\mathrm{H} 1$, which is not part of the nucleosome per se. PTMs can occur on all histones, and although the shorter COOH-terminal tail of the core histones can also undergo modification, the majority of histone PTMs oc- curs on the $\mathrm{NH}_{2}$-terminal tail and consists of acetylation, methylation, phosphorylation, ubiquitination, and sumoylation. Due to their chemical properties, these epigenetic modifications are capable of altering the condensation of the chromatin and, as a consequence, the accessibility of the DNA to the transcriptional machinery.

A) ACETYLATION. Histones can become acetylated on lysine $(\mathrm{K})$ residues (Fig. $3 B$ ). Histone acetylation has been linked to transcriptional activation, since the acetyl group addition neutralizes the positive charge of the $\epsilon$-amino group of the lysine, leading to decreased affinity between the histone tail and the negatively charged DNA (37). The enzymes regulating histone acetylation consist of the histone acetyltransferases (HATs) and histone deacetylases (HDACs), the latter of which is divided into two functional categories. Eleven zinc-dependent HDACs comprise the class I, IIa, IIb, and IV HDACs, in addition to the seven members of the class III $\mathrm{NAD}^{+}$-dependent HDACs, the sirtuins (156). It is interesting to note that some acetylateable residues are functionally more consequential than others. For instance, in the yeast Saccharomyces cerevisiae, H4K16 affects its own subset of genes, whereas other genes are overlappingly regulated by all of H4K12, K8, and K5 acetylation marks, but not by K16 (75).

B) METHYLATION. Histone methylation occurs on both lysine and arginine $(\mathrm{R})$ residues (Fig. $3 B$ ). This epigenetic modification is a double-edged sword in terms of its effect on transcriptional activity, as it has been shown to associate with both transcribed and silenced genes (168, 271). Moreover, arginine residues can be both mono- and dimethylated, and lysine residues can be mono-, di-, and trimethylated. These degrees of histone methylation can have differing roles on the regulation of gene expression (312), most likely because effector proteins, such as transcriptional coactivators, recognize mono-, di-, and trimethylated epitopes with different affinities (168). For example, monomethylated H3K4 has been found on both expressed and repressed genes, whereas trimethylated H3K4 is exclusively associated with silenced genes (192). Finally, the exact location of the methylation within a given genetic region is crucial for determining its effect on gene transcription. H3K9 methylation within the coding region of a gene has been found to correlate with the gene being expressed, whereas the same modification is associated with inactive transcription when found in the promoter region of a gene (192). Enzymatically, histone methylation is controlled by histone methyltransferase (HMTs) specific to K and $\mathrm{R}$ residues (312), as well as by histone demethylases (HDMs) such as peptdidylarginine deiminase (PADI), jumonji-C domain containing histone demethylases (JMJCs), and lysine-specific demethylases (LSDs) (168).

C) PHOSPHORYLATION. Histone phosphorylation occurs on serine $(\mathrm{S})$, threonine $(\mathrm{T})$, and tyrosine $(\mathrm{Y})$ residues and 


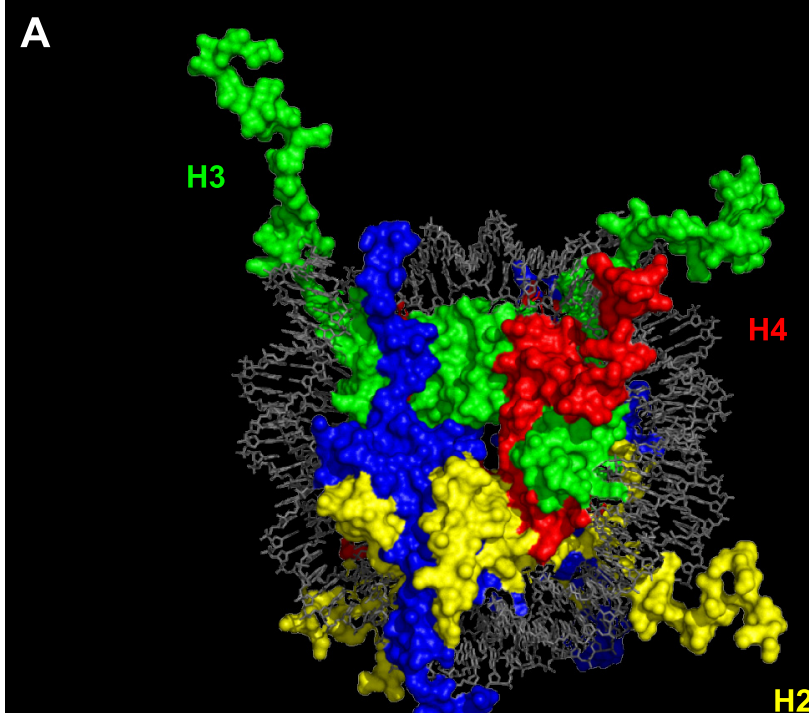

$147 \mathrm{bp}$ (1.65 turns)

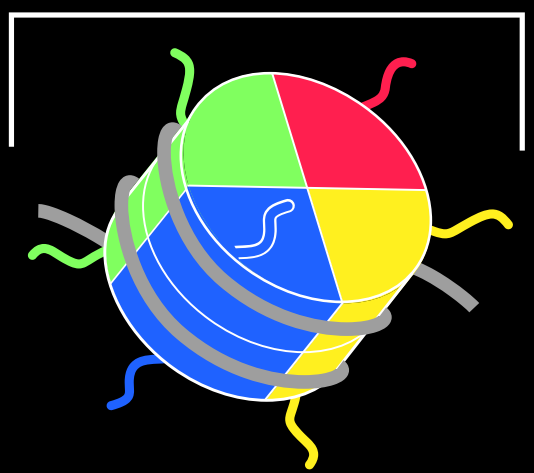

B
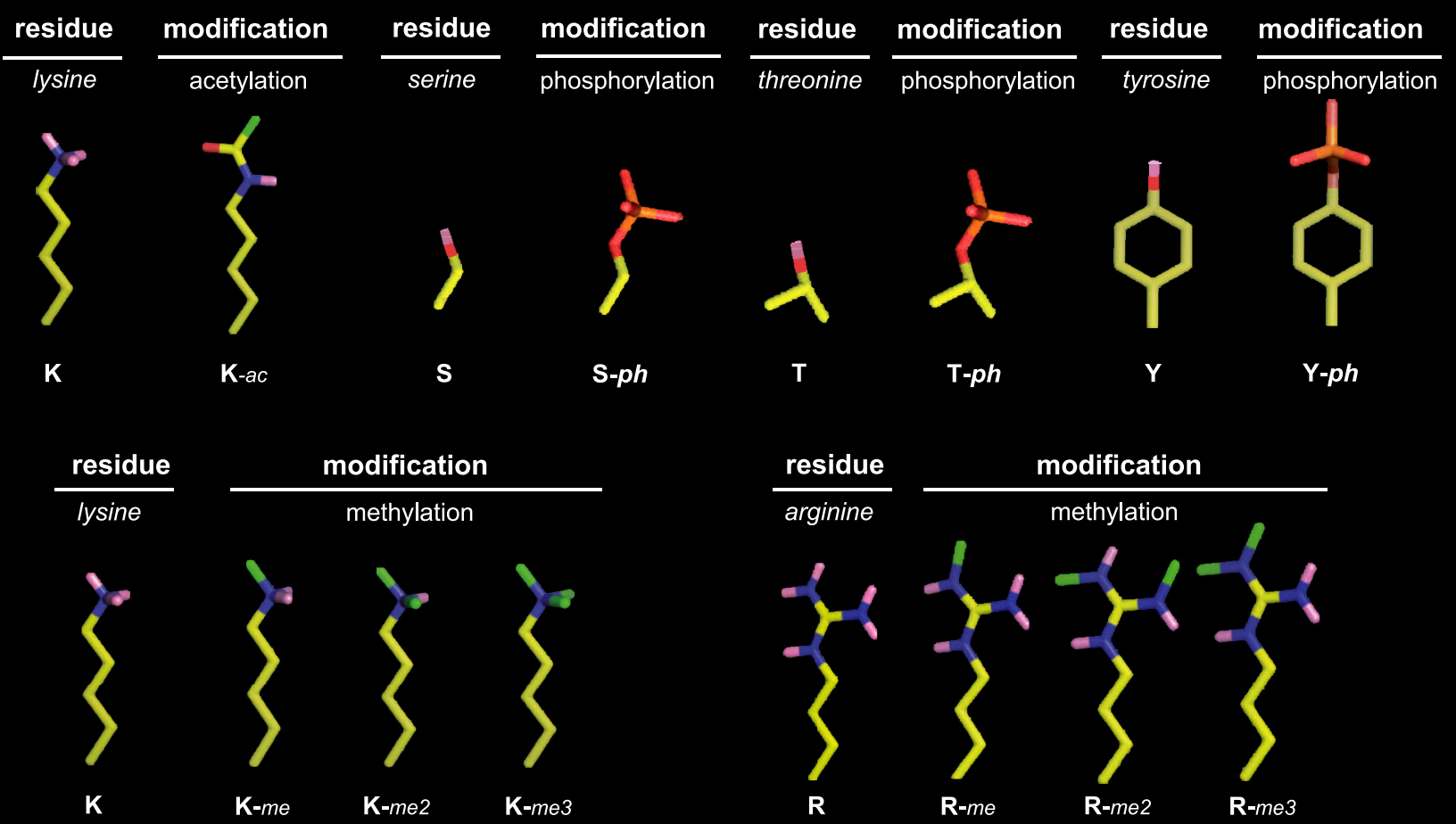

modification

methylation

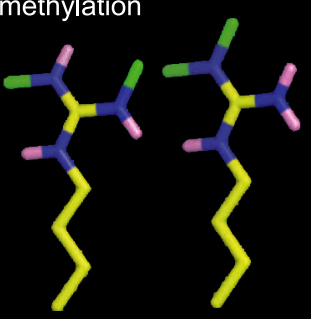

$\mathbf{R}$

R-me

$\mathbf{R}-m e 2$

R-me3

FIG. 3. The nucleosomal core particle and the most common posttranslational histone modifications. A, left: X-ray crystallographic representation of the nucleosome heteroctameric protein core with DNA wrapped around it. Histone components are visualized by electrostatic surface representation and have been color-coded for ease of viewing: histone H2A, blue; histone H2B, yellow; histone H3, green; histone H4, red. DNA is represented in stick and ball format and is colored gray. Right: schematic representation of the figure at left, utilizing identical color-coding schemes. [Adapted from Luger et al. (208), with permission from Nature Publishing Group.] B: stick illustrations of the major histone posttranslational modifications covered in this review. The unmodified side chain of posttranslationally modifiable residues is first presented, followed by representations of the residue on which the posttranslational modification has occurred at respective sites. Abbreviations are as follows: K, lysine; $\mathrm{R}$, arginine; $\mathrm{Y}$, tyrosine; $\mathrm{S}$, serine; $\mathrm{T}$, threonine; -ac, acetylation; -me, monomethylation; -me2, dimethylation; -me3, trimethylation; -ph, phosphorylation. The color code is as follows: yellow, carbon; blue, nitrogen; pink, polar hydrogen; red, oxygen; orange, phosphorus; green, methyl groups of posttranslational modifications. [Modified from Taverna et al. (335), with permission from Nature Publishing Group.] 
is most commonly associated with transcriptional activation (203), because the negative charge of the phosphate group creates a repulsive force between the histone and the negatively charged DNA (Fig. 3C). Histone phosphorylation is regulated by protein kinases (PKs) and protein phosphatases (PPs) (116). Histone phosphorylation is perhaps the most intriguing histone modification in the CNS insofar as it establishes a direct link between the epigenetic machinery and important intraneuronal signaling pathways that heavily utilize protein kinases and phosphatases (189).

D) UBIQUitination. Histone ubiquitination refers to the attachment of the 76-amino acid protein ubiquitin to the histone core proteins $\mathrm{H} 2 \mathrm{~A}$ and H2B. H2A and H2B ubiquitination have different consequences on the transcription of the gene on which they are located. Whereas H2A ubiquitination is considered repressive, H2B ubiquitination has been associated with both active and repressed genes (357). Interestingly, H2A and H2B ubiquitination and histone methylation often cross-talk, in particular via $\mathrm{H} 3 \mathrm{~K} 4 \mathrm{di}-$ and trimethylation. $\mathrm{H} 2 \mathrm{~B}$ ubiquitination is thought to be a prerequisite for H3 methylation, but H2A inhibits this methylation $(312,357)$.

E) SUMOYLATION. Lastly, histones can be sumoylated. SUMO proteins are similar to ubiquitin, roughly 100 amino acids long and added to their targets by specific ligases, the actions of which are reversed by proteases (103). Histone sumoylation is a mark of transcriptional repression $(252,311)$, because of its interaction with other repressor complexes and by its prevention of histone acetylation (103).

\section{Histone variants}

Histone variants result from sequential and structural variations of the core histones. These variations can comprise the replacement of large groups of amino acids in the histone tails, in the globular central domains, or entail only a few amino acid substitutions (192). Whereas the four core histones are incorporated into the nucleosomal structure exclusively during DNA replication, histone variants can be integrated into specific regions of the genome throughout the cell cycle. Their integration can then alter the local regulation of gene transcription (275, 333). Because the core histones and their variants are structurally similar, they can be readily exchanged, although the precise mechanisms behind this operation are not fully understood.

In some cases, single histones, or even entire histone octamers, can be displaced in a phenomenon termed "histone eviction," which has a profound impact on the compaction of chromatin and, thus, on gene transcription (192).

\section{Nucleosome Remodeling}

Nucleosome remodeling refers to the process by which change in the structure of chromatin is produced and which requires a net energy input. Nucleosome remodeling is carried out by enzymes that are catalytically dependent on ATP as an energy source. In eukaryotes, these enzymes are defined by containing the SWI/SNF subunit of ATPases (79). With ATP as a substrate, they facilitate the sliding of histone octamers to adjacent DNA sequences and thereby the enrichment of accessible DNA on the surface of nucleosomes (for a review, see Ref. 19).

With all these levels of possible epigenetic modifications, it is important to realize that epigenetic mechanisms are part of a highly complex and interwoven network, including multiple positive and negative feed-forward and feedback pathways (e.g., Refs. 43, 181, 183) that span both the DNA and the histone level as well as higher order chromatin structure. As a result, on many occasions, several epigenetic modifications are found to be jointly altered, although the precise mechanisms behind these observations remain only poorly understood.

\section{PHYSIOLOGICAL FUNCTIONS OF EPIGENETIC REGULATION IN THE CNS}

The epigenetic regulation of gene expression plays an important role in such diverse processes as the development and differentiation of the nervous system, synaptic plasticity, learning and memory, as well as the maintenance and survival of neurons. In the following sections, we describe in detail the implications of epigenetic mechanisms for each of these physiological processes.

\section{A. Development of the Nervous System and Cellular Differentiation}

Any given tissue of an organism consists of specific cell types that have acquired precise and well-defined functions during development, a process called differentiation. Differentiated cells originate from a common precursor cell through the activation of genes important for that given tissue, and the silencing of genes that are not. Epigenetic mechanisms regulating gene expression arose as potential candidates to confer such tissue-specific gene expression (193). Indeed, Waddington himself in 1957 had already proposed that a cell differentiates into its final destination by taking specific paths throughout the "epigenetic landscape" (352, reviewed in Ref. 317; Fig. 4A).

This is also true for the nervous system and its three major cell types: neurons, astrocytes, and oligodendrocytes. These cell types have their origin in neural stem cells (NSC), multipotent, predifferentiated stem cells that will develop into neuronal and glial lineages, but that 
A

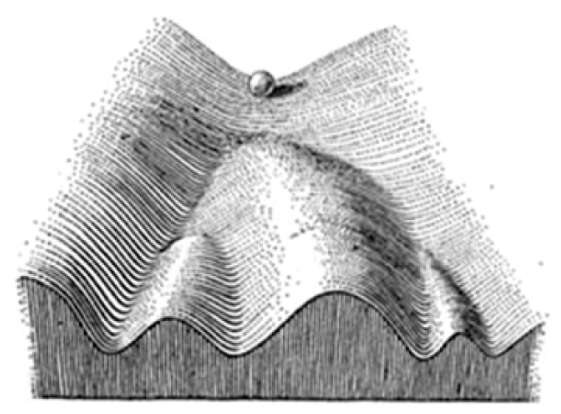

C

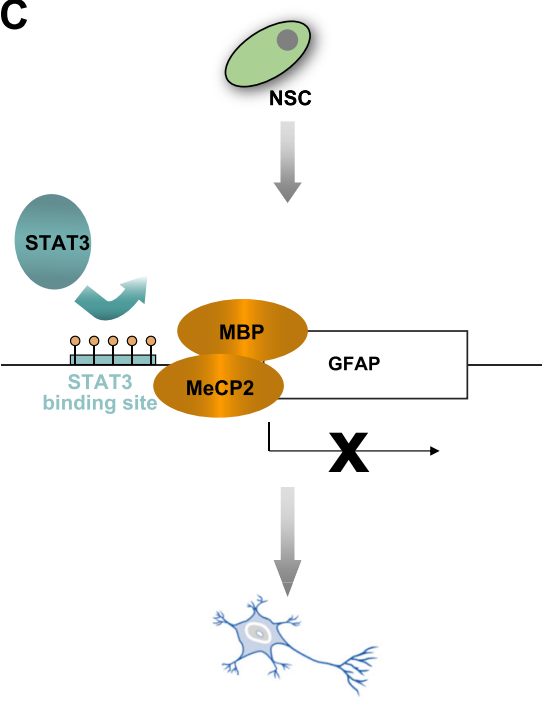

Non-astrocyte cell type, e.g. neuron

B

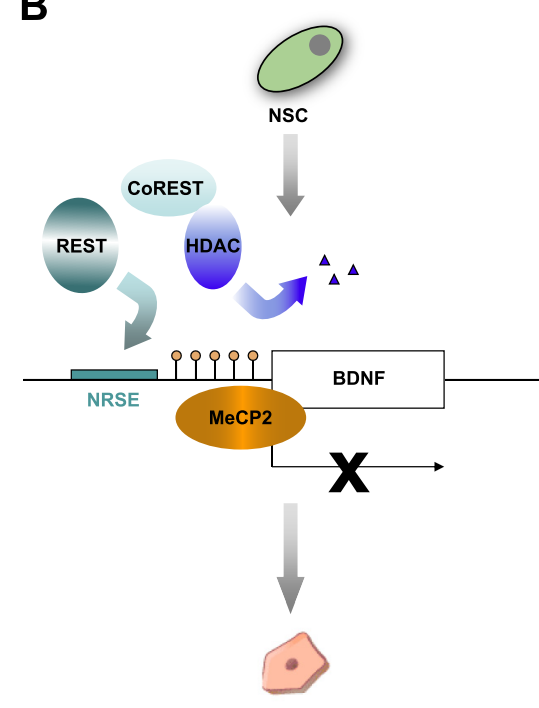

Non-neuron cell type, e.g. epithelial cell

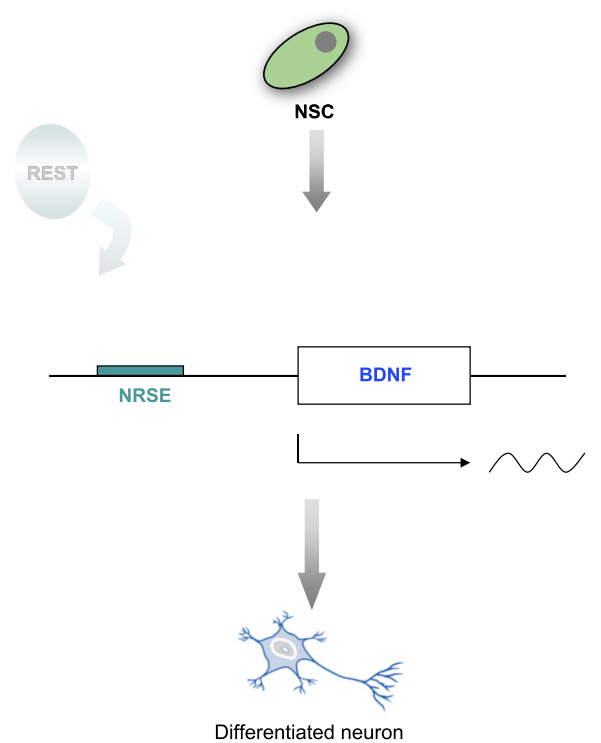

Differentiated neuron

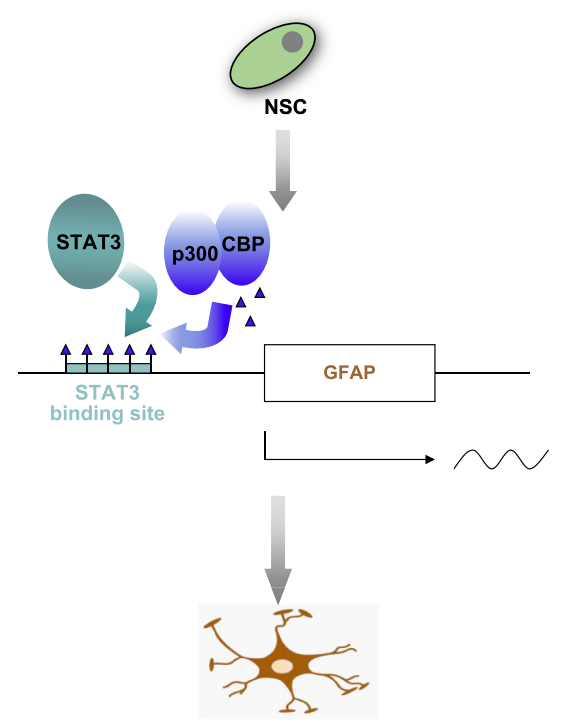

Differentiated astrocyte
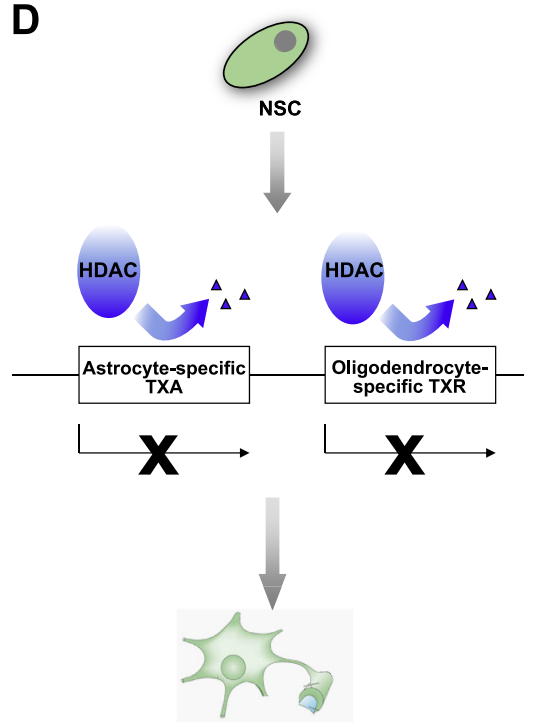

Differentiated oligodendrocyte

FIG. 4. Epigenetic mechanisms in the development of the nervous system. A: a drawing by the developmental biologist Conrad Hal Waddington (1905-1975) depicting his vision of an "epigenetic landscape." The ball represents a cell, which has the potential to travel along various developmental "valleys," i.e., paths. These valleys are surrounded by hills that are made up of specific epigenetic codes and thus define the developmental trajectory. In the case of the nervous system, this cell would be a neuronal stem cell. [From Slack (317), with permission from Nature Publishing Group.] B: schematic illustrating an example of epigenetic mechanisms at play during neuronal development. Left: future non-neuronal cell types, e.g., epithelial cells, are characterized by the binding of the transcriptional repressor REST to the NRSE element in the promoter region of neuronal genes such as BDNF. This binding subsequently triggers the recruitment of an epigenetic silencing machinery constituted by MeCP2 as well as HDACs, which increase DNA methylation and decrease histone acetylation, respectively. As a result, neuronal genes are silenced in nonneuronal cell types. Right: in neurons, REST is not active and neuronal genes can be transcribed. $C$ : schematic illustrating an example of epigenetic mechanisms at play during astrocyte development. Left: in non-astrocytic cell types such as neurons, the promoter region of the astrocyte-specific gene GFAP is highly methylated and bound by MeCP2 and MBP proteins, which prevents the transcription factor STAT3 from binding and GFAP from being expressed. Right: during astrocyte differentiation, the STAT3 binding site is no longer methylated, but instead its histones hyperacetylated by p300 and CBP, which allows STAT3 to bind and GFAP expression to occur. $D$ : schematic illustrating two examples of epigenetic mechanisms at play during oligodendrocyte development. Unlike neurons and astrocytes, the differentiation of oligodendrocytes is characterized by an overall decrease in histone acetylation, which has been shown to occur on non-oligodendrocyte-specific transcriptional activators, and on oligodendrocyte-specific transcriptional repressors. Both mechanisms allow for the expression of oligodendrocyte-specific transcriptional programs. Note that histone methylation is also involved in this process, but not depicted here. See text for gene names and more details. 
retain the ability to self-renew (100). During neurodevelopment, neurons differentiate first, followed by astrocytes and oligodendrocytes during late gestation (336). Therefore, during the course of early and midgestation, only neuronal genes must be active in the pool of neuronal stem cells that are later to become fully differentiated neurons.

\section{Neural differentiation}

The best-described pathway guiding neural differentiation involves the selective inactivation of neuronal genes in non-neuronal tissue via the regulatory element neuron-restrictive silencer element (NRSE) in their promoter region (241) (Fig. 4B). The NRSE is a 21- to 24-bplong sequence present upstream of the start codon of neuronal genes, which was first described to silence the expression of the type II sodium channel in non-neuronal cultured rat cells, and of the synapsin I gene in human cell lines $(195,223)$. The precise functioning of this element remained, however, unclear, although it was speculated that the NSRE acts through the additional binding of transcriptional repressors (241).

The first such repressor identified to bind the NRSE was RE1-silencing transcription factor (REST) (57). The in vitro expression of a recombinant REST protein in neuronal cells, which normally lack the native REST protein, resulted in increased silencing of neuronal genes. Conversely, the expression of a dominant-negative form of REST in non-neuronal cell types abolished the silencing function of the normal protein (57). The deletion of REST during embryonic development in vivo further caused a derepression of neuron-specific genes in nonneuronal cell types and led to embryonic lethality (52). Accordingly, the overexpression of REST in the developing spinal cord of chicken embryos led to increased axon guidance errors due to erroneous gene expression, and consequently to developmental dysfunctions (264). Thus REST-dependent gene silencing has been shown in vitro and in vivo to be a factor determining neuronal cell fate (17).

REST-mediated gene repression involves epigenetic modifications, since the NRSE sequence not only recruits REST, but also several corepressors. Among these corepressors is methyl-CpG-binding protein 2 (MeCP2), and DNA methylation in the promoter region of various genes such as sodium channel type II, brain-derived neurotrophic factor (BDNF), and calbindin has been shown to be required for their transcriptional silence $(16,209)$. Remarkably, this DNA methylation does not seem to be confined to the actual NRSE sequence alone, but extends several thousand base pairs up- and downstream of the NRSE region, indicating a silencing effect that includes neighboring genes (209). Of note, REST binding to the NRSE in the promoter region of calbindin was further decreased when sources of maternal choline were restricted, which led to increased expression levels of calbindin and disrupted neural development (230). This effect was accompanied by decreased H3K9 methylation and increased DNA methylation, suggesting a hitherto unidentified cross-talk between histone and DNA methylation during neural differentiation.

In addition to REST, other corepressors associated with the NRSE element include mSin3 and CoRest (9, 139, 251), which complex with HDACs type I and type II, respectively $(15,139,251,290)$. These findings suggest that NRSE/REST-mediated gene silencing in developing nonneuronal cells requires both decreased histone acetylation and increased DNA methylation, two epigenetic modifications that condense the chromatin.

But also outside the NRSE/REST pathway does chromatin remodeling, in particular chromatin decondensation at neuron-specific genes play a role in neural development. For instance, treatment of NSCs with HDAC inhibitors (HDACis) such as [ $N$-(2-aminophenyl)-4- $N$-(pyridine-3-ylmethoxycarbonyl)aminomethyl]benzamide (MS-275) and suberoylanilide acid (SAHA) promoted neural differentiation via increased expression levels of the neuron-specific transcription factor NeuroD (314). NeuroD is also stimulated by the HAT complex p300/CREB-binding protein (CBP) that is regulated by neurogenin (324). Likewise, neuronspecific transcriptional activity of the inhibitor of cyclindependent kinase I (Cdkn1c) is accompanied by elevated H3K9/K14 acetylation levels (12). Most likely, these effects are the result of the concerted action of decreased HDAC activity and increased HAT activity in differentiating neurons. Correspondingly, leucine-rich acidic nuclear protein (LANP), a member of the inhibitor of HAT complex (INHAT), constrains neurite outgrowth, which is accompanied by reduced histone acetylation at the neurofilament light chain (NFL) promoter (174). Neural differentiation appears, therefore, to be characterized by elevated histone acetylation levels at neuron-specific genes.

Similarly, the patterns of histone methylation at neuron-specific genes also seem to reflect chromatin-relaxing mechanisms. Two recent studies found that H3K4 dimethylation, a marker of transcriptional activity, was enhanced in the promoter region of neuron-specific opioid receptors, whereas H3K9 trimethylation, a marker of transcriptional repression, was reduced $(51,265)$. Another study found that the histone H3K27-specific histone demethylase JMJD3 is necessary for neural differentiation, as it demethylates H3K27, a modification indicating transcriptional repression, at the neuron-specific nestin promoter (38).

Furthermore, several studies indicate that DNA methylation in NSCs needs to be reduced for neural commitment to occur. A deficiency in methylated CpG binding protein 1 (MBD1), a member of the MBPs, promoted 
increased neural differentiation of NSCs, presumably via the reduced repression of fibroblast growth factor 2 (FGF2), which maintains NSCs in their multipotent state (196). Likewise, reduced DNA methylation, and a concomitant increase in histone acetylation, were also detected in the enhancer regions of SOX2 in proliferating NSCs (315).

These findings suggest that the expression of neuronspecific genes during neural commitment is guaranteed by an overall relaxation of the chromatin structure via increased histone acetylation, residue-specific histone methylation changes, and decreased DNA methylation. At least in the case of DNA methylation, however, it has to be noted that a reduction in DNA methylation is only beneficial for neural differentiation when it occurs on neuronspecific genes. A recent study has indeed found that the hypomethylated cortical neurons of conditional DNMT1 knockout mice exhibit impaired neuronal excitability and increased neuronal cell death (141). In addition, shRNAmediated silencing of DNMT3b also reduced neuronal differentiation (14). It is therefore important to extend the existent examples to genome-wide epigenetic analyses to prove their overall validity. In this respect, it will be of great value to compare the epigenomic and transcription profiles between NSCs and fully differentiated cells of the nervous system, and also between differentiated cell types.

Lastly, it remains to be noted that the composition of core histone variants also changes during neural differentiation (31), but the functional consequence of this change remains unknown.

\section{Astrocytic differentiation}

Astrocyte differentiation occurs during late gestation and is characterized by the activation of the transcription factor Janus kinase signal transducer and activator of transcription 3 (STAT3) (16). Activated STAT3 binds to the promoter regions of astrocyte-specific proteins such as glial fibrillary acidid protein (GFAP) and induces their expression (Fig. 4C). Several studies imply a role for epigenetic mechanisms in governing GFAP expression. During early and mid-gestation, the STAT3-binding element in the GFAP promoter is methylated, preventing STAT3 from binding and the astrocytes from differentiating (332). Accordingly, the conditional knock-out of DNMT1 in NSCs resulted in precocious astrocytic differentiation (81). GFAP expression is further absent from differentiated neurons, in which the STAT3 element is also methylated and bound by MeCP2 and MBPs (250). Importantly, as a recent genome-wide DNA methylation profiling study revealed, DNA methylation until midgestation is not restricted to genes containing a STAT3 element, but also occurs on other astrocyte-specific genes, such as the glial potassium channel KCNJ10 (130).
In addition to DNA demethylation, chromatin-decondensing histone PTMs are also implicated in regulating GFAP expression in astrocytes. During astrocytic differentiation, the HAT CBP is recruited to the STAT3-binding element in the GFAP promoter by fibroblast growth factor 2 (FGF2), which is accompanied by increased H3K4, and decreased H3K9, methylation (332), markers of transcriptional activation and repression, respectively (192). The HAT p300 is also part of the transcriptional complex responsible for the expression of GFAP during astrocytic development (324). Remarkably, the same complex is removed from the GFAP promoter during neural differentiation (324), indicating a timely and highly orchestrated employment of similar epigenetic mechanisms for the differentiation of different cell types.

\section{Oligodendrocytic differentiation}

Oligodendrocytes, the myelin-producing cells of the CNS, develop during late gestation and the early postnatal period. Unlike neural or astrocytic differentiation, oligodendrocytic differentiation is initiated by a global histone deacetylation (217), which confers cell-lineage specificity for developing oligodendrocytes. This deacetylation is thought to operate via two mechanisms (62) (Fig. 4D). On one hand, deacetylation has been shown to inhibit transcriptional activators of other cell lineages such as the glial-specific transcription factor Sox2 (212). On the other hand, the same deacetylation operates to inhibit transcriptional repressors of oligodendrocytic differentiation such as SRY-box containing gene 11 (Sox11) (131). Accordingly, treatment of NSCs with the HDACis MS-275, SAHA or valproic acid (VPA) led to a reduced proportion of oligodendrocytes resulting from higher numbers of neurons and astrocytes $(198,314)$. A recent report identified the types of HDACs involved in oligodendrocyte differentiation (367). When both HDAC1 and HDAC2, but not either enzyme alone, were deleted from the developing oligodendrocytic lineage, all oligodendrocytes were lost, without the neuronal or astrocytic cell population being affected. Mechanistically, the HDAC1/2 double lossof-function resulted in a stabilization of $\beta$-catenin, a member of the Wnt-signaling pathway, which negatively regulates oligodendrocyte differentiation (313). These findings therefore suggest redundant roles for HDAC1 and HDAC2 in the development of oligodendrocytes, which is in contrast to the roles of these two enzymes in learning and memory (see sect. IIIC).

In addition to reduced histone acetylation, the differentiation of oligodendrocytes is further characterized by increased H3K9 dimethylation (309), another indicator of transcriptional repression (192). Subsequently, histone hypoacetylation and H3K9 hypermethylation have been proposed to constitute an oligodendrocyte-specific "epigenetic memory" (310). Such a concept is in agreement 
with the notion of the "histone code" that stipulates that different cell types are characterized by specific histone modifications (150,342), also within the CNS (189). As we will see later, it is precisely this "epigenetic memory" that can become severely disturbed during aging and disease.

\section{Adult neurogenesis}

Mammalian adult neurogenesis refers to the process of the continuous production of new neurons in the subventricular zone and the subgranular layer (SGL) of the dentate gyrus throughout life. The initial indication of the involvement of epigenetic mechanisms in this process came from mice lacking the transcriptional repressor MBD1. These mice have decreased neurogenesis and increased chromosomal instability in the SGL of the dentate gyrus (369). In agreement with a role for DNA methylation in adult neurogenesis, the growth arrest and DNA-damage-inducible protein 45 (GADD45) was shown to act as or to trigger the action of other demethylases (213). GADD45 expression is induced by neuronal activity resulting from behaviors such as the exploration of a novel environment, or electroconvulsive treatment, and GADD45 activity induces the proliferation of adult neuroprogenitors, in part by reducing DNA methylation in the promoter regions of BDNF and FGF1, two genes critical for neurogenesis.

Another hint that epigenetic mechanisms, this time in terms of histone acetylation, are at play during adult neurogenesis was the finding that administration of the HDACi VPA blocked seizure-induced aberrant neurogenesis (151), but the identity of the relevant HDACs and the precise histone acetylation changes have not yet been elucidated. Remarkably, however, another HDACi, sodium butyrate (SB), was recently found to stimulate neurogenesis under ischemic conditions (161). In these instances of adult neurogenesis, therefore, changes in histone acetylation seem to be important, but the relevant mechanisms await further clarification.

Finally, a third line of evidence suggests a criticial role for histone methylation in adult neurogenesis. Mixedlineage leukemia 1 (Mll1), a member of the evolutionarily conserved trithorax group of transcriptional activators, was found to directly bind to the promoter region of the homeobox protein Dlx2, an important regulator of SGL neurogenesis, where it elevated H3K4 trimethylation, a marker of transcriptional activation (192), and increased Dlx2 gene expression (197). Consistently, in Mll1-deficient NSCs, Dlx2 expression was reduced, in part because, in addition to $\mathrm{H} 3 \mathrm{~K} 4$, the repressive chromatin marker H3K27 was strongly increased in the promoter region of Dlx2.

As the original purpose of epigenetic programs was to promote differentiation and define cell fate during development, which includes neurogenesis, future work is likely to identify more chromatin-modifying enzymes and other epigenetic mechanisms involved in promoting adult neurogenesis.

\section{B. Synaptic Plasticity}

After its differentiation is complete, the CNS neuron embarks on its various physiological functions. One important function is the regulation of synaptic plasticity, i.e., the strengthening or weakening of synaptic connections following neuronal activation, often regarded as the molecular correlate of learning and memory (363). Synaptic plasticity has been most extensively studied in the marine mollusk Aplysia califormica as well as in the mammalian hippocampus. Long-lasting forms of synaptic plasticity have been shown to involve changes in the expression of genes involved in synaptic functioning (for review, see Ref. 273), and in recent years, evidence has been accumulating that epigenetic mechanisms play crucial roles in promoting these long-lasting changes (Table 1).

\section{Non-mammalian synaptic plasticity}

In Aplysia, the sensorimotor synapse shows two forms of long-term synaptic plasticity. Long-term facilitation (LTF), which is a lasting, often transcriptional-dependent amelioration of transmission across synapses; and long-term depression, which is a deterioration of such transmission. Importantly, the same synapse can be the site of both forms of synaptic plasticity, and therefore requires an inducible, reversible, and bidirectional molecular "switch" mechanism. In an elegant study using cultured sensory-motor neurons of Aplysia, Guan et al. (122) have shown that the increase and decrease of acetylated histones might constitute such a switch. Long-term facilitation was accompanied by increased binding of the HAT $\mathrm{CBP}$ to the promoter region of $\mathrm{C} / \mathrm{EBP}$, a gene downstream of the CREB transcription factor. Concurrently, H3K14 and H4K8 acetylation, as well as the transcriptional rate of C/EBP, were increased. Long-term depression, on the other hand, was correlated with the opposite effects, in part through the recruitment of HDAC5. Interestingly, administration of the HDAC inhibitor trichostatin A (TSA) resulted in a switch from short- to long-term facilitation upon the same electrical stimulation, suggesting that a global change in acetylation can modify synaptic plasticity in invertebrates.

\section{Mammalian synaptic plasticity}

In mammals, the molecular correlate of long-term memory is termed long-term potentiation (LTP), which is an increase in the efficiency of synaptic transmission as a result of high-frequency stimulation (for a review, see Ref. 28). In the hippocampus, various signaling pathways, in- 
TABLE 1. Epigenetic mechanisms in synaptic plasticity

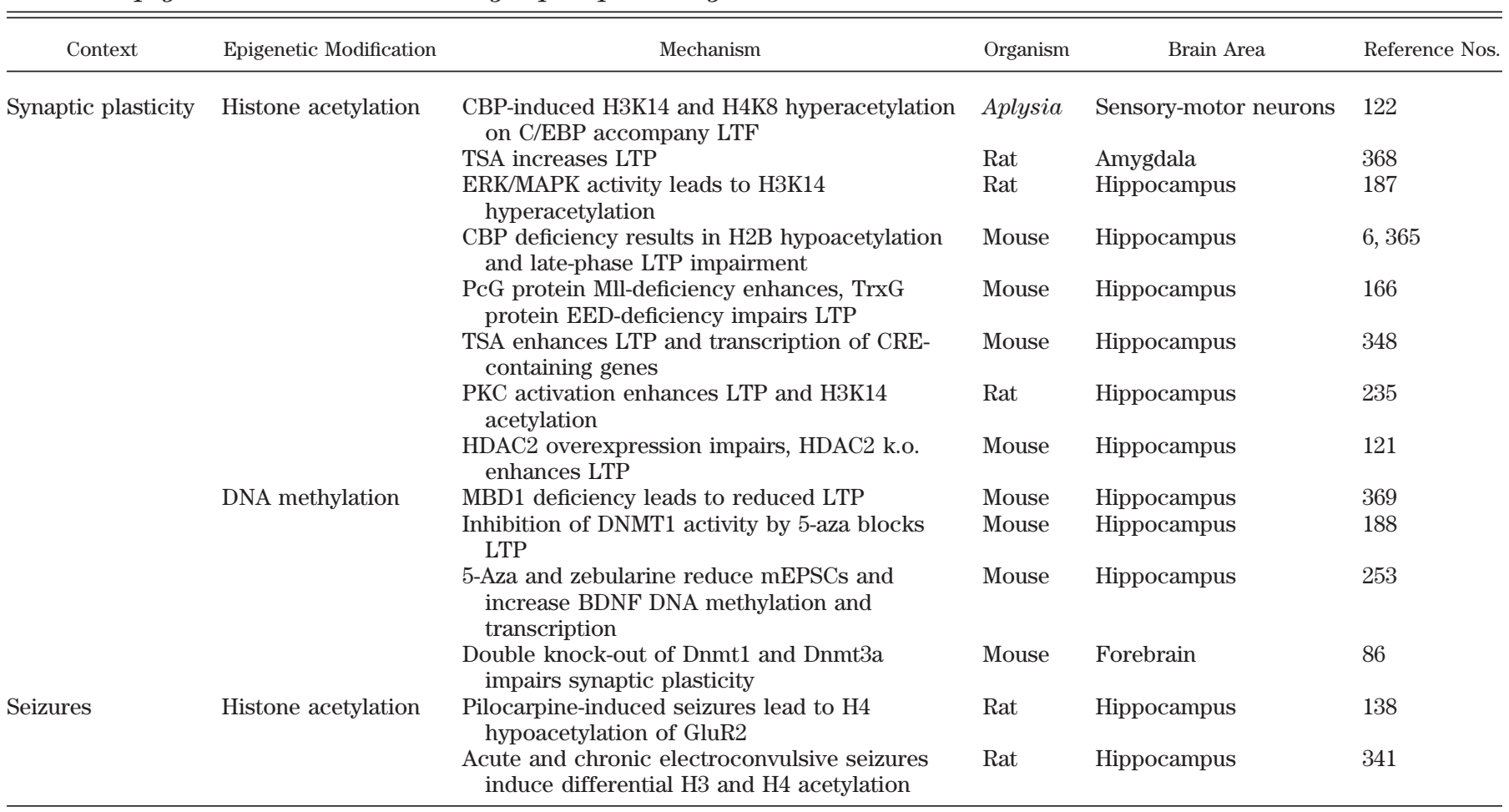

BDNF, brain-derived neurotrophic factor; CBP, CREB-binding protein; CRE, CREB-response element; C/EBP, CCAAT/enhancer-binding protein; DNMT1, DNA methyltransferase 1; ERK/MAPK, extracellular regulated kinase/mitogen-activated protein kinase; GluR2, glutamate receptor 2; H, histone; HDAC2, histone deacetylase 2; K, lysine; k.o., knock-out; LTF, long-term facilitation; LTP, long-term potentiation; MBD1, methyl-CpG binding protein 1; mEPSC, miniature excitatory postsynaptic current; PcG, polycomb-group; PKC, protein kinase C; S, serine; TrxG, trithorax-group; TSA, trichostatin A; 5-aza, 5-aza-2-deoxycytidine.

volving dopaminergic, acetylcholinergic, and glutamatergic signaling, have been implicated in synaptic plasticity $(30,96,140)$. When these three pathways were individually stimulated by the systemic administration of the receptor-specific drugs SKF82958 (a dopaminergic receptor agonist), pilocarpine (a muscarinic acetylcholine receptor agonist), and kainate (a kainate glutamate receptor agonist), respectively, mouse hippocampi displayed increased H3S10 phosphorylation and H3K14 acetylation. This correlated with an increased expression of the immediate early gene FBJ osteosarcoma oncogene ( $c$-fos), in the promoter region of which these epigenetic modifications were found (68). Interestingly, changes in the pattern of H3 phosphorylation paralleled those in the phosphorylation of the extracellular regulated kinase (ERK), a member of the mitogen-activated protein kinase (MAPK) pathway, a signaling cascade implicated in different forms of memory and synaptic plasticity (reviewed in Ref. 328). Furthermore, activation of ERK through the protein kinases PKC and PKA also increased H3K14 acetylation, and activation of $N$-methyl D-aspartate (NMDA) receptors resulted in a similar increase of acetylated $\mathrm{H} 3$, which could be blocked by inhibition of the ERK signaling (187). These studies provided the first evidence that the intracellular signaling
ERK/MAPK pathway also interacts with the epigenetic machinery to modulate synaptic plasticity.

Importantly, acetylation changes appear to be an integral part of synaptic plasticity, as administration of the HDAC inhibitors TSA and SB enhanced the induction of LTP in wild-type rats (187). This was further confirmed in mice lacking the HAT $\mathrm{CBP}\left(\mathrm{CBP}^{+/-}\right)$or its HAT domain $(\mathrm{CBP} \Delta 1)(6,365) . \mathrm{CBP}^{+/-}$mice show a decrease in the overall acetylation of $\mathrm{H} 2 \mathrm{~B}$, and the induction of the transcription-dependent late-phase LTP in hippocampal slices was significantly impaired, whereas the transcription-independent early-phase LTP was not changed. Treatment with the HDACi SAHA ameliorated the defects in latephase LTP (6). Similarly, CBP $\Delta 1$ mice show impaired late-phase LTP, while the early phase of LTP is unaffected (365). These genetic and pharmacological studies suggest a direct link between the levels of histone acetylation and late-phase LTP performance, and the rescue of late-phase LTP with HDAC inhibition.

Two recent studies have now revealed the identity of at least one HDAC that is causally regulating LTP formation (121) and thus emerges as a potential target of HDAC inhibition. HDAC2, but not the structurally highly related HDAC1, impairs LTP formation in the adult hippocampus, 
as mice with neuron-specific overexpression of HDAC2 exhibited decreased postsynaptic currents, whereas HDAC1 overexpressing mice did not (121). In line, neuronal cultures with a loss-of-function allele of HDAC2, but not HDAC1, showed facilitated synaptic transmission plus an increase in synapse numbers (5). Remarkably, during neuronal development, both HDAC1 and HDAC2 loss-offunctions result in facilitated synaptic transmission (5), pointing to a developmental switch in the expression and/or importance of HDAC1 and HDAC2. In adulthood, the specificity of HDAC function appears to be mediated by the preferential binding of HDAC2, but not HDAC1, to genes involved in synaptic plasticity such as $\operatorname{PKM} \zeta$, Cdk5, or NMDA receptors (121).

Members of the Polycomb (PcG) and trithorax (trxG) group proteins, which are crucial epigenetic regulators of developmental gene expression, also impact synaptic plasticity. Mice with a heterozygous deletion for eed, a member of the transcriptional repressor PcG family, display enhanced LTP, whereas mice heterozygous for $M l l$, a member of the transcriptional activator trxG family, have decreased hippocampal LTP, the latter finding correlating with an overall hypoacetylation of H4 (166).

Similar to the hippocampus, administration of the HDACi TSA into the rat amygdala increases LTP (368), confirming the importance of histone acetylation in distinct brain areas. Remarkably, however, such administration of an HDAC inhibitor does not alter the epigenome globally, but site-specifically (348). Upon application of TSA to hippocampal slices of fear-conditioned animals, only a subset of CRE-containing genes was shown to be transcriptionally upregulated. This effect was CREB dependent, since no such upregulation was observed in mice with targeted deletions of the alpha and delta isoforms of CREB (348). Although this study specifically focused on the CREB signaling pathway, which is one of the most prominent pathways regulating gene expression changes in synaptic plasticity, its findings are of broad interest, as they indicate gene-specific actions of HDACis, although the mechanisms underlying this target specificity remain unidentified. Genome-wide binding studies of the different classes of HDACs should resolve this question.

Alongside histone posttranslational modifications, DNA methylation constitutes another epigenetic mechanism that regulates synaptic plasticity. Mice lacking the methylated DNA-binding transcriptional repressor MBD1 display reduced hippocampal LTP (369), which presumably occurs through the aberrant gene expression of plasticity-related genes. LTP induction is efficiently blocked when mouse hippocampi are treated with zebularine and 5-aza-2-deoxycytidine (5-aza) (188), two potent inhibitors of DNMT activity. Additionally, activation of PKC through the administration of phorbol esters led to a decrease in the methylation of the promoter region of reelin, a gene implicated in the induction of synaptic plasticity in the hippocampus, as well as to an upregulation of gene expression of $c$-fos (188). This finding suggested, for the first time, that DNA methylation, long considered to be a stable epigenetic mark, is both dynamically regulated and involved in mammalian synaptic plasticity. Interestingly, PKC activation also led to increased H3K14 acetylation, which could be blocked by zebularine treatment (235), thus providing a hitherto unknown link between dynamic DNA methylation and histone acetylation in LTP formation.

A recent study has now identified at least two enzymes responsible for maintaining DNA methylation in adult neurons, Dnmt1 and Dnmt3a (86). Interestingly, neuron-specific knockout of either of these enzymes alone had no effect on LTP and spatial memory, suggesting a redundant role for these enzymes on synaptic plasticity in the adult brain.

Lastly, LTP is not the only form of synaptic plasticity that is modulated by epigenetic mechanisms; the same applies to miniature excitatory postsynaptic currents (mEPSCs), which result from the temporary depolarization of postsynaptic membranes by small amounts of released neurotransmitters. Treatment of mouse hippocampal cultures with the DNMT inhibitors 5-aza and zebularine resulted in decreased mEPSCs, which was accompanied by increased DNA methylation of the BDNF gene promoter 1 and enhanced BDNF gene expression (253).

\section{Seizures}

Seizures may be considered as an extreme case of synaptic plasticity, since they occur following excessive electrical activity in the CNS. Seizures can be experimentally induced both chemically and electrophysiologically, and both types of induction alter the expression of a variety of genes, including the glutamate receptor 2 (GluR2) and BDNF (reviewed in Ref. 190). Chemically induced seizures, using the muscarinic acetylcholine receptor agonist pilocarpine, downregulated GluR2 expression, and this correlated with decreased $\mathrm{H} 4$ acetylation on the GluR2 promoter (138). Treatment of rat hippocampal slices with TSA reversed this hypoacetylation and, in parallel, upregulated $B D N F$ expression, which correlated with $\mathrm{H} 4$ hyperacetylation of the $B D N F \mathrm{P} 2$ promoter.

Epigenetic changes are also observed following electroconvulsive seizures (ECS) (341). After ECS, H4 acetylation in the promoter region of the $c-f o s, B D N F$, and $C R E B$ genes correlated with altered mRNA levels, displaying hyperacetylation of the promoters with increased gene expression, and vice versa. However, no such clear correlation could be drawn for the acetylation (K9 and K14) and phosphoacetylation (S10 and K14) levels of H3, suggesting a more general role for $\mathrm{H} 4$ acetylation and a 
more specific, albeit unknown role, for $\mathrm{H} 3$ acetylation and phosphorylation, in seizure-induced plasticity. Of note, there appears to be a difference in the epigenetic mechanisms induced by acute versus chronic ECS. Whereas H4 acetylation changes were observed both upon acute and chronic ECS in the promoters of BDNF (P2), c-Fos, and $C R E B, \mathrm{H} 3$ acetylation changes were observed only during chronic ECS, at least for BDNF (341). These results support the increasing body of evidence that manifold forms of synaptic activity result in specific and complex epigenetic tagging of histones that influence gene expression. But they also emphasize that more detailed studies are required to elucidate these mechanisms.

\section{Learning and Memory}

As with long-lasting forms of synaptic plasticity, longterm memories require stable gene expression changes (153). Hence, epigenetic mechanisms remodeling the chromatin structure at genes important for learning and memory are likely candidates to guarantee such enduring changes (Table 2).

\section{Novel taste learning}

The first indication that epigenetic modifications might be involved in memory formation stems from a study addressing the molecular correlates of novel taste learning in the insular cortex, a brain region important for taste memories. Treatment of insular cortex slices with the HDAC inhibitor TSA resulted in increased acetylation of histones $\mathrm{H} 2 \mathrm{~A}$ and $\mathrm{H} 4$, whereas $\mathrm{H} 2 \mathrm{~B}$ and $\mathrm{H} 3$ acetylation remained unchanged (326). Novel taste learning was further associated with an increased phosphorylation of MAPK, an indication of increased MAPK activity, suggesting that the ERK/MAPK pathway might be involved in regulating histone acetylation. Although the precise mechanisms relating ERK/MAPK activation to alterations in histone acetylation still remain unknown, it is possible that MAPK interacts with enzymes that modify histone acetylation and thus, indirectly, triggers the observed changes. As we will see in the next section, such a cascade was indeed observed for the molecular counterpart of protein kinases, protein phosphatases.

\section{Spatial memory}

There is ample evidence that histone acetylation, phosphorylation, and methylation, as well as DNA methylation, are implicated in spatial memory formation, and indeed, several enzymes promoting these epigenetic modifications have been identified. Spatial memory formation depends on the hippocampus (242), and all molecular results described herein are located within this brain region.
The first reports relating histone acetylation to spatial memory addressed the role of the HAT CBP. While Alarcon et al. (6) used mice heterozygous for $\mathrm{CBP}\left(\mathrm{CBP}^{+/-}\right)$, Korzus et al. (170) tested mice with point mutations in the CBP HAT domain (CBP/HAT ${ }^{-}$) with no HAT function. Intriguingly, however, spatial memory, as assessed by the Morris water maze, was only impaired in $\mathrm{CBP} / \mathrm{HAT}^{-}$mice (170), but unaffected in $\mathrm{CBP}^{+/-}$mice (6). This suggests that some compensatory effect might be at play in the mouse model with the more substantial CBP decrease. In the $\mathrm{CBP} / \mathrm{HAT}^{-}$mice, administration of the HDACi TSA was shown to rescue the spatial memory deficits, which correlated with increased H3 acetylation levels (170). Mice completely lacking the HAT domain of CBP (CBP $\Delta 1)$, which showed equally impaired spatial memory (365), corroborated these findings. In contrast, however, mice lacking the HAT domain of another HAT, p300

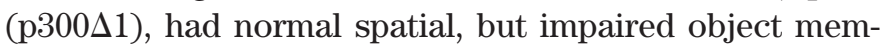
ory (259). This may again point to unidentified compensatory mechanisms at play, or alternatively, to the specific employment of different HATs for different forms of memory.

In addition to HATs, several studies have demonstrated a role of their molecular counterparts, the HDACs, in spatial memory. While the HDACi TSA rescued spatial memory deficits in the CBP/HAT ${ }^{-}$mice (170), the HDACi SB had the same effect in mice following traumatic brain injury (72), and in the CK-p25 mouse model of neurodegenerative disease (92), which is characterized by impaired synaptic plasticity and memory $(69,91)$. Recently, Guan et al. (121) demonstrated that these effects are most likely due to HDAC2, and not HDAC1, as mice overexpressing HDAC2 (but not HDAC1) had impaired spatial memory (121).

In addition to histone acetylation, histone phosphorylation and methylation have lately also been identified as histone PTMs relevant for spatial memory. H3S10 phosphorylation (but not H3T3, H3T11, and H3S28 phosphorylation) as well as H3K36 trimethylation (but not H3K4 dimethylation) were upregulated in mice with enhanced spatial memory caused by the inhibition of nuclear protein phosphatase 1 (PP1) (171), a molecular constraint of learning and memory (108). These modifications resulted from the reduced binding of PP1 to the chromatin, and a reduced interaction between PP1 and JMJD2A, an H3K36specific HDM, whereas the interaction between PP1 and lysine-specific demethylase 1 (LSD1), an H3K4-specific HDM, was unperturbed (171). Importantly, the findings that spatial learning induces H3 phosphorylation, together with $\mathrm{H} 3$ and $\mathrm{H} 4$ acetylation, were recently independently confirmed in both mice and rats (286).

Finally, one study indirectly reported a role for DNA methylation in spatial memory, as mice lacking MBD1 did not remember the location of the platform on the Morris 


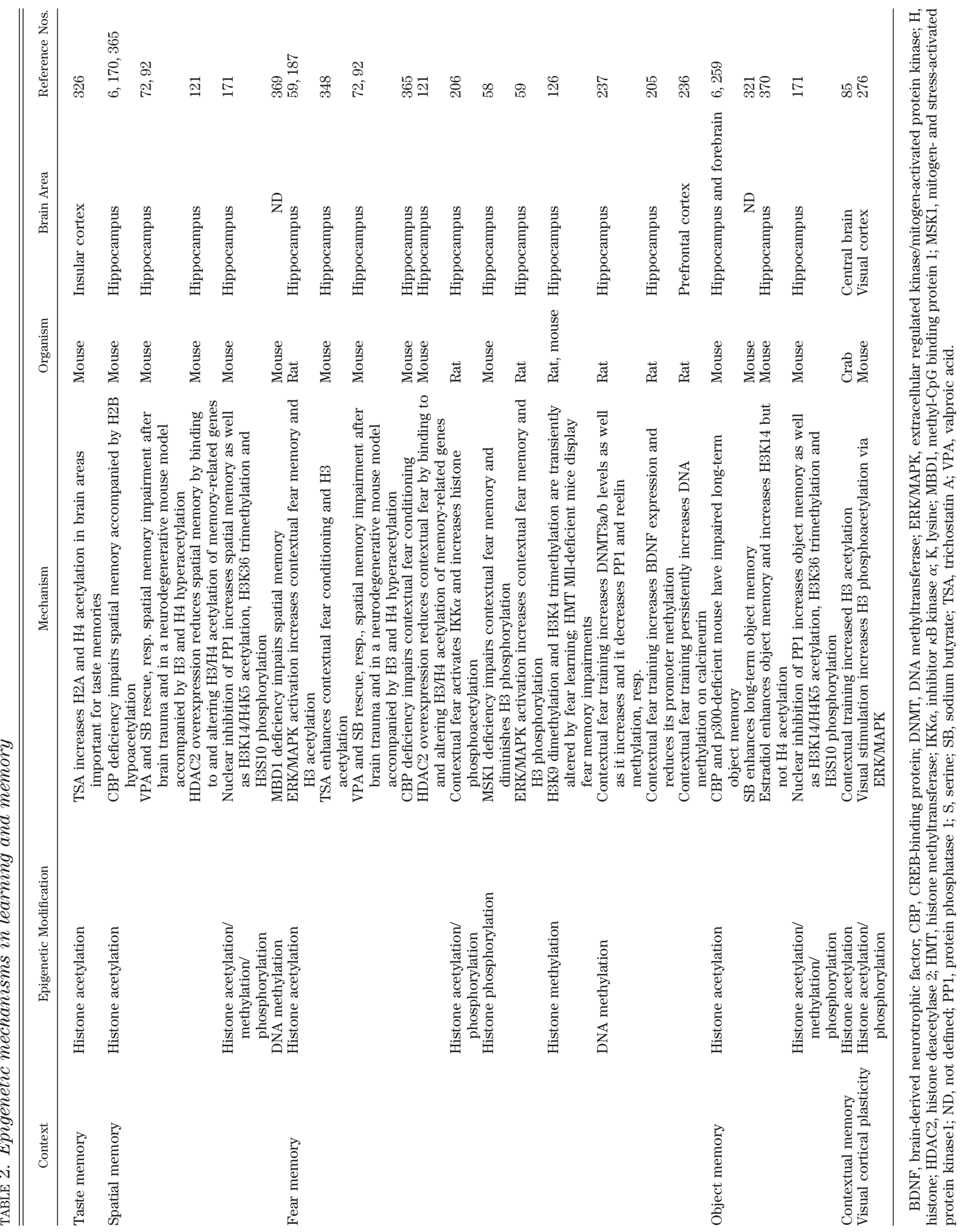


water maze (369). The underlying mechanisms, however, remain unknown.

\section{Fear memory}

Direct evidence that DNA methylation is, indeed, involved in memory formation and maintenance was obtained by three studies addressing fear memory. In the first, contextual fear conditioning was shown to be associated with increased DNMT3a and DNMT3b expression, accompanied by increased promoter methylation and decreased transcription of the memory suppressor gene PP1 (237). Conversely, the extracellular matrix and memorypromoting gene reelin displayed decreased promoter methylation, and increased transcription levels. Importantly, DNMT inhibition by 5-aza and zebularine erased $P P 1$ hypermethylation, elevated $P P 1$ transcription, and, consequently, impaired fear memory. In the second study, similar results were obtained for BDNF and its promoter region (205). Thus hippocampal BDNF exon IV expression was increased after contextual fear conditioning, which was associated with decreased BDNF P4 promoter methylation. H3 phosphoacetylation (assessed with a H3S10/H3K14 pospho/acetyl-specific antibody) was also increased at the BDNF P4 promoter after learning, which is indicative of a reenforcing cross-talk between DNA methylation and histone acetylation. Unexpectedly, zebularine treatment, in conjunction with contextual fear conditioning, led to no further DNA hypomethylation in $\mathrm{BDNF} \mathrm{P} 4$, but rather a reversal of the acetylation changes and a deterioration of memory performance (205). Likewise, another study found that DNMT inhibition via 5-aza led to a decrease in $\mathrm{H} 3$ acetylation (235). However, if DNA methylation and histone acetylation are to work in concert to regulate gene expression changes, as observed in other model organisms (147), the opposite would have been expected. There is no clear-cut explanation for this finding, but since DNMTs not only regulate DNA methylation, but also DNA demethylation (234), and DNA methylation at promoter region is a highly dynamic phenomenon occurring in cycles (154), zebularine treatment might have far more complex consequences than expected. Alternatively, compensatory mechanisms might also be at work.

Lastly, in the third and most recent study, fear conditioning-induced DNA methylation marks were still present in the prefrontal cortex 30 days after the learning event (236), where they efficiently silenced the expression of the memory suppressor gene calcineurin. This finding indeed suggests that DNA methylation could serve as a stable mnemonic mark.

Several other studies have shown a role for histone acetylation and phosphorylation in fear memory. For example, contextual fear memory formation is associated with increased overall $\mathrm{H} 3$ acetylation, which is paralleled by the activation of the ERK/MAPK signaling cascade (187). Latent inhibition, in contrast, is associated with overall H4 hyperacetylation (187), indicating the possibility that different histone codes underlie different types of memories (189). In addition, contextual fear conditioning led to a transient increase in both H3S10 phosphorylation and $\mathrm{H} 3$ acetylation, which again correlated with the activation of ERK (59) identifying, at least indirectly, ERK as a histone kinase. Mice lacking mitogen and stress-activated kinase 1 (MSK1) showed impaired fear memory and reduced histone phosphorylation and acetylation levels (58), thereby defining MSK1 as another histone kinase that controls histone phosphorylation as well as acetylation. A third member was added to the "family" of histone kinases, the inhibitor $\kappa \mathrm{B}$ kinase $\alpha(\operatorname{IKK} \alpha)$ (206), which is part of the $\mathrm{Nf} \kappa \mathrm{B}$ pathway. Accordingly, retrieval of contextual fear led to the activation of IKK $\alpha$ and a concomitant increase in $\mathrm{H} 3$ phosphoacetylation.

Several HDACis have proven useful for the enhancement of conditioned fear memories. TSA enhanced contextual fear memory and increased H3 acetylation levels (348) in wild-type mice, and VPA and SB administration enhanced contextual fear learning in wild-type and traumatic brain-injured mice, respectively $(34,72)$. Furthermore, SB injections facilitated contextual fear conditioning in both wild-type and neurodegenerative CK-p25 mice, and concomitantly elevated both $\mathrm{H} 3$ and $\mathrm{H} 4$ acetylation levels (92).

Interestingly, VPA as well as SB and TSA also facilitated extinction and reconsolidation $(34,182)$, which can be interpreted as relearning or the original memory trace (246). In contrast to the effect of HDACi administration for the facilitation of contextual fear learning, the VPAfacilitated extinction of contextual fear was associated with increased $\mathrm{H} 4$, but not $\mathrm{H} 3$ acetylation levels, at the BDNF promoter $\mathrm{P} 4$ (35). This finding indicates once more potentially different roles of these two acetylation modifications in different memory tasks or phases. The diverging results in terms of $\mathrm{H} 3$ acetylation might also be explained by the use of different types of HDACis that have different half-lives and different substrate specificity (128, 156). Clearly, more refined HDACi assessment is still needed to confidently identify memory-type specific histone codes.

Two more enzymes of the acetylation machinery have been reliably shown to regulate fear memories: the HAT CBP (365) and HDAC2 (121). CBP 11 mice had impaired contextual fear memory, whereas HDAC2 conditional knockout mice excelled over their control littermates (and over HDAC2-overexpressing mice) in fear remembrance. In the case of HDAC2, this memory improvement can likely be explained by the specific binding of HDAC2 to important memory-related genes such as $c$-Fos or $B D N F$, where it induces significant $\mathrm{H} 3$ and $\mathrm{H} 4$ deacetylation (121), and, presumably, gene silencing. 
Lastly, histone methylation has long been an epigenetic candidate to be associated with fear memories, but until recently, evidence for this has been completely lacking. Recently, however, the first HMT to be implicated in fearful memories has been identified $(126,301)$. Neuronspecific deficiency of the HMT complex G9a-like protein (GLP)/G9a in mice resulted in impaired cued and contextual fear conditioning, which was accompanied by decreased H3K9 dimethylation in forebrain neurons. This suggests that H3K9 dimethylation plays an important role in contextual fear memories. Corroborating this notion, another study found that hippocampal H3K9 dimethylation was upregulated $1 \mathrm{~h}$ after fear conditioning, in particular in the promoter region of the immediate early gene Zif268 and Bdnf (126). Similar to H3K9, the methylation of $\mathrm{H} 3 \mathrm{~K} 4$, in this case trimethylated H3K4, a mark of transcriptional activity, was significantly enhanced at this timepoint after contextual fear conditioning, and mice lacking the H3K4-specific HMT Mll displayed fear memory impairments (126). Surprisingly, these methylation marks seem to be of a transient nature, as one day after fear training, histone methylation levels were again at baseline levels. Interestingly, the HDACi SB also altered the hippocampal methylation profile, which is indicative of an important cross-talk between histone acetylation and methylation during fear memory formation. The precise interplay between these two (and other) epigenetic "mnemonic" marks remains to be determined.

\section{Object memory}

Histone acetylation also plays a role in object memory formation. Both $\mathrm{CBP}^{+/-}$and p300 1 mice have deficits in long-term object memory as assessed by a novel object recognition (NOR) task $(6,259)$, during which mice have to learn to discriminate between novel and familiar objects. Interestingly, whereas the hippocampus of $\mathrm{CBP}^{+/-}$ mice showed reduced acetylated $\mathrm{H} 2 \mathrm{~B}$, but unchanged $\mathrm{H} 2 \mathrm{~A}, \mathrm{H} 3$, and $\mathrm{H} 4$ acetylation, p300 $\Delta 1$ forebrains, including the hippocampus, had a reduction in $\mathrm{H} 3$ acetylation (other histones were not examined). This difference might originate in varying substrate specificities of CBP and p300, but until all histone acetylation modifications have been fully examined, this remains speculative.

Further evidence that histone acetylation is critical for object memories was provided by the finding that the HDACi SB ameliorates long-term object memory retention with no effect on short-term memory (321). A more direct support for histone acetylation in object memory comes from a recent study that addressed PP1-dependent histone PTMs at the CREB promoter 1 day after NOR training. At this timepoint, the CREB promoter was hyperacetylated at H3K14, concurrent with increased H3S10 phosphorylation and H3K36 trimethylation, which correlated with increased $C R E B$ expression levels (171). Inter- estingly, these PTMs were potentiated in mice in which neuronal nuclear PP1 was inhibited, and which showed enhanced object memory. A similar observation was made upon estrogen treatment, which has been known to ameliorate object memory (87), and which has now been shown to concomitantly increase H3, but not $\mathrm{H} 4$ acetylation levels in the dorsal hippocampus of mice undergoing an object memory task (370).

These findings are indicative of a marked correlation between the strength of a memory and the amount to which epigenetic modifications are present. In the future, it will be interesting to determine whether naturally fast learners can further increase their memory capacity by the use of epigenetic drugs such as HDACis.

\section{Other types of memory}

Generally speaking, memory formation is ameliorated by experience-dependent plasticity of the nervous system (327). Interactions with the environment such as environmental enrichment (EE) provide a means for such plasticity, and several histone PTMs have been found to be upregulated following $\mathrm{EE}$ in the mouse forebrain (92). In both the hippocampus and the cortex, several loci on $\mathrm{H} 3$ and $\mathrm{H} 4$ showed increased acetylation, and, exclusively in the cortex, H3K4 methylation was increased. These results point to an overall relaxation of the chromatin structure following EE, presumably responding to new experiences with enhanced rates of gene transcription.

In addition to EE-induced plasticity, visual cortical plasticity, i.e., the period during which ocular dominance is established, represents another form of experiencedependent plasticity. Ocular dominance refers to one eye being associated with visual inputs from a particular receptive field, which is physiologically represented by neurons in the visual cortex being connected to only that eye, and not the other. In rodents, ocular dominance is fully established several weeks after birth (see Ref. 327). Interestingly, visual stimulation led to ERK/MAPK-dependent H3 phosphoacetylation (i.e., H3S10 phosphorylation plus H3K14 acetylation) changes in young animals (4 wk old), but not in older ones (12 wk old) (276). Remarkably, upon administration of the HDAC TSA in adults, plasticity was reestablished, suggesting that histone PTMs are molecular mechanisms underlying visual cortical plasticity.

Furthermore, epigenetic mechanisms underlying memory formation are not only restricted to rodents, but have recently also been demonstrated in an arthropod, the crab Chasmagnathus granulatus (85). Here, intensive contextual learning resulted in increased $\mathrm{H} 3$ acetylation, whereas weak learning did not. Accordingly, administration of the HDACis SB and TSA allowed the animals to remember the context also after weak training.

From the examples presented above, it is becoming obvious that evidence for epigenetic regulation of mem- 
ory formation is rapidly accumulating, not only for histone PTMs, but also for DNA methylation. It is therefore important to extend the notion of a histone code for memory formation (189) to that of an epigenetic code (113) for memory formation. Indeed, it is tempting to consider such codes on the chromatin as "mnemonic" marks, which would enable the brain to store and retrieve stored pieces of information. To determine whether or not this will turn out to be the case, epigenetic codes will have to be investigated more thoroughly. The types of questions that should be addressed, as well as techniques available to do so, will be discussed in the last section of this review.

\section{Neuroprotection}

The proper functioning of the nervous system requires the integrity of all of its components, which need to be maintained and protected against both extra- and intracellular noxious signaling cascades. In the case of neurons, an additional level of cellular integrity needs to be preserved. As neurons are nondividing cells, the cell cycle machinery must be permanently suppressed. In recent years, epigenetic mechanisms, in particular the histone acetylation machinery, have been found to play an integral part in the following crucial aspects of neuroprotection and neuronal maintenance. Paradoxically, epigenetic research to date has provided strong evidence for both HDACs and HDACis as being neuroprotective.

\section{Neuroprotection against apoptosis}

Adult neurons need to survive for the lifetime of an organism and must be protected against programmed cell death (apoptosis). This can be achieved by activating neurotrophic pathways, or, more commonly, by silencing proapoptotic pathways within the cell (21). In regards to the former mechanism, the HDACi VPA has been found to not only activate the expression of $B D N F$ in neurons (98), but also of glial cell line-derived neurotrophic factor $(G D N F)$ in astrocytes, and of HDAC1 gene expression (42). For the latter, VPA has, on the one hand, been shown to increase the expression of anti-apoptotic genes such as B-cell lymphomia/leukemia 2 (Bcl2) $(47,316)$ and heatshock protein 70 (HSP 70 ) (316), and, on the other hand, to decrease the expression of genes with pro-apoptotic properties such as interleukin-6 (IL-6) (316). This last finding was recently confirmed by showing that TSA and SB-mediated HDAC inhibition leads to the decreased activity of caspase 3, another gene with pro-apoptotic properties (137). How VPA treatment results in such bidirectional gene expression changes is unknown. However, VPA administration was associated with increased H3 acetylation levels (316); therefore, the elevated expres- sion levels of the anti-apoptotic genes seem likely to be a direct effect of this treatment.

At least two HDACs are implicated in maintaining low expression levels of pro-apoptotic genes in neurons. HDAC1, in conjunction with histone deacetylase related protein (HDRP), has been shown to deacetylate the promoter region of c-Jun and thereby to inactivate its expression (243). Likewise, HDAC1 has been demonstrated to be recruited by E2F4, a member of the E2F family of transcriptional regulators, to the promoter region of the proapoptotic gene B-myb, which was transcriptionally silenced upon being deacetylated (200). Of note, the chromatin condensing effect of histone deacetylation is supported by the HMT Suv39H1, which forms a complex with HDAC1 at E2F4 to methylate B-myb promoter histones at K9 (200).

HDAC3 has also been identified in the context of neuronal antiapoptotic processes. Like HDAC1, HDAC3 binds to another member of the E2F family, E2F1 (263). Upon caspase-mediated apoptosis, HDAC3 protein levels are reduced, which might in turn lead to deregulated E2F1 transcription and further promotion of apoptosis, although this has not been specifically tested.

\section{Maintenance of neuronal identity}

For neurons to maintain their identity, not only do neuron-specific genes need be active, but cell-cycle genes must be silenced. Two HDACs have recently been shown to prevent cell cycle progression. The activity of the first, HDAC1, was found to be downregulated in the CK-p25 mouse model of neurodegeneration (69), which led to a reduced binding of HDAC1 to the chromatin, and an upregulation of cell-cycling genes (159). Correspondingly, virus-mediated overexpression of HDAC1, but not HDAC2, not only blocked cell-cycle reentry, but also protected against caspase-mediated apoptosis and DNA damage. Similarly, a class IIa HDAC, HDAC4, was shown to inhibit the progression of HEK293T cells through the cell cycle (214). Again, this effect was accompanied by substantial neuroprotection, in neuronal culture, against $\mathrm{K}^{+}$mediated apoptosis and oxidative stress. Remarkably, whereas the neuroprotective effect of HDAC1 could be specifically attributed to its catalytic domain (159), HDAC4 was still neuroprotective even without its catalytic domain (214). This finding could be indicative of an acetylation-independent effect of HDAC4 in neuronal maintenance and protection, but further studies are needed to clarify this point.

Both HDACs and HDACis thus seem to confer neuronal identity as well as protection against intracellular apoptotic pathways. This apparent discrepancy is likely due to gene-specific modes of action by both epigenetic modulators, and further studies investigating these effects on a genome-wide scale are highly warranted. 


\section{Neuroprotection against noxious extracellular signals}

HDACis have been demonstrated to be neuroprotective against various noxious extracellular signals such as excitotoxicity, ischemia, hemorrhage, and inflammation. Excitotoxicity is defined as the process by which neurons are damaged in response to extracellular, glutamate-mediated overactivation, which results in pathologically high levels of intracellular $\mathrm{Ca}^{2+}$. Neuronal excitotoxicity can be efficiently blocked by administration of VPA $(80,185$, $186,218)$, as well as TSA, SB $(185,186)$, and phenylbutyrate (186). Although the molecular mechanisms have not been fully investigated in all cases, they seem to involve the upregulation of genes with neuroprotective properties such as HSP70 (218) or $\alpha$-synuclein (185). TSA and SB have also proven efficient against two models of ischemic cell death: oxygen-glucose deprivation in primary cortical neurons (231) and middle cerebral artery occlusion in rats (178). These effects were mediated by the actin-binding proteins gelsolin and p21, respectively, as no neuroprotection was observed in neurons lacking these proteins. Although pathologically the opposite of ischemic conditions, intracerebral hemorrhage (ICH) and the resulting neuronal damage could also be attenuated by administration of an HDAC. Thus VPA administration after ICH induction led to the transcriptional upregulation of $H S P \% O$, and concomitantly to the transcriptional downregulation of the proapoptotic gene Il6 (316). Finally, VPA, TSA, and SB have also been shown to bestow neuronal protection against inflammation. Surprisingly, however, this occurred not via the prevention of apoptotic pathways, but via their induction in microglia (48). Thus, upon HDACi treatment of primary neuron/glia cultures, microglia underwent apoptosis, which subsequently protected the adjacent neurons from microglia-induced inflammation. Seemingly, therefore, HDACis differ in their mode of action in different cell types in the CNS, which might be caused by the differential expression of HDACs in the brain (36) and their different sensitivity to HDACis.

Apart from the above-mentioned examples, several HDACis have been attributed neuroprotective or other beneficial effects in the context of neurodevelopmental, neuropsychiatric, and neurodegenerative disorders. In the following sections, we will cover the implication of epigenetic mechanisms in these disorders and summarize the potential of HDACis as pharmacological treatments against these disorders where applicable.

\section{PATHOLOGICAL EPIGENETIC REGULATION I: DEVELOPMENTAL DISORDERS}

Considering the pervasive nature of epigenetic regulation across the many facets of CNS development and function, it is not surprising that the deregulation of epigenetic regulation has been implicated in a number of neurodevelopmental disorders (Table 3). Fortunately, these drugs targeting epigenetic modifications have demonstrated therapeutic potential in animal models for many of these.

Mutations in genes involved in epigenetic regulation have been identified in disorders in which CNS development proceeds abnormally, resulting in defects ranging from subtle changes in synapse formation to gross abnormalities in brain formation. Collectively, these disorders have provided direct evidence for the crucial role of epigenetic regulation in brain development, and have formed the foundations for developing relevant animal models and therapeutic strategies. It should be noted that some of the mechanisms that are deregulated in the disorders listed below are not limited to a developmental role. For example, the HAT CBP, which is disrupted in RubinsteinTaybi syndrome, appears also to be necessary for normal learning and memory in the adult. The diseases listed below, however, are manifested during the period of brain development and synapse maturation, and thus can be classified as developmental disorders.

\section{A. Rubinstein-Taybi Syndrome}

A considerable number of neurodevelopmental disorders have been shown to involve abnormal histone acetylation. This is well-exemplified in Rubinstein-Taybi syndrome (RTS), a rare congenital disorder (1:100,000125,000 prevalence in the United States) that is characterized by varying degrees of mental retardation, craniofacial and skeletal abnormalities, as well as increased risk of cancer (272). In the brain of affected people, RTS manifests gross abnormalities such as abnormal cortical infolding and decreased white matter, as well as regional hypoplasia $(18,306)$. Most RTS patients have mutations that are mapped to the gene coding for the HAT CBP, and many of these mutations have been shown to result in a loss of HAT activity.

Critical insights into this disease have been gained from transgenic animal models. Several mouse models for RTS have been generated, including a straight CBP knockout displaying skeletal abnormalities and embryonic lethality. A heterozygous truncated CBP mouse displays a phenotype that is more severe than the heterozygous null mutant, suggesting a dominant-negative effect that may compromise faithful recapitulation of RTS (6, 32, 170, 258, 365). Mice heterozygous for a truncated mutant CBP allele, while displaying a more severe skeletal abnormality phenotype than the heterozygous null mice display the same defects in long-term memory with normal shortterm memory capacity $(32,258,365)$. It appears, however, that mice heterozygous for the CBP null allele may provide the most accurate model for RTS. These animals display pathogenic features including growth retardation, 
skeletal abnormalities, and reduced long-term spatial memory (170). Interestingly, $\mathrm{CBP}^{+/-}$mice have a normal short-term memory capacity, but defective long-term memory as tested by contextual and cued fear conditioning, and object recognition tests (6). Long-term spatial memory, however, as tested by the Morris water maze, was intact, which may indicate that only specific subsets of neural circuits that underlie learning and memory are epigenetically deregulated in RTS.

When synaptic plasticity was examined at the electrophysiological level in $\mathrm{CBP}^{+/-}$mice, early-phase short term LTP (E-LTP) was not impaired, but long-term (or late) LTP (L-LTP) was significantly impaired, which correlates with the observed behavioral abnormalities (170, 365). At a molecular level, reduced acetylation of histone
H2B was observed (6). These findings suggest that mental retardation in RTS may involve defects in synaptic plasticity too. However, an important question remaining is what are the specific cellular processes that are disrupted to cause defects in synaptic plasticity and learning and memory. A large body of evidence demonstrating acute roles for CBP in a variety of neuronal processes such as axon outgrowth or neuronal survival suggest that multiple factors may be in play in RTS $(105,255)$.

While pretreatment with the general HDAC inhibitor SAHA did not alter basal synaptic transmission in $\mathrm{CBP}^{+/-}$ mice, it increased histone 2B (H2B) acetylation and ameliorated the reduced long-term LTP in these mice to near wild-type levels. Furthermore, both SAHA and TSA treatment resulted in a rescue of long-term memory, as mea-

TABLE 3. Epigenetic mechanisms in neurodevelopmental disorders

\begin{tabular}{|c|c|c|c|c|c|}
\hline Disorder & Epigenetic Modification & Mechanism & Organism & Brain Area & Reference Nos. \\
\hline $\begin{array}{l}\text { Rubinstein-Taybi } \\
\text { Syndrome }\end{array}$ & Histone acetylation $\Downarrow$ & $\begin{array}{l}\text { Reduced global HAT activity } \\
\text { due to loss-of-function in } \\
\text { CBP }\end{array}$ & Mouse & Hippocampus & $6,170,258,365$ \\
\hline \multirow[t]{3}{*}{ Rett syndrome } & DNA methylation $\Downarrow$ & MeCP2 mutations lead to & Human lymphocytes & NA & 8 \\
\hline & & $\begin{array}{l}\text { reduced functioning of } \\
\text { MeCP2, which normally } \\
\text { recognizes methylated } \\
\text { CpG islands and acts as a } \\
\text { transcriptional repressor }\end{array}$ & Mouse & $\begin{array}{l}\text { Hippocampus, } \\
\text { cortex, cerebellum }\end{array}$ & $49,61,127$ \\
\hline & $\begin{array}{l}\text { DNA methylation } \Downarrow \text {, } \\
\text { histone acetylation } \\
\Uparrow, \text { histone } \\
\text { methylation } \Uparrow \Downarrow\end{array}$ & $\begin{array}{l}\text { MeCP2 mutations cause } \\
\text { aberrant transcriptionally } \\
\text { permissive histone } \\
\text { acetylation and } \\
\text { methylation marks }\end{array}$ & $\begin{array}{l}\text { Mouse and murine cell } \\
\text { culture }\end{array}$ & Cortex, cerebellum & 220,307 \\
\hline \multirow[t]{2}{*}{ Fragile X } & DNA methylation $\Uparrow$ & $\begin{array}{l}\text { Nucleotide expansions } \\
\text { within FMR1 and - } 2 \\
\text { results in CpG island } \\
\text { hypermethylation }\end{array}$ & $\begin{array}{l}\text { Human and mouse cell } \\
\text { culture }\end{array}$ & NA & $11,55,56$ \\
\hline & $\begin{array}{l}\text { DNA methylation } \Uparrow, \\
\text { histone acetylation } \\
\Downarrow \text { histone } \\
\text { methylation } \Uparrow \Downarrow\end{array}$ & $\begin{array}{l}\text { 5-Aza treatment of FXS cell } \\
\text { lines not only alters DNA } \\
\text { methylation but also } \\
\text { histone acetylation and } \\
\text { methylation }\end{array}$ & $\begin{array}{l}\text { Human patient-derived } \\
\text { cell lines }\end{array}$ & NA & 330,331 \\
\hline \multirow[t]{2}{*}{ Schizophrenia } & DNA methylation $\Uparrow$ & $\begin{array}{l}\text { GAD67 and SOX10 promoter } \\
\text { regions are } \\
\text { hypermethylated } \\
\text { correlating with reduced } \\
\text { mRNA levels }\end{array}$ & $\begin{array}{l}\text { Human post mortem } \\
\text { brain }\end{array}$ & Cortex & $124,136,146,349$ \\
\hline & DNA methylation $\Downarrow$ & $\begin{array}{l}\text { COMT promoter is } \\
\text { hypomethylated } \\
\text { correlating with increased } \\
\text { mRNA levels }\end{array}$ & $\begin{array}{l}\text { Human post mortem } \\
\text { brain }\end{array}$ & Frontal lobe & 1 \\
\hline \multirow[t]{2}{*}{ ATRXS } & DNA methylation $\Uparrow \Downarrow$ & $\begin{array}{l}\text { Mutations in ATRX result in } \\
\text { aberrant DNA methylation } \\
\text { patterns }\end{array}$ & $\begin{array}{l}\text { Human patient-derived } \\
\text { cell lines }\end{array}$ & NA & 109,110 \\
\hline & & $\begin{array}{l}\text { ATRX forms a silencing } \\
\text { complex with MeCP2 that } \\
\text { is disturbed in ATRXS }\end{array}$ & Mouse & Forebrain & 157 \\
\hline $\begin{array}{l}\text { Coffin-Lowry } \\
\text { syndrome }\end{array}$ & $\begin{array}{l}\text { Histone } \\
\text { phosphorylation? }\end{array}$ & $\begin{array}{l}\text { Substrates for RPS6KA3, } \\
\text { mutated in Coffin-Lowry, } \\
\text { include histones }\end{array}$ & $\begin{array}{l}\text { Human patient-derived } \\
\text { cell lines }\end{array}$ & NA & 233,319 \\
\hline
\end{tabular}

ATRX, X-linked $\alpha$-thalassemia/mental retardation; ATRXS, X-linked $\alpha$-thalassemia/mental retardation syndrome; COMT, catechol-O-methyl transferase; CBP, CREB-binding protein; FMR1, fragile X mental retardation 1; GAD67, glutamic acid decarboxylase 67; HAT, histone acetyltransferase; MeCP2, methyl CpG binding protein 2; NA, not applicable; PTM, posttranslational modification; RPS6KA3, ribosomal protein S6 kinase, 90 kDa, polypeptide 3; SOX10, SRY-related HMG-box 10. 
sured by cued and contextual fear conditioning to levels similar to controls $(6,170)$. These results establish RTS as a disorder of defective histone acetylation, and provide evidence that HDAC inhibitors may be useful as a therapeutic strategy against disorders involving defective histone acetylation.

\section{B. Rett Syndrome}

Rett Syndrome (RTT) is a relatively common CNS developmental disorder, which is manifest almost exclusively in females by virtue of it being transmitted as an $\mathrm{X}$-linked dominant trait and thus being lethal in males (221). RTT has a prevalence of 1 in 10,000 females in the United States. RTT can be classified as a progressive developmental disorder, as cases follow a period of normal development up to $18 \mathrm{mo}$, followed by regression in motor and language skills and deceleration of head growth. This regression results in mental retardation and autistic features; thus RTT is also considered an autism spectrum disorder. At the anatomical level, significant reductions in both gray and white matter are observed at the regressive stage (249). At the cellular level, neurons in RTT patients may have a reduced density of dendritic spines (180), and murine RTT models display axonal and dendritic spine abnormalities (20). Moreover, mouse models of RTT exhibit an overall decrease in exploratory activity $(49,127)$, show severe cognitive deficits, and have impaired synaptic plasticity (61).

The underlying defect in $\sim 80 \%$ of RTT cases has been mapped to mutations in the $\mathrm{MeCP} 2$ gene, which impair MeCP2 function (8). Importantly, the cognitive deficits observed in RTT mouse models can be reversed by overexpression of wild-type human MeCP2 protein in young (10-wk-old) animals (61). Intriguingly, however, in 20-wkold mice, human MeCP2 overexpression induces seizures, suggesting that an overdose of MeCP2 can have deleterious effects, presumably by silencing genes that, under physiological conditions, are active and required for a proper brain functioning.

One identified target of MeCP2 is the Bdnf gene. MeCP2 mutant mice have reduced BDNF levels. This reduction, and the neuronal atrophy characteristic of RTT, can be reversed by forebrain-specific overexpression of Bdnf in vivo (46), an effect that was recently confirmed in cultured hippocampal neurons (180). In addition to $B d n f$, a recent study identified seven other genes as direct binding targets of MeCP2 in the mouse brain (346), including myelin-associated proteins and dopamine decarboxylase. Yet more genes are likely to be discovered, as MeCP2 has been associated with dendritic growth and spine maturation (371), which is thought to occur through the derepression of target genes involved in development processes $(44,318)$.
In addition to regulating DNA methylation, MeCP2 also influences histone PTMs, particularly histone acetylation and methylation. At the promoter region of $B d n f$, this is mediated by the formation of a complex between MeCP2 and HDAC1 (220), which reduces the acetylation of both histone $\mathrm{H} 3$ and H4. This effect is accompanied by the increased dimethylation of H3K9 and the decreased dimethylation of H3K4, two posttranslational histone modifications that inhibit and promote gene transcription, respectively (172). This suggests a cooperative contribution of epigenetic modifications for gene silencing and is consistent with the observation that mice with deficient MeCP2 have hyperacetylated H3 (307). Accordingly, a recent study found that infusion of the HDACi SAHA in the mouse amygdala produces behavioral deficits reminiscent of RTT (3).

These results strongly argue for an overall increase in gene transcription in RTT, due to loss of MeCP2-mediated gene silencing, possibly in conjunction with aberrant histone PTMs. However, in light of the recent observation that MeCP2 also fulfills other roles, such as transcriptional activation and mRNA splicing (44), these functions cannot be ruled out as mechanisms underlying RTT pathology.

\section{Fragile X Syndrome}

Fragile X Syndrome (FXS) is the most common inherited form of mental impairment, with a prevalence of $1: 4,000$ to $1: 8,000$ in the United States (102). FXS manifests as a spectrum of abnormalities, mostly CNS related, which range from mild to severe. These include mental retardation, autism, and mild skeletal and muscular abnormalities. The cause of FXS has been identified as 200 or more copies of CGG and CCG trinucleotide expansions at the $5^{\prime}$ end of the fragile $\mathrm{X}$ mental retardation gene (FMR1) and, in rare instances, a second gene, FMR2 (11, $107,120)$. These expansions result in extensive CpG methylation, which in turn leads to the silencing of the entire genetic region, and a constriction of the chromosome band Xq27.3, giving the "fragile" appearance from which the syndrome derives its name. FXS brains appear grossly normal, but a key feature of FXS is that certain areas of the brain display abnormally long and thin dendritic spines, reminiscent of immature spines, at an abnormally high density (102). Thus, within the brain, the predominant defect appears to be that of spine maturation.

Importantly, treatment of lymphoblastoid cell from FXS patients with 5-aza reversed FMR1 promoter hypermethylation and restored FMR1 mRNA and protein expression to control levels (56). When 5-aza was combined with the HDACis 4-phenylbutyrate, SB, and TSA, FMR1 expression is further potentiated (55), suggesting a joint deregulation of histone acetylation and DNA methylation 
as causative mechanisms of FXS. Two other studies further demonstrated an implication of histone methylation in FXS. Gene-silencing H3K9 methylation was decreased with 5-aza treatment, which simultaneously increased gene-activating H3K4 methylation, together with an increase in FMR1 gene expression (330, 331). It should be noted, however, that these findings are based on only a few case studies, and therefore require further confirmation.

In conclusion, FXS is an example of a rare congenital disorder that does not involve mutations in the coding sequence of a gene, but instead a mutation (expansion) in a noncoding sequence that results in the abnormal recruitment of several epigenetic markers. This, in turn, leads to an epigenetic repression of a gene pivotal for synapse development.

\section{Other Developmental Disorders}

\section{X-linked alpha thalassemia mental retardation syndrome}

X-linked alpha thalassemia mental retardation syndrome (ATRXS) is an extremely rare and poorly understood X-linked disorder (168 reported cases as of 2006), which is only manifest in males, with normal female carriers (109). ATRXS is characterized by mental retardation, occasional autistic-like behavior, alpha thalassemia (a form of anemia), and other abnormalities. ATRXS is caused by mutations in the alpha thalassemia/mental retardation syndrome $\mathrm{X}$-linked homolog $(A T R X)$ gene, a member of the helicase/ATPase family proteins, which regulate various processes of nucleosome remodeling, DNA repair, and chromosome segregation. A recent report found that ATRX functionally interacts with MeCP2 and cohesin to form a silencing complex that was shown to repress an imprinted locus, H19 under physiological conditions, but which in ATRXS becomes pathologically expressed (157). Furthermore, ATRXS patients display changes in the methylation of highly repetitive DNA sequences in heterochromatin regions (110), which provides further evidence for the involvement of epigenetic mechanisms in ATRXS.

\section{Coffin-Lowry Syndrome}

Some congenital syndromes featuring defective CNS development may also involve epigenetic mechanisms in their etiology, although definite links have not been established. For example, Coffin-Lowry Syndrome (CLS) is a rare (estimated 1 in 40,000-100,000) X-linked condition with severe mental retardation in males and varying degrees of cognitive defects in females; additional symptoms include delayed postnatal growth as well as cardiovascular and skeletal defects (219). This disorder is caused by mutations in RPS6KA3, a ribosomal protein $\mathrm{S} 6$ kinase family member that is involved in the MAPK signaling pathway, and for which multiple substrates have been identified (233). As targets of ribosomal protein $\mathrm{S} 6$ kinase family members include histones, it is plausible that CLS may involve a deregulation of histone homeostasis triggered by dysfunctional RPS6KA3. Yet, alternative roles of mutated RPS6KA3 on other targets genes cannot be ruled out.

\section{The case of imprinted genes}

Imprinted genes, i.e., genes that, via epigenetic mechanisms (281), are either exclusively maternally or paternally expressed, represent a class of genes with both a physiological function and an inherent pathological potential, as the beneficial effects of diploidy are in effect overturned (364). The epigenetic imprint of these genes is established during embryonic development, and although imprinting has been detected in a wide variety of somatic tissues, an intriguingly high percentage of these genes is also expressed in the brain. As a matter of fact, over 1,300 loci or more than 300 gene show parent-of-origin patterns in gene expression in the brain $(117,118)$, and many of these patterns vary from one brain region to the other, leading to the question of whether imprinted genes have a specific function in the brain.

Here, precise evidence is still scarce, but there seems to be an overall trend of expression patterns of imprinted genes that is in accordance with the "intragenomic conflict" theory of imprinting (240). This theory stipulates that it is in the interest of the mother, and thus of maternally expressed genes, to distribute resources between offspring and between mother and infant fairly, whereas it is in the interest of the father and thus paternally expressed genes to maximize resources. This is exemplified by the textbook example of imprinted genes, paternally expressed insulin-like growth factor 2 (Igf2) and maternally expressed insulin-like growth factor receptor 2 (Igf2r) that are also expressed in the brain (118). Other examples include paternally expressed gene 3 (Peg3), which is involved in oxytocin production, or maternally expressed ubiquitin protein ligase $3 \mathrm{a}$ (Ube3a), which interacts with the receptors for the sex hormones progesterone and androgen (reviewed in Ref. 364).

Two recent studies have now started to shed light onto how an epigenetic deregulation of genomic imprints can lead to behavioral deficits. The first one assessed the functions of the transcription factor YY1 by RNAi (164). Knockdown of YYI drastically upregulated Peg3 in the neonatal mouse brain by changing the methylation profile in its promoter region, which concomitantly also reduced the birth weight of the pups. The second investigated the role of the zinc-finger protein Krüppel-associated box (KRAB)-associated protein 1 (KAP1) by lentivirus-medi- 
ated forebrain-specific knockdown (148). Mice deleted for KAP1 showed increased anxiety-like behaviors and cognitive impairments, which was accompanied by abnormally high expression levels of normally silenced imprinted genes, including $M k r n 3$, which, like Ube3a, is a ubiquitin ligase. Focusing on PTMs of histones, the promoter region of $M \mathrm{krn} 3$ was found to be hyperacetylated on $\mathrm{H} 3$ and $\mathrm{H} 4$ compared with control brains, and hypomethylated on H3K9, which are all three marks of transcriptionally active genes. These two studies clearly show the inherent pathological potential of imprinted genes in the brain. With the advances of the techniques at our hands to more thoroughly investigate epigenetic mechanisms, more such examples of deregulated imprinted genes in the brain are likely to surface. This in turn will eventually lead to the deciphering of their physiological function.

\section{PATHOLOGICAL EPIGENETIC REGULATION II: PSYCHIATRIC DISORDERS}

Neuropsychiatric disorders are mental disorders that can change a personality entirely. Addictive-like behaviors, depression, anxiety-related disorders, and abnormal stress vulnerability all fall into that category. The often long-lasting and repeatedly occurring nature of these behaviors designate lasting gene expression changes and an epigenetic regulation thereof as key underlying molecular candidates (Table 4).

\section{A. Addiction}

Drugs with psychoactive properties can be broadly divided into psychostimulants such as cocaine and amphetamine, sedatives such as benzodiazepines and alcohol, and analgesic opiates such as opium and morphine. They profoundly influence human (and animal) behavior by increasing or decreasing the brain's excitability or by manipulating the brain's reward pathway, including the dopaminergic neurons connecting the ventral tegmental area (VTA) to the nucleus accumbens (NAc). Often, repetitive exposure to such drugs can lead to the brain "asking for" increasing amounts of that drug, which ultimately can lead to substance dependence, i.e., addiction. A substantial body of evidence suggests that epigenetic mechanisms underlie addictive-like behaviors for all three types of psychoactive drugs.

\section{Addiction to psychostimulants}

A) COCAINE. Cocaine exposure can either occur acutely and chronically, whereby the latter is often reached by self-administration (also in animal models). Acutely a single injection of cocaine was found to increase overall $\mathrm{H} 4$ acetylation in the promoter region of the immediate early gene $c$-fos, and of the transcription factor FosB in the rat striatum (175). Additionally, for $c$-fos, but not FosB, the promoter region was phosphoacetylated at H3. These findings were replicated for at least the $\mathrm{H} 4$ acetylation (on K5) and H3 phosphorylation (on S10) independently by another study (33). Mechanistically, the acetylation changes seem to be mediated by the HAT CBP, which bound to the promoter of $F o s B$ upon acute cocaine administration (191), whereas the phosphorylation changes seem to be caused by the protein kinase MSK1, since MSK1 knockout mice did not display H3 phosphorylation following acute cocaine administration (33).

Similar to acute cocaine exposure, repeated injections of cocaine were found to increase phosphoacetylation in the mouse striatum, and drug-seeking behavior could be further amplified by the HDACi SB (298). In more gene-specific studies, chronic cocaine exposure led to hyperacetylated $\mathrm{H} 3$ in the rat striatum in the promoter region of $F o s B$, as well as of $B d n f$ and $C d k 5$ (175), two genes implicated in chronic cocaine exposure $(24,119)$. The expression of $c$-fos, however, was not changed, consistent with its promoter region not undergoing H3 hyperacetylation (175). Similar to FosB and Bdnf, H3 hyperacetylation was also observed in the promoter region of calmodulin kinase II $\alpha$ (CamKII $\alpha)$ in the rat NAc following chronic cocaine exposure (353). Accordingly, in both studies, the HDACi SB increased the cocaine dependency as indicated by more craving-like behaviors, and virusmediated overexpression of the class IIa HDAC, HDAC4 into the corresponding brain areas abolished such behavior $(175,353)$. Interestingly, virus-mediated overexpression of HDAC5, another class IIa HDAC into the striatum, reduced drug-seeking behaviors in a similar way. However, no such reduction could be detected when a third class IIa enzyme, HDAC9, was overexpressed (285). These findings could be due to differential tissue distribution of class IIa HDACs (36), or of a preferential activation of HDAC4 and -5 upon cocaine exposure, but more refined studies are needed to clarify this point.

To verify if chronic cocaine administration is globally characterized by transcription-facilitating hyperacetylation changes, a recent study compared the expression profiles and the epigenetic promoter regulation of genes induced upon chronic cocaine administration on a genome-wide scale (284). This study found that overall H3 acetylation and methylation levels were, as a matter of fact, bidirectionally changed. This was accompanied by an equally frequent binding of the transcription factor $\Delta$ FosB to gene-activating hyperacetylated $\mathrm{H} 3$ and $\mathrm{H} 4$ levels as to gene-silencing hypermethylated H3K9/K27 levels, highlighting its cross-talk with epigenetic marks and confirming its dual effect on gene transcription (226). Another interesting finding of this study was that chronic, but not acute, cocaine administration significantly enhanced the expression of the class III HDACs, the sirtuins, 
TABLE 4. Epigenetic mechanisms in psychiatric disorders

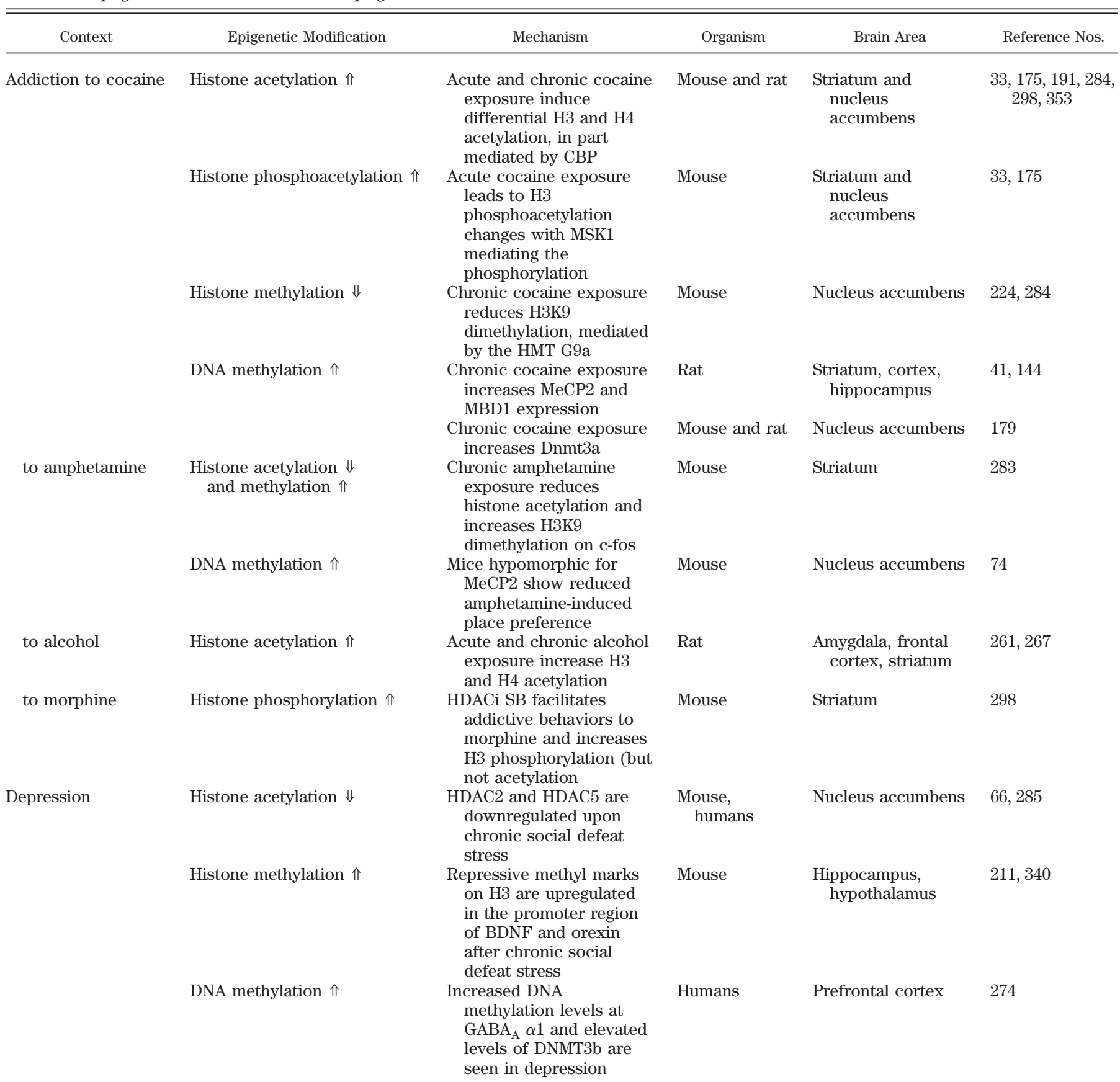

BDNF, brain-derived neurotrophic factor; CBP, CREB-binding protein; DNMT3b, DNA methyltransferase $3 \mathrm{~b}$; GABA $\mathrm{A}_{\mathrm{A}} \alpha 1, \gamma$-aminobutyric acid A receptor $\alpha 1$; H, histone; HDAC, histone deacetylase 2; HDACi, HDAC inhibitor; K, lysine; MBD1, methyl-CpG binding protein 1; MSK1, mitogen- and stress-activated kinase 1; SB, sodium butyrate.

in particular SIRT1 and SIRT2. Their inhibition via sirtinol and their activation via resveratrol decreased and enhanced the spine number in the NAc, respectively, suggesting a critical role for sirtuins in mediating plasticity changes following addiction.

A recent study has now identified the first HMT responsible for the altered histone methylation upon chronic cocaine administration. Thus chronic cocaine ad- ministration not only led to reduced dimethyl H3K9 levels, but concomitantly diminished the expression of the H3K9-specific HMT G9a, and not of other HTMs, in the NAc (224). With the use of double transgenic mice inducibly overexpressing $\Delta \mathrm{FosB}$, the downregulation of G9a was found to be mediated by $\Delta \mathrm{FosB}$, substantiating the predominant role of this transcription factor in cocaine addiction. 
In addition to histone PTMs, several studies have determined that DNA methylation and its enzymatic mediators also regulate cocaine addiction. Thus chronic cocaine exposure led to increased expression levels of Dnmt3a (but not of Dnmt1 or Dnmt3b) in the NAc, and virus-mediated overexpression of this enzyme in control animals abolished cocaine-induced place preference (179). Morphologically, these behavioral effects were accompanied by increased spine density in the NAc. Of note, the enhanced expression of Dnmt3a seems to be itself caused, at least in part, by epigenetic modifications, since the transcription-enabling trimethyl H3K4 mark was found in its promoter region, but not in that of the other enzymes examined. Similar to Dnmt3a, MBD1 and MeCP2 levels were increased following chronic cocaine self-administration in the rat dorsal striatum, cortex, and hippocampus $(41,144)$, and virus-mediated knock-down of MeCP2 decreased cocaine intake (144). Interestingly, MeCP2 regulates cocaine addiction via downregulating microRNAs miR-212 and miR-132, which then allows for increased expression levels of $B D N F$, a molecule known to promote cocaine self-administration (114).

Focusing on the reversal of addiction, a recent study revealed that also extinction of cocaine-induced behavior can be facilitated by the HDACi SB, which was accompanied by increased H3K14 acetylation levels in the mouse NAc (215). This finding is thus somewhat in contrast to other studies reporting that HDACis facilitate cocaine addiction $(175,298,353)$, but reminiscent of the fact that VPA can facilitate extinction of fear memory (34). These observations would therefore speak in favor of extinction being a relearning of the nonconditioned state, be that nonaddictive or non-fear-conditioned, rather than simple erasure of the memory trace (247). The future challenge lies here to determine what occurs molecularly by HDAC inhibition that facilitates extinction.

Finally, it is interesting to note that at least for the genes surveyed in these studies, acute and chronic cocaine exposures seem to differ in the epigenetic programming they activate (339), with acetylated H3 being a preferential mark for the chronic type. This observation is reminiscent of the differential epigenetic programming elicited by acute and chronic seizures, in which chronic, but not acute, ECS altered H3 acetylation (341). Hence, H3 acetylation might represent an epigenetic mark preferentially installed on continuously activated genes.

B) AMPHETAmine. Similar to chronic cocaine exposure, the expression of $c$-fos was found unchanged after chronic amphetamine exposure (283), whereas the expression of $\triangle F o s B$, a stable splice product of FosB was transcriptionally increased (227). As it turns out, $\Delta$ FosB is the causative agent of c-fos silencing. Thus, after chronic amphetamine exposure, $\Delta \mathrm{FosB}$ was found to bind to the $c$-fos promoter region and to interact with HDAC1, which was accompanied by decreased $c$-fos promoter acetyla- tion (283). Indicative of a cross-talk between $\Delta \mathrm{FosB}$, HDAC1, and the HMT Suv39H1, the mRNA expression of which was upregulated, dimethylation of H3K9 was increased at the $c$-fos promoter, thus further substantiating $c$-fos' transcriptional silence in the context of amphetamine addiction.

Equally similar to cocaine addiction, a recent report also demonstrated a role for DNA methylation in amphetamine addiction. Thus mice hypomorphic for $\mathrm{MeCP} 2$ showed reduced conditioned place preference, a measure of addiction, to amphetamine, and phosphorylation of MeCP2, a mark of the protein's activation, was significantly increased following amphetamine exposure in the NAc (74).

\section{Addiction to sedatives}

A) ALCOHOL. Alcohol addiction is a chronic recurring disorder that causes alterations in synaptic plasticity and related neuronal functions in the brain (reviewed in Ref. 238). Although some evidence has already suggested a contribution of epigenetic mechanisms to alcohol-mediated addiction (see Ref. 113), most of these studies have focused on peripheral tissue, but not the brain. Recently, however, epigenetic alterations following both acute and chronic alcohol consumption have also been shown to occur in the brain.

The first such study found a striking correlation between the anxiolytic effects of acute alcohol consumption and an increase in $\mathrm{H} 3$ and $\mathrm{H} 4$ acetylation in the rat amygdala, which was accompanied by decreased HDAC activity and increased protein levels of the HAT CBP (261). Conversely, withdrawal from chronic alcohol consumption led to the exact opposite molecular effects, which, together with the anxiety-like behavior upon withdrawal, could be reversed by TSA administration.

Chronic alcohol consumption was further shown to not only affect amygdala epigenetics, but also cortical and striatal mechanisms. Four- to five-week-old rats were chronically administered ethanol for several consecutive days, and their brains were analyzed 2 days later. Both the frontal cortex and the NAc had hyperacetylated H3K14 and H4K12 levels, whereas no change was found in the hippocampus (267). Interestingly, however, striatal acetylation levels were decreased, and adult rats exposed to the same dose of alcohol showed no epigenetic changes in their brain. This suggests two things: 1) alcohol administration elicits brain-region specific histone codes, and 2) there seems to be a critical period as to when alcohol exposure can elicit brain-specific epigenetic changes. However, more studies are still required to circumscribe this time-window better. Alternatively, the amount of alcohol and whether or not it was administered in bulk or repetitively might also result in different epigenetic out- 
comes. Indeed, in a rat model of "binge" drinking, no epigenetic changes were found in the brain (165).

\section{Addiction to analgesic opiates}

A) MORPHINE. Morphine is one of the most common analgesic opiates, which, when repetitively administered, can lead to addiction. In the brain, morphine acts via $\mu$-opioid receptors (MORs), which are unevenly distributed throughout different brain areas. This distribution pattern seems to be caused, at least in part, by brain-area specific DNA methylation and histone PTMs (143). In the cerebellum, for instance, the MOR promoter DNA is highly methylated and bound by both DNMT1 and MeCP2, which results in low $M O R$ expression. In the hypothalamus, in contrast, the MOR is transcriptionally active, which is associated with low DNA methylation patterns and absent binding or DNMT1 and MeCP2. Accordingly, in vitro, MOR expression could be induced by the demethylating drug 5-aza, and also by the HDACi TSA, suggesting that histone acetylation coregulates MOR expression (143). On the behavioral level, the HDACi SB facilitated morphine-induced addictive behaviors and increased phosphorylated H3S10 in a subpopulation of striatal neurons in mice (298). However, the mechanisms underlying these observations, and in particular whether the behavioral changes are due to epigenetic alterations of the $M O R$ promoter remain to be elucidated.

\section{B. Depression}

Depression is a very common enduring mood state characterized by despair, helplessness, and social withdrawal. Often, antidepressant treatments can only change this condition when given repeatedly and over a long period, suggesting the involvement of stable molecular changes (339). In animals, depression can be mimicked by social defeat, a behavioral paradigm in which the experimental subject is exposed to a more aggressive conspecific (22). When brought together again, chronically exposed animals tend to avoid contact with the aggressor (339). On the level of the chromatin, such social avoidance was shown to result in stable hippocampal downregulation of two splice variants of Bdnf, BdnfIII, and $B d n f I V$, accompanied by increased transcriptionally repressive H3K27 dimethylation of their promoter regions (340). Strikingly, this histone modification was still present several weeks after the removal of the aggressor, indicating a persistent epigenetic mark of these two Bdnf transcripts. Similarly, chronic social defeat stress was recently found to increase the repressive mark H3K9 trimethylation in the promoter region of orexin, a gene implicated in emotional processes, in the murine hypothalamus (211).
Treatment of these mice with the antidepressant imipramine reversed the repression of the Bdnf transcripts, surprisingly, however, not through reversal of the dimethylated H3K27, but via increased H3 acetylation (on K9/K14) and H3K4 dimethylation (340), markers of transcriptional activation (172). The upregulated H3K4 dimethylation upon imipramine treatment was further corroborated in an in vitro study using another class of antidepressants, monoamine oxidase (MAO) inhibitors, which resulted in the same H3K4 dimethylation increase (184).

A potential explanation for at least the acetylation changes is the downregulation of HDAC5 upon chronic imipramine administration (340). Presumably, the methylation changes would then be caused by an HDAC5mediated epigenetic cross-talk. Accordingly, viral-mediated overexpression of HDAC5 reversed the imipramineinduced antidepressant increase in $\mathrm{H} 3$ acetylation and $B d n f I I I$ and BdnfIV transcription (340). Based on these grounds, HDACis came soon into the focus as potential antidepressants (339), which was experimentally confirmed when SB was found to exert antidepressant effects not only in the chronic social defeat model (340), but also in mice undergoing a tail suspension test (302), a behavioral paradigm to assess despair. However, it should be noted that the HDACi SB failed to exert antidepressantlike effects in the forced swim test (125), another test for behavioral despair. Therefore, it is likely that different types of HDACis are differently effective as antidepressants by each modifying distinct cellular targets.

Notably, chronic social defeat was found to have the opposite effect on HDAC5 in a different brain region, the NAc (285). Here, chronic stress decreased the mRNA levels of $H D A C 5$, whereas imipramine treatment increased them. Accordingly, HDAC5 knockout mice showed strong signs of depression, which could not be ameliorated by imipramine treatment. In agreement with these results, NAc levels of another HDAC, HDAC2 (but not of HDAC1 or HDAC3), were found to be significantly downregulated after chronic social defeat in mice, and in human post mortem NAc samples of persons with a history of clinical depression (66). Given such downregulation of HDACs in depression, it is therefore somewhat surprising that HDACis have been demonstrated to have antidepressant properties. This may be due to either other HDACs that have not been monitored in these studies, to the brain-region specific distribution of HDACs (36), or, although unlikely, to HDAC-unrelated properties of HDACis. Notwithstanding, providing further support for the efficacy of HDACis against depression, in situ injections of MS-275, a class I HDAC-specific inhibitor, reversed the depressive-like phenotypes in mice after chronic social defeat (66). This effect could be replicated by the HDACi SAHA and was further accompanied by increased H3K14 acetylation (66). 
In addition to histone PTMs, there is evidence for an impact of antidepressants on DNA methylation. Chronic antidepressant treatment with fluoxetine not only increased HDAC2 mRNA levels accompanied by hypoacetylated levels of $\mathrm{H} 3$ on $\mathrm{K} 9$ and K14, but it also enhanced $M e C P 2$ and $M B D 1$ transcription in the rat forebrain, including the frontal cortex, hippocampus, and striatum (41). The antidepressant-dependent increase in $\mathrm{MeCP} 2$ was specific to GABAergic interneurons (41). This finding is of particular interest, since abnormal GABAergic transmission and abnormalities in GABA-related gene methylation have been linked to major depression and suicide. Depressed patients who committed suicide have higher levels of methylation in the $\mathrm{GABA}_{\mathrm{A}} \alpha 1$-receptor subunit promoter, and increased DNMT3b mRNA and protein in the prefrontal cortex compared with control individuals who died of other causes (274). This suggests the intriguing possibility that antidepressant treatments might specifically target the epigenetic machinery in cell types affected by depression, but this remains speculation for the time being.

\section{Schizophrenia}

Schizophrenia is a common form of psychosis, with an approximate prevalence of $1-2 \%$ in the United States among people 18 years old and older (280). Schizophrenia is characterized by "positive" symptoms such as hallucinations and thought disorder as well as "negative" symptoms such as asociality, anhedonia, and an overall lack of motivation. While the causes of schizophrenia are not well understood, they are likely to involve a genetic predisposition as well as environmental factors during the pre- and postnatal development (reviewed in Ref. 84).

The molecular mechanisms underlying the influence of such environmental factors upon the onset and progression of schizophrenia are not fully understood, but several lines of evidence suggest that schizophrenia is associated with aberrant epigenetic regulation in both neurons and oligodendrocytes. Initial studies implicated the extracellular matrix protein reelin, a glycoprotein that is expressed in GABAergic neurons during development and adulthood, and is important for neuronal migration $(64,83)$. Post mortem analyses in schizophrenic patients revealed that reelin mRNA and protein expression are significantly reduced in several brain regions $(123,145)$. This reduction may be caused by an alteration of the methylation profile of the reelin promoter, possibly by hypermethylation, since in vitro administration of the DNMT inhibitor 5-aza increases reelin gene expression (50).

Glutamate decarboxylase (GAD67), which catalyzes the production of GABA, provides an even better-documented example of the involvement of DNA hypermeth- ylation in schizophrenic GABAergic dysfunction. GAD67 mRNA and protein expression are downregulated in cortical structures of schizophrenic patients $(123,145)$. This decrease is paralleled by increased methylation of the GAD67 promoter (136) and, indicative of cross-talk between histone acetylation and DNA methylation, inversely correlated to HDAC1 levels (308). Similar to the GABAergic system, increased methylation of the CpG island of the promoter region of the oligodendrocyte-specific transcription factor $S O X 10$ and the decreased mRNA expression of SOX10 were observed in the brains of schizophrenic patients (146).

The abnormal hypermethylation of the GAD67 and SOX10 promoters are hypothesized to be caused by elevated levels of SAM and increased expression of DNMT1 $(124,349)$. Indeed, the administration of SAM can induce psychotic episodes in some schizophrenic patients (10). Due to the aberrant hypermethylation observed in the schizophrenic brain, DNMT inhibitors have been proposed as potential therapeutic agents for this disease (50, $63,189)$.

Unlike the hypermethylation in the GABAergic system observed in schizophrenic patients, hypomethylation was detected in the dopaminergic system. Increased activation of catechol-O-methyltransferase (COMT), an enzyme involved in the degradation of dopaminergic neurotransmitters, is associated with impaired attention and working memory, and with an elevated risk for schizophrenia (347). Reduced methylation of the COMT promoter has been observed in the frontal lobe of schizophrenic patients and is associated with increased activation of the gene (1).

The chromatin in the brains of schizophrenic patients is also characterized by differential histone PTMs. For instance, VPA, a potent HDACi, is regularly prescribed as a mood stabilizer in the treatment of schizophrenia (112). Notably, VPA administration not only decreases HDAC activity, but also increases reelin expression both in vitro and in vivo by decreasing reelin promoter methylation $(50,338)$. While the mechanism explaining the relationship between HDAC inhibition and altered DNA methylation is still unknown, HDAC inhibition is thought to operate via regulating the accessibility of DNMTs to promoter regions, or by direct induction of DNA demethylase activity $(176,339)$. Additionally, two antipsychotic drugs that act as dopamine D2 receptor antagonists, haloperidol and raclopride, induce phosphoacetylation of $\mathrm{H} 3$ in the mouse striatum (194). Thus it appears that decreased acetylation is also involved in the pathology of schizophrenia, which, in conjunction with aberrant DNA hypermethylation, can be readily reversed by HDACis. However, due to the nonspecific effects of the antipsychotics described above, direct evidence for this hypothesis is lacking. 


\section{Vulnerability to Stress}

Heightened stress vulnerability and inappropriate stress-coping behaviors are common brain dysfunctions. It is now widely recognized that an organism's stress resistance is predetermined by the early life environment, both before and after birth $(210,304)$. The environments experienced during these periods, i.e., in utero and under maternal care, are thought to induce epigenetic modifications of gene expression in the brain that persist into adulthood when they can ultimately contribute to maladaptive stress-coping behaviors (329). On top of that, epigenetic modifications of the stress response are not limited to the environment during early life. As described above, chronic social defeat stress, an animal model to induce depressive-like behaviors in adult animals, acts in part via persistent changes of the epigenome, and so do other "stressors" in adulthood, which we will describe at the end of this section.

\section{Postnatal early life stress}

In mammals, the quality of early life is primarily determined by maternal care and accessibility to nutrition. In mice and rats alike, maternal care takes the form of arched-back nursing (AB) and licking/grooming (LG), two behavioral traits exhibited by most rodent species but which vary greatly between strains (45). These two maternal demeanors critically influence the offspring's behavior and shape their responsiveness to stress and their level of anxiety (229). At the molecular level, such responsiveness is in part regulated by glucocorticoid and glucocorticoid receptors (GR). High levels of circulating glucocorticoids raise the body's alertness and increase the stress response, while lower levels result in a more "relaxed" behavior and attenuate the stress response. Conversely, high levels of GR in forebrain areas such as the hippocampus provide a negative feedback that reduces the production of glucocorticoids and thereby dampens the stress response (reviewed in Ref. 305). Intriguingly, offspring of high-LG-ABN mothers show increased GR expression and reduced reactivity to stress, whereas offspring of low-LG-ABN mothers have decreased GR expression and increased stress reactivity (199).

Both the reactivity to stress and the GR system are subject to epigenetic modifications in early life (Fig. 5). In the offspring of high LG-ABN female rats, the expression of $G R$ exon $1_{7}$ is increased, which is accompanied by DNA hypomethylation and H3K9 hyperacetylation in its promoter region, which is bound by the transcription factor NGFI-A (also known as Egr-1 or Zif268) (360). In contrast, in the offspring of low LG-ABN females, the $G R$ exon $1_{7}$ promoter is unchanged in terms of histone acetylation, yet hypermethylated at the DNA level, and less bound by
NGFI-A, which is accompanied by increased $G R$ exon $1_{7}$ expression. Remarkably, the binding of NGFI-A to the GR promoter region is required for the occurrence of DNA methylation changes, as site-directed mutagenesis against the 3 ' binding site of NGFI-A within the GR promoter not only abolished NGFI-A binding, but also promoter methylation (358). This finding suggests that the transcription factor NGFI-A itself or its yet to be determined interaction with members of the DNA methylation machinery convey the methylation changes.

Importantly, although stable, these epigenetic changes can be reversed by environmental or pharmacological manipulations. Cross-fostering of pups, or treatment with the HDACi TSA, leads to GR promoter DNA hypomethylation and histone hyperacetylation in low LG-ABN offspring (360). Likewise, methyl supplementation via the administration of L-methionine, a SAM precursor, can reverse the GR-mediated maternal programming of the stress response (361). Both treatments have further been shown to modulate the transcriptome in the hippocampus in both high and low LG-ABN offspring (359), which suggests that the type of maternal care not only influences DNA methylation and histone acetylation at the GR promoter, but also on other genes.

Crucially, the implication of epigenetic regulation of GR was recently confirmed in a study involving post mortem human brain samples (228). In this study, the mRNA levels of hippocampal $G R$ exon $1_{\mathrm{F}}$, the human homolog of the rat exon $1_{7}$, were decreased and the DNA methylation level in its promoter region correspondingly increased in suicide victims with a history of childhood abuse, but not in age-matched control subjects including suicide victims without such history and people having died from other causes. These findings strongly suggest that in rodents and humans alike, childhood neglect can cause life-long epigenetic alterations of gene expression in the brain's stress system (Fig. 5).

It should be noted, however, that a recent study found a somewhat contradictory result in that DNA methylation might not be causally involved in reducing $G R$ expression (7). Thus human post mortem hippocampal samples of persons with major depressive disorder did not exhibit changes in the DNA methylation of the $G R$ promoter region, despite its mRNA levels being reduced. Instead, NGFI-A levels were significantly reduced, suggesting that the GR expression is rather caused by a depression-related deficit in NGFI-A. However, as the samples in these studies did not have a history of childhood abuse, it cannot be ruled out that the pathomechanisms leading to stress differ depending on the etiological circumstances.

Early life stress can further be experimentally induced by exposing neonates to maternal separation or to an aggressive foster mother. Investigating the epigenetic and behavioral consequences of maternal separation in 

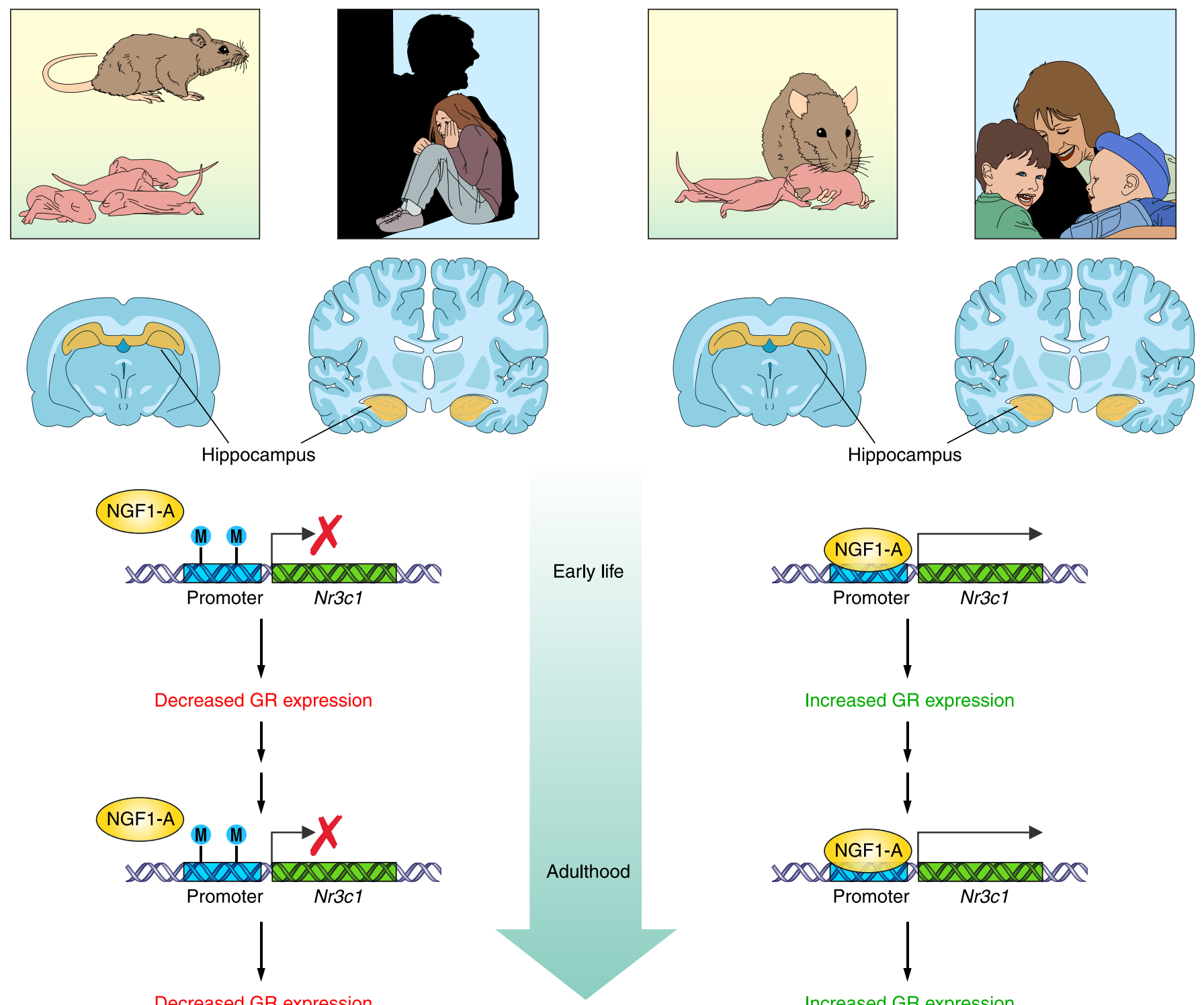

Decreased GR expression

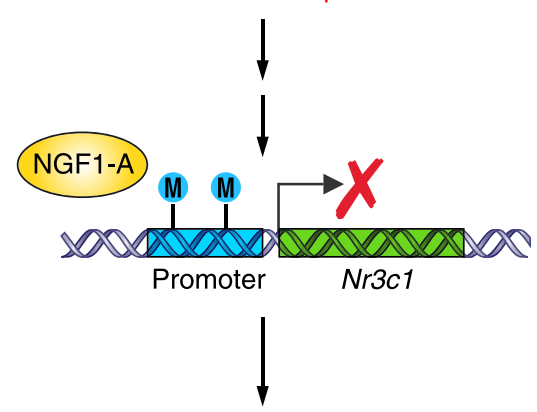

Decreased GR expression

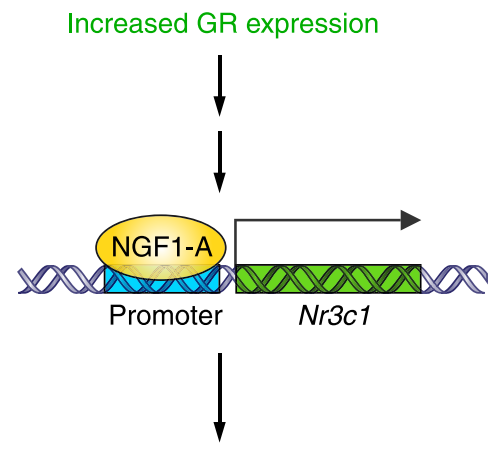

Increased GR expression

FIG. 5. The early life environment epigenetically shapes the stress response later in life in both rats and humans. A: in rats, low maternal care, and in humans, parental abuse, lead to increased DNA methylation in the promoter region of the glucocorticoid receptor (GR) gene, which impinges on its gene expression in the hippocampus, a brain area implicated in the stress response. Note that in rats, the expression of the GR gene has in addition been shown to depend on the transcription factor NGF1-A, which cannot bind the GR promoter region when hypermethylated. These epigenetic and gene expression changes persist into adulthood, when they lead to a heightened stress response, at least in the rat model. $B$ : high maternal care in rats, indicated by a high rate of licking and grooming and arch-back nursing, and the absence of parental abuse in humans, do not increase the promoter methylation of the glucocorticoid receptor, which in turn allows for elevated gene expression that is, at least in rats, mediated by NGF1-A. Again, both epigenetic and gene expression changes have been shown to persist into adulthood, when they result in a lowered stress response, at least in the rat model. Note that in humans, the behavioral consequences of low versus high GR promoter methylation are not known.

mice, a recent study found that periodic mother-infant separations led to DNA hypomethylation in the promoter region of the arginine vasopressin (avp) gene and a concomitant increase in the expression of avp in the hypothalamus (245), a gene and brain region, respectively, implicated in the brain circuitry activated by stress-coping. These molecular changes were installed as early as 6 wk of age, persisted into adulthood, and were accompanied by increased helplessness towards stressful situations.
Another study investigated whether early life abuse mimicked by a stressed and abusive foster mother results in epigenetic programming of adult behavior. Early life maltreatment was found to induce persistent DNA hypermethylation in the BDNFIV and $I X$ promoter regions in the rat prefrontal cortex that lasted into adulthood and magnified with age (292). DNA hypermethylation was further accompanied by decreased total $B D N F$ expression, and both could be reversed by infusion of the DNMT1 inhibitor zebularine. 
Although these animals were not tested behaviorally, this study provides further evidence that the early life environment can leave life-long marks on the epigenome. Noteworthy, such marks might get installed with some delay, as the $G R$ exon $1_{7}$ promoter DNA methylation was found to be unchanged until 7 days after the last maternal separation in the rat hippocampus (70).

Finally, a highly intriguing observation of early life stress is that it might also affect subsequent generations. For instance, rat pups raised by mothers that display high nurturing levels become high nurturing mothers themselves (93), raising the possibility that the epigenetic programming of the stress response can have behaviorally transmitted transgenerational effects. Two recent studies further extended this observation to the chromatin level itself. In the first, female pups of abusive mothers gave birth to offspring with DNA methylation profiles in the prefrontal BDNF promoter strikingly similar to their own (292). And in the second, maternal stress-induced DNA methylation changes at the $M e C P 2, C B 1$ (cannabinoid receptor 1) and CRFR2 (corticotropin-releasing factor 2) genes were similar in the sperm of males subjected to maternal stress, and fascinatingly, also in the brain of their offspring, which themselves did not experience any maternal stress, but showed comparable levels of anxiety and depression-like phenotypes (95). If such behaviorally induced transgenerational epigenetic inheritance will get further confirmed, and its evidence extended from the mere, albeit stunning correlative evidence to a more firm proof, epigenetics would have the potential to revolutionize the perception of the inheritance of acquired traits.

\section{Prenatal early life stress}

The brain and with it the stress response are highly susceptible to environmental contingencies during development, which also includes the prenatal period $(23,210)$. Although the consequences of an aversive prenatal environment have been investigated for a long time, surprisingly few studies have experimentally addressed the potential of epigenetic mechanisms in mediating these longterm consequences (71). In mice, chronic variable stress to pregnant mothers led to increased depressive-like behaviors in their male offspring, which was accompanied by increased amygdala transcription of the stress hormone corticotropin-releasing factor $(C R F)$ and decreased hippocampal transcription of $G R$ (244). These changes were paralleled by decreased and increased promoter DNA methylation, respectively, which suggests that prenatal stress activates the epigenetic machinery to modulate the stress response later in life. Interestingly, these changes were only observed when prenatal stress occurred during the first trimester, but not later, highlighting this period as very susceptible to environmental influ- ences. Also, the behavioral and molecular differences were exclusively observed in male offspring, which is indicative of sex differences in brain development during that time and warrants further studies.

Stunningly, in humans, pregnant women with depression or anxiety-related disorders during their third trimester were found to have neonates (both sexes) with a hypermethylated promoter region of $G R$ exon $1_{\mathrm{F}}$ in leukocytes, which correlated proportionally with the degree of maternal depression (256). Intriguingly, 3 mo later, infants with hypermethylated $G R$ exon $1_{\mathrm{F}}$ at birth displayed higher saliva corticosterone levels. Follow-up studies are still pending. From the present standpoint it is, however, not clear how maternal stress, which is supposedly "perceived" in the mother's brain, could translate onto the epigenetic niveau in the blood and brain of the offspring. One contact point between the mother and the fetus is the placenta, where early pregnancy stress did indeed reduce DNMT1 levels (244). But, whether this is also the case for late pregnancy stress, plus the exact signaling pathways behind this observation, remain to be determined.

\section{Other postnatal "stressors"}

Novelty, threats, and forms of physical discomfort all represent stressful situations, and several examples thereof have been demonstrated to activate the epigenetic machinery in the adult brain.

A) NOVELTy. Remarkably, the exposure to a novel environment alone, be that an unfamiliar box or a water tank, has been shown to be sufficient to induce H3 phosphoacetylation changes in the rat hippocampus $(25,60)$. Although no memory tasks have been performed in these studies, their findings highlight the necessity for proper control groups when memory-related epigenetic mechanisms are under investigation. The "stress-alone" group, i.e., before the actual learning procedure starts, should also to be taken into consideration.

B) THREATS. Similar to chronic social defeat stress leading to depressive-like phenotypes, the mere reminder of an aggressor or a predator, i.e., its odor, can lead to symptoms reminiscent of posttraumatic stress disorder. For example, the exposure to cat odor was recently shown to not only lead to heightened anxiety, but also to broad DNA methylation changes in the rat hippocampus, including the promoter region of disc-large associated protein 2 (Dlgap2) (53), a component of the postsynaptic density.

C) RESTRAINT. Finally, physical restraint for $2 \mathrm{~h} /$ day led to a transient decrease in $B D N F$ mRNA (exons I, IV, and IX) expression as soon as $2 \mathrm{~h}$ after the end of the immobilization, which was accompanied by hypoacetylated H3 and $\mathrm{H} 4$ levels in their respective promoter regions in the rat hippocampus (97). Twenty-four hours after immobili- 
zation, both the transcript and acetylation levels were back to baseline.

Taken together, these findings underscore the rapid dynamics of epigenetic changes in response to a variety of environmental stimuli, and as a consequence, the need for proper experimental design to rule out confounding variables in response to stress. This is particularly important when learning and memory are under investigation, as animals are often trained with novel objects or in novel environments.

\section{PATHOLOGICAL EPIGENETIC REGULATION III: NEURODEGENERATIVE DISORDERS}

In contrast to the developmental disorders listed above, which have an obvious epigenetic component, the evidence for an epigenetic implication in adult-onset neurodegenerative disorders is not as clear-cut. Nonetheless, emerging evidence indicates that epigenetic mechanisms are indeed involved in the pathogenesis of various neurodegenerative disorders (Table 5), be that causally or at least in a modifying manner. This in turn is increasingly often leading to the use of epigenetic drugs to treat these disorders, with justified therapeutic potential. However, as in the case of Alzheimer's disease, multiple and diverging findings suggest multiple and complex mechanisms of an epigenetic deregulation that once again illustrate the need for a more thorough understanding of these aberrant mechanisms.

\section{A. Huntington's Disease}

Huntington's disease (HD) is a rare, hereditary neurodegenerative disorder with the hallmark symptom being a loss of coordinated movement, as well as additional symptoms such as progressive cognitive decline and muscle atrophy. Symptoms are generally first manifest between midlife (ages 35-50), but can appear from any age. During HD progression, neurons are progressively lost. The striatum is the brain region most prominently affected, although multiple other regions including substantia nigra, cortex, and cerebellum are also struck by HD. On a cellular level, spiny neurons of the striatum appear to be the most vulnerable cellular subtype.

TABLE 5. Epigenetic mechanisms in neurodegenerative disorders

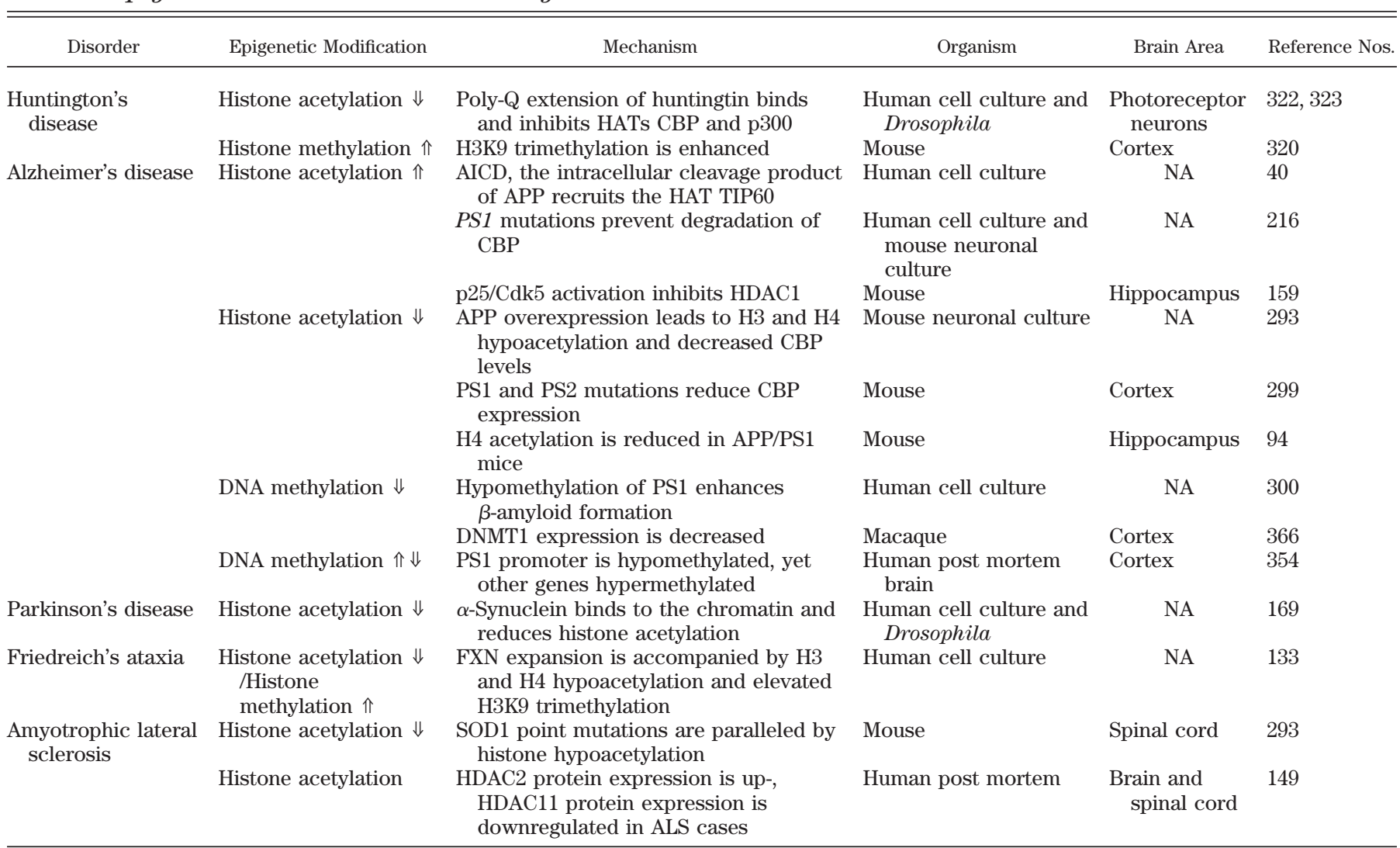

AICD, APP intracellular domain; ALS, amyotrophic lateral sclerosis; APP, amyloid precursor protein; CBP, CREB-binding protein; Cdk5, cyclin-dependent kinase 5; DNMT1, DNA methyltransferase 1; FXN, frataxin; H, histone; HAT, histone acetyltransferase; HDAC, histone deacetylase; K, lysine; NA, not applicable; PS, presenillin; Q, glutamine; SOD1, superoxide dismutase 1. 
HD is caused by an abnormally high number (over 36) of CAG repeats in the $5^{\prime}$ end of the coding region of the huntingtin gene. The number of repeats affects the severity and age of onset of disease. Thus, while a critical component of HD is inheritance of a HD allele with large number of repeats, this number can be increased or reduced between generations. High numbers of repeats result in a mutant Huntingtin protein containing a $5^{\prime}$ polyglutamine repeat region, which has altered characteristics such as a gain of self-aggregation properties (29).

A number of differing theories exist as to the precise mechanism for progressive neuronal death observed in HD. Both loss-of-function and toxic gain-of-function theories have been proposed, but recent studies using transgenic mouse models overexpressing high-CAG-repeat huntingtin, which recapitulates many of the features of $\mathrm{HD}$, strongly support a gain-of-function. One of the theories for mutant huntingtin toxicity is based on the finding that the polyglutamine repeat region binds to the acetyltransferase domain of two histone acetyltransferases, $\mathrm{CBP}$ and p300/CBP-associated factor $(322,323)$. This appears to sequester these actyltransferases, resulting in globally reduced $\mathrm{H} 3$ and $\mathrm{H} 4$ acetylation levels, and altered gene expression. Further supporting the notion of HD as a disease of aberrantly reduced histone acetylation, treatment with various HDAC inhibitors has been shown to rescue histone acetylation levels and to improve neurodegeneration and pathological symptoms in cellular, Drosophila, and mouse models (88, 104, 135, 296, 322, 337) (Table 6).

Despite the wealth of evidence that histone acetylation is deregulated but amenable to pharmacological treatments in $\mathrm{HD}$, it is important to note that beneficial effects of HDACis might also be mediated by cytoplasmic proteins, rather than histone proteins. Thus, upon treatment of mouse striatal cultured cells with HD pathology with the HDAC6-specific inhibitor tubacin, $\alpha$-tubulin acetylation was increased and some of HD pathology were reversed (77). Likewise, genetic and pharmacological HDAC6 inhibition proved also beneficial against oxidative stress-induced neuronal damage, and this effect was seemingly transcription-independent (288). It is thus entirely possible that more non-histone proteins are affected by the use of HDACis, and further studies are required to determine the precise contribution of both histone and non-histone protein hypoacetylation in HD (for a review, see Ref. 39).

In addition to acetylation, histone methylation is also altered in mouse models of $\mathrm{HD}$, in which $\mathrm{H} 3 \mathrm{~K} 9$, a mark for transcriptional repression (172), was found to be hypermethylated (89, 320). Interestingly, these epigenetic marks and HD-typical locomotor deficits could be restored by intraperitoneal injection of DNA/RNA-binding anthracyclines, potent anticancer drugs (320), as well as by the HDACi phenylbutyrate (104). These findings point to a joint deregulation of both histone acetylation and methylation in $\mathrm{HD}$, but the precise molecular mechanism linking these epigenetic marks remains to be investigated.

\section{B. Alzheimer's Disease}

Alzheimer's disease (AD) is the most common of all neurodegenerative disorders, with current worldwide estimates of 20 million affected people. $\mathrm{AD}$ is clinically characterized by a progressive decline in cognitive abilities, and histologically by amyloid plaques, neurofibrillary tangles, and neuronal loss. Neurons are progressively lost during disease progression from the hippocampus, cortex, and other regions. Almost all $\mathrm{AD}$ cases are sporadic, but various rare hereditary forms of $\mathrm{AD}$ have been identified, all of which involve mutations in amyloid precursor protein (APP), or in presenilins 1 and 2 (PS1 and -2), which are involved in the processing of APP to form the $\beta$-amyloid constituents of amyloid plaques.

A number of differing epigenetic abnormalities pertaining to histone acetylation have been reported in $\mathrm{AD}$. During the processing of APP, an intracellular fragment is released into the cytosol, which was shown in vitro to interact with the HAT TIP60 through the protein Fe65, and the resulting complex was suggested to enhance gene transcription (40). This complex may also play a role in histone $\mathrm{H} 4$ acetylation required for DNA repair, an interesting notion considering that the amount of DNA doublestrand breaks are increased in $\mathrm{AD}$ and $\mathrm{AD}$ models $(4,159)$. Furthermore, PS1 was shown to play an inhibitory role on the HAT CBP through proteasomal degradation, and mutations in PS1 found in hereditary AD were shown to result in aberrantly high CBP activity (216). Also, p25/ $\mathrm{Cdk} 5$, a kinase complex implicated in $\mathrm{AD}$ and other neurodegenerative disorders, was shown to inhibit HDAC1, rendering neurons susceptible to DNA damage, cell cycle reentry, and ultimately cell death (159). These findings suggest that $\mathrm{AD}$ could be a disease of aberrantly increased histone acetylation. In support of this notion, it was shown that overexpression of HDAC1 could rescue against p25/Cdk5-mediated DNA damage and neurotoxicity. Along similar lines, overexpression of the class III HDAC SIRT1 rescued neurons not only against p25/Cdk5mediated neurotoxicity (160), but also against another transgenic mouse model of AD (APP/PS1) (78) via mechanisms involving p53 and $\alpha$-secretase, respectively, although it is not clear whether in these cases SIRT1 had a deacetylating effect on histones as well.

On the other hand, paradoxically, a substantial body of evidence rather supports the notion that inhibition of HDACs can be protective and beneficial in AD. Thus APP overexpression in cultured cortical neurons led to H3 and $\mathrm{H} 4$ hypoacetylation, and was paralleled by decreased CBP levels (293). Similarly, loss-of-function mutations in genes 
coding for PS1 and PS2 not only impaired synaptic plasticity, and spatial and contextual memory, but also reduced the expression of $C B P$ and CBP/CREB target genes such as $c$-fos and BDNF (299). Moreover, in the p25/Cdk5 model of neurodegeneration, treatment with the broad HDACi SB not only increased H3 and H4 acetylation levels, but also resulted in the reestablishment of learning abilities, as well as access to long-term memories that had been ablated by prior hyperactivation of p25/Cdk5 (92). Similarly, both general and class I-selective HDAC inhibitors have been shown to ameliorate cognitive defects in transgenic $\mathrm{AD}$ mouse harboring hereditary $\mathrm{AD}$ mutation $(158,287)$. Together, this second line of data collectively suggests that $\mathrm{AD}$ is characterized by an overall hypoacetylation, which might be amenable to rescue with the use of HDACis. One recent preliminary study indeed supports this notion, in that $\mathrm{H} 4$ acetylation was decreased, yet reversible by TSA treatment in the hippocampus of the APP/PS1 mouse model of AD (94).

How can these two differing lines of evidence be reconciled? One possibility is that the onset of neurodegeneration pathologically differs from later stages of the disease. Under this scenario, p25/Cdk5 hyperactivity might at first result in HDAC1 inhibition, which triggers aberrant gene expression programs such as that of cell cycle genes. Since such a program is, however, against the destiny of neuronal cells, these supposedly react by counteracting this hyperactivation and by permanently shutting down any further gene expression increases, likely via epigenetic mechanisms including histone hypoacetylation. This, in turn, would then explain why at later disease stages, HDACis have been shown to be efficient against several $\mathrm{AD}$ and $\mathrm{AD}$-related pathologies. However, this remains speculation at this point.

Alternatively, histone hyper- and hypoacetylation are not contradictory, and it might as well be that they cooccur depending on brain area, cell type, or even in the same cell at different loci. Thus the epigenetic mechanisms at play in $\mathrm{AD}$ are most likely more complex than anticipated. Furthermore, as the HDAC inhibitors reported to ameliorate $\mathrm{AD}$ symptoms are either general or only partially selective, more specific (e.g., genetic) means are required to identify the $\mathrm{HDAC}(\mathrm{s})$ that are responsible for the therapeutic effects, and thus may also be involved in $\mathrm{AD}$ pathology. For example, it was recently found that HDAC2, but not HDAC1, is a negative regulator of memory formation and synaptic plasticity, and that HDAC2 is responsible for the beneficial effects of HDAC inhibitors on learning and memory in wild-type mice (121). It is therefore tempting to speculate that HDAC2 may mediate the effects observed in the $\mathrm{AD}$ models, yet other HDACs might also be at work.

In addition to histone acetylation, changes to DNA methylation have also been implicated in $\mathrm{AD}$ pathogenesis. Thus hypomethylation of the PS1 promoter region was found to enhance PS1 expression and $\beta$-amyloid formation in a culture model $(99,300)$. Additionally, in a primate model of $\mathrm{AD}$, DNMT1 was decreased in the cortex and associated with increased $A P P$ mRNA expression (366). Moreoever, the PS1 promoter was found to be hypomethylated in late-onset $\mathrm{AD}$ brains compared with controls (354), providing further evidence for DNA hypomethylation to be critically involved in $\mathrm{AD}$. However, as other AD-related genes were hypermethylated (354), a more thorough examination of specific loci and identification of the specific mechanisms are still required to better understand the importance of DNA methylation in $\mathrm{AD}$ pathology.

\section{Parkinson's Disease}

Parkinson's disease (PD) is the second most common late-onset neurodegenerative disorder, affecting between 0.5 and 1 million individuals in the United States as of 2000 (152). This disease is characterized by progressive loss of muscle rigidity and tremor, and slowing of physical movement. The primary affected region is the substantia nigra, in which loss of dopaminergic neurons results in decreased formation and action of dopamine. While the majority of PD cases are sporadic in nature, a number of mutations have been identified as causing hereditary PD, including $\alpha$-synuclein, a component of large intracellular eosinophilic aggregations found in PD called Lewy bodies, PARK2, ubiquitin COOH-terminal hydrolase L1 (UCHL1), components of the ubiquitin/proteasome machinery, and PTEN induced putative kinase 1 (PINK1), a kinase involved in mitochondrial stress response. Because of these genes, defects in the ubiquitination/proteasome machinery resulting in loss of protein clearance, and mitochondrial dysfunctions have been hypothesized to be pathological mechanisms in PD (239).

Over the recent years, epigenetic components to PD pathology have also been detected. For example, nuclear $\alpha$-synuclein was found to directly bind to histones and to reduce levels of histone acetylation in a Drosophila model of $\mathrm{PD}$, suggesting that histone hypoacetylation may be causally involved in PD pathology (169). Supporting this notion, inhibition of SIRT2 has been shown to rescue neurotoxicity in Drosophila (260), although it is not known whether this affected also the histone level. However, treatment of dopaminergic cell lines with the HDACi TSA exacerbated PD-related neurotoxic damage, cautioning against the general use of HDACis in PD (355).

\section{Other Neurodegenerative Diseases}

\section{Friedreich's ataxia}

Friedreich's ataxia (FA) is a neurodegenerative disease characterized by severe coordination problems as 
well as vision and hearing impairments. FA has a prevalence of 1:50,000 in the United States and is thought to be caused primarily by a GAA triplet expansion in the gene coding for frataxin (FXN), which leads to silencing of the mitochondrial protein product of this gene (262). This gene silencing was accompanied by $\mathrm{H} 3$ and $\mathrm{H} 4$ hypoacetylation and by increased H3K9 trimethylation (133), suggesting the implication of epigenetic mechanisms in FA. Interestingly, HDACis TSA and SAHA proved effective in reversing these acetylation deficits in FA patient-derived cell culture (133), and a novel HDACi, HDACi 106 had the same effect in a mouse model of FA (278). HDACis have therefore been proposed as therapeutic potential against FA-related pathologies.

\section{Amyotrophic lateral sclerosis}

Some evidence also points to the therapeutic potential of HDACis against amyotrophic lateral sclerosis (ALS) symptoms. ALS is a neurodegenerative disease mainly affecting motor neurons with symptoms broadly encompassing loss of control of voluntary muscle movements and muscular atrophy. The prevalence of ALS in the United States is $\sim 1$ in 300,000 . Although most cases of ALS occur sporadically, $\sim 10 \%$ are inherited, and these are thought to be caused by mutations in the gene superoxide dismutase 1 (SOD1). In a SOD1 point mutation mouse model of ALS, ALS symptoms were molecularly accompanied by reduced CBP levels in motorneurons (293), but VPA and TSA administration restored the resulting histone acetylation deficits together with the motor deficits back to baseline (294). However, it should be noted that VPA failed to reduce the premature mortality of these mice. A recent human post mortem study provided further evidence for a deregulation of histone acetylation in ALS. Comparing the protein expression levels of all class I, II, and IV HDACs in the ALS brain and spinal cord, HDAC2 and HDAC11 were up- and downregulated, respectively (149). The functional consequences in terms of histone acetylation changes and resulting gene expression changes remain, however, unclear.

From the examples presented above, a general picture emerges that the core pathological pathways for a given neurodevelopmental, neuropsychological, or neurodegenerative disorder often interact or interfere with components of the epigenetic machinery (Fig. 6). However, this is a relatively recent notion, and our knowledge of epigenetic mechanisms at play in these disorders is still in the stages of infancy. As illustrated by the body of research in $\mathrm{AD}$, there are likely multiple bidirectional changes to the epigenetic machinery, and resulting complex changes to the chromatin landscape. Hence, these epigenetic changes will have to be painstakingly examined for various types of modifications at a global scale to gain a clearer idea of the changes that occur during the progression of a given disorder. In turn, such an approach may identify unanticipated epigenetic changes, even in brain disorders for which pathological epigenetic mechanisms have not yet been identified.

\section{PATHOLOGICAL EPIGENETIC REGULATION IV: OTHER BRAIN DISORDERS}

\section{A. Glioma}

While cancers of the brain are relatively rare, they are among the most aggressive and lethal types. This is well exemplified by Glioblastoma Multiforme (GBM), the most common form of brain tumor which, at the relatively rare occurrence of 2-8 cases per 100,000 in the United States, still accounts for over half of all primary brain parenchymal tumors $(257,303)$. The median survival time after diagnosis is less than 12 mo, and current treatment options are largely limited to palliative and symptomatic measures. With the exception of glioblastoma observed in some cancer-prone hereditary disorders such as Li-Fraumeni Syndrome, Turcot Syndrome, or neurofibromatosis, GBMs originate in a sporadic manner (303). Amplifications of oncogenes such as epidermal growth factor receptor (EGFR), or tumor suppressors such as phosphatase and tensin homolog (PTEN), are often observed and are considered to contribute to progression of the disease. The specific cell of origin for GBMs has not been conclusively determined, but is thought to be of glial, glial progenitor, or neural progenitor identity (202).

Aberrant changes to DNA methylation are a frequently occurring and important feature of GBM that has been noted since the 1980s (101). At a gross level, it is a loss of DNA methylation that is most often observed. While the implications of this epigenetic alteration are poorly understood, it has been shown that global hypomethylation triggers genomic instability and is sufficient to lead to tumorigenesis (106).

On the other hand, controversially, subsequent genome-scale examination of DNA methylation has revealed that many loci, in particular promoter CpG islands, are hypermethylated in GBM, leading to transcriptional suppression. One of the best-characterized genes silenced in this manner is O6-methyl guanine methyltransferase (MGMT). MGMT is a DNA repair protein, which removes methyl and chloroethyl groups from $\mathrm{O} 6$ of guanine, thus repairing a potentially apoptosis-triggering DNA lesion. MGMT expression/activity positively correlates with resistance against various alkylating chemotherapeutics such as temozolomide. Conversely, methylation of MGMT, which is expected to result in reduced expression, has been found to be an important determinant of whether tumor cells are responsive to temozolomide: tumors which displayed MGMT methylation were found to be 


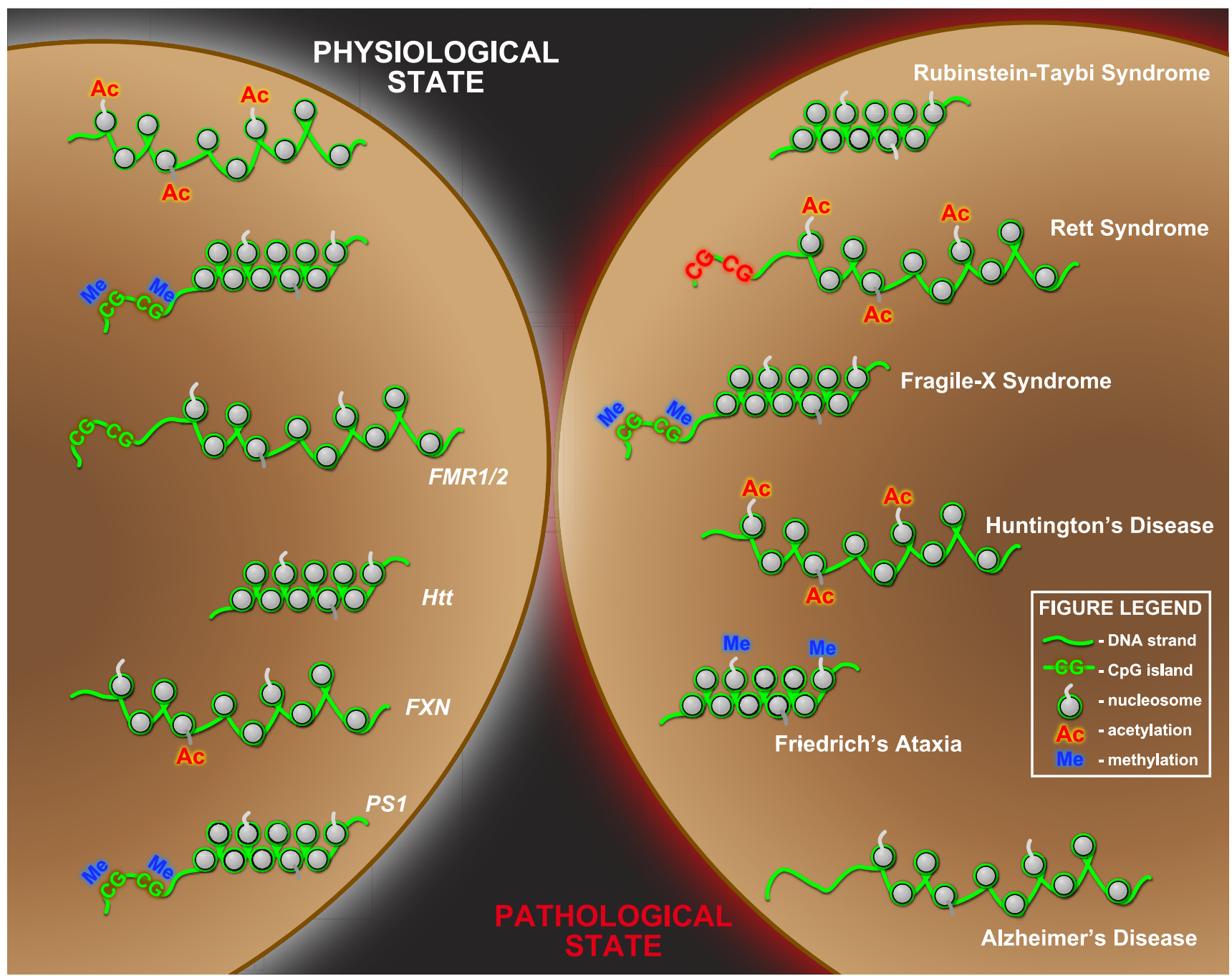

FIG. 6. Overview of the best-documented examples of epigenetic deregulation in neurodevelopmental and neurodegenerative disorders. For example, Rubinstein-Taybi Syndrome is characterized by an overall histone hyperacetylation under pathological conditions, whereas a hallmark of Rett Syndrome is an overall decrease in DNA methylation associated with increased histone acetylation. For some of the diseases, the epigenetic deregulation could be attributed to particular loci. For instance, under physiological conditions, the FMR1 and -2 genes are transcriptionally active, whereas in the neurodevelopmental disease Fragile-X Syndrome, they are silenced due to DNA hypermethylation. Conversely, the gene huntingtin (Htt) is silenced under physiological conditions, whereas in the neurodegenerative disease Huntington's Disease it becomes hyperacetylated and, as a consequence, transcriptionally active. Another example is the gene FXN, which under healthy conditions is acetylated, but in the neurodegenerative disease Friedreich's Ataxia undergoes deacetylation plus gene-silencing histone methylation. Finally, the gene PS1 is under physiological conditions strongly methylated, but in Alzheimer's Disease there is evidence that this is no longer the case, which results in increased PS1 gene transcription. Epigenetic modifications that silence gene expression are depicted in blue; epigenetic modifications that favor gene expression are in red. For details and gene names, see text.

more responsive to temozolomide chemotherapy than those which did not (132). Thus tumor biopsy evaluation of MGMT methylation may become a routine diagnostic tool to determine therapeutic approaches for individual patients.

Importantly, numerous important tumor suppressors such as PTEN, P16INK4A, or p53 have also been shown to be hypermethylated and reduced in expression in subsets of $\operatorname{GBM}(13,65,111)$, indicating that epigenetic suppression of various tumor suppressors may constitute strategies by which cancer cells gain a selective advantage during tumor formation/progression. While there is signif- icant variation among individual cases in the tumor suppressor genes that are hypermethylated and/or suppressed, in particular, P16INK4A was estimated to be reduced in expression in over $70 \%$ of GBMs, and in these cases, over $70 \%$ exhibited hypermethylation of the promoter region. Thus it appears that $\mathrm{CpG}$ island hypermethylation is highly relevant in GBM, both as a diseasedriving mechanism and as an important modifier for chemotherapy efficacy. However, the mechanisms that drive this hypermethylation are still poorly understood, but one possibility is the overexpression and/or hyperactivation of DNMTs (201). 
In addition to aberrant changes in DNA methylation, there are a few reports of changes in HDAC expression, and even mutations in HDACs and HMTs in GBM (207, 266). Thus it is possible that histone modifications may also play a role in GBM pathogenesis. Furthermore, as with many other cancer types, HDAC inhibitors have been tested in cellular and animal models for GBMs as well as other brain tumors, and have been shown to negatively affect cell growth and survival, and increase the sensitivity to radiation and chemotherapy (248).

It is important to note that cancers of the brain such as GBMs are diseases of a highly different nature compared with neurodegenerative disorders, involving hyperproliferation of non-neuronal populations. Another important distinction is that the goal of brain cancer therapy is the targeted toxicity and/or growth suppression of selected subpopulations (cancer cells), as opposed to the goal of protection against toxicity in neurodegenerative disorders. However, some important parallels can be made in that GBMs also appear to involve complex deregulation of epigenetic mechanisms, as exemplified by the involvement of both hypomethylation and hypermethylation of DNA in GBM pathogenesis. As in $\mathrm{AD}$ and other neurodegenerative disorders, it is clear that a more detailed understanding of the epigenetic changes that occur, as well as the development of more selective drugs that target the epigenetic machinery, are still required. Finally, understanding the role of epigenetics in the two different types of diseases may go hand in hand. For example, when designing a therapeutic strategy against one, epigenetic mechanisms that may trigger or contribute to the other should not be targeted. Conversely, tools and drugs developed for the therapy of neurodegenerative disorders may prove to be useful in therapy of brain cancers as well.

\section{B. Stroke/Ischemia}

Stroke and ischemia are the cause of death for an average of more than 137,000 persons in the United States every year $(134,232)$. Cellularly, ischemic damage results in an increased transcription rate of genes that control cellular stress, inflammatory, and apoptotic response genes. Interestingly, several groups have reported that treatment with various HDACis, SAHA, SB, and TSA, both prior to and following stroke induction, confers neuroprotection $(82,115,142,161,162,277,282,316)$. The idea that HDACis might be neuroprotective against ischemic cell damage originates in the observation that following cerebral artery occlusion, an animal model to induce ischemia, H3 acetylation levels show a pronounced decrease (82).

The neuroprotective effects of HDACis resulted in a decrease in infarct volume $(82,162,282)$, behavioral im- provements relative to animals not given inhibitors (162, 282), decrease in expression of several factors associated with apoptosis $(142,162,277)$, and cellular stress and inflammation $(82,162,282)$, in addition to stimulation of neurogenesis following ischemic damage (161). Molecularly, administration of HDACis led to an overall increase in $\mathrm{H} 3$ and $\mathrm{H} 4$ acetylation, potentially mediated by HDAC4 (82), which was accompanied by increased gene expression of the transcription factors $C R E B$ and $B D N F$ (161), as well as several molecular chaperones such as heatshock protein HSPrO (82, 162, 282). However, so far, gene-specific promoter analyses addressing the effect on histone acetylation both before and after HDACi treatment are to date still lacking. Nonetheless, these studies point to a potential use of HDACis against stroke and merit to be evaluated more thoroughly in the future.

\section{The Aging Brain}

The aged brain differs drastically from its adult counterpart in terms of gene expression programs (204), which are thought to contribute to age-associated memory impairments (269). Recently, two studies have shown that age-related epigenetic differences might account for cognitive decline during aging. The first assessed histone acetylation changes that are induced by learning in both aged (16 mo old) and adult (3 mo old) mice (268). Stunningly, of several histone PTMs examined, only H4K12 acetylation was absent after learning in the aged animals, specifically of the promoter region of learning and memory-related genes. SAHA treatment in the aged group not only restored their learning deficits, but also H4K12 levels comparable to nonaged animals, promoting this HDACi treatment as a potent memory enhancer. The second study examined the DNA methylation of Arc (activity regulated cytoskeletal-associated protein), a gene important for memory consolidation and synaptic plasticity. Arc transcripts were downregulated in aged rats (24-32 mo old) compared with adult animals (9-12 mo old), which was accompanied by increased DNA methylation in the promoter region of the gene in the hippocampus (270). Two studies with the same conclusion: the aged brain seems to be characterized by accumulating epigenetic silencing modifications, which shut down the expression of genes that are important for learning and memory. The aged brain is seemingly less plastic because of increased chromatin condensation.

\section{SYNOPSIS AND OUTLOOK}

From the collective body of literature on epigenetic mechanisms under both physiological and pathological conditions in the brain, two summarizing statements can be made. First, it is becoming increasingly evident that 
epigenetic mechanisms play an important modulatory role in many (if not all) biological processes throughout the brain. Second, these mechanisms are highly complex (Fig. 6). When first mentioned, the concept of the "histone code" stipulated that the reaction of a given cell to a given environment can be characterized by a given set of histone modifications $(150,344)$. Over the past year it has become obvious that such a code is indeed applicable, but must be extended to a more general concept of an "epigenetic code" that also includes DNA methylation (113, 343), and hence bears an intensive and extraordinarily complex cross-talk among these different levels of epigenetic modifications $(43,181)$.

In the brain, one of the most heterogeneous tissues overall, the complexity of epigenetic modifications is even further potentiated. First, different brain areas react differently to the same environmental challenge. For instance, whereas chronic treatment with the antidepressant imipramine decreased HDAC5 levels in the hippocampus, the same treatment increased HDAC5 levels in the NAc $(285,340)$. Second, within the same brain area, different cell types are not only by default characterized by a specific epigenomic profile (see Ref. 54 for a recent approach to characterize neuronal and non-neuronal cell types in terms of trimethylation of H3K4 in the human prefrontal cortex), but they also react differently to identical environmental stimuli. This is illustrated by the case of GABAergic and dopaminergic neurons that in the brain of schizophrenic patients seem to be characterized by DNA hyper- and hypomethylation, respectively $(1,123$, 145). Third, another level of complexity that has so far received little attention is the observation that sex differences in the brain are in part caused by epigenetic differences, and that consequently, environmental factors such as maternal nutrition can have sex-dependent effects (225). Finally, our understanding of the brain's epigenetic machinery is far from being complete. For instance, using a large-scale proteomic approach on nuclear proteins in the brain, several hitherto unidentified histone PTMs could be detected (345), the function of which remains enigmatic. Likewise, a recent study unveiled an entirely new type of epigenetic modification in the CNS, 5-hydroxymethylcytosine (173), with still mostly unclear function.

But even outside the brain, we are far from a complete picture of precisely how the epigenetic machinery works. Although HATs and HDACs are commonly regarded as transcription-activating and -repressing epigenetic enzymes, respectively, both have recently been found to bind to actively transcribed genes (356), suggesting that their impact on gene transcription is more subtle than anticipated. Moreover, enzymes of the epigenetic machinery themselves can be posttranslationally regulated (e.g., Ref. 254), the significance of and the extent to which this occurs remain poorly understood. Another observation is that although epigenetic enzymes such as HDACs supposedly act primarily in the nucleus, some HDACs such as class IIb HDACs are predominantly cytoplasmic (156). The functions of HDACs outside the nucleus have only recently started to be explored. Similar open questions concern the mechanisms that govern the shuttling of HDACs to and from the nucleus (e.g., Ref. 334 ) and the regulating pathways upstream of the epigenetic machinery (291).

\section{A. Clinical Considerations}

Despite this complexity of epigenetic mechanisms and the multitude of open questions, several epigenetic drugs have received considerable attention and have spurred justified hope as therapeutic approaches against both neurodevelopmental and neurodegenerative diseases. This is particularly true for HDAC inhibitors (2, 90, $128,156)$ because histone acetylation is not only downregulated in $\mathrm{AD}, \mathrm{HD}$, and $\mathrm{RTT}$, but also reversible by HDACis, which was accompanied by other alleviating effects for these disorders (Table 6). As a consequence, several HDACis are currently in preclinical or phase I/II trials for the treatment of $\mathrm{HD}$ and $\mathrm{AD}$.

Surprisingly, however, most of the currently used HDACis still act unspecifically and target several classes of HDACs, if not non-histone targets as well (156). Moreover, as they are often administered systemically, i.e., intraperitoneally in animals models and orally in human subjects, such treatments face the risk of undesired sideeffects, not only in the target tissue, but also body-widely. Plus, whether a treatment regimen with general HDAC inhibitors in humans is feasible for prolonged periods is another unresolved question. Likewise, little is known about the downstream effect of one epigenetic drug on other epigenetic marks, as the epigenetic machinery is characterized by the above-mentioned extensive crosstalks $(43,181)$. Indeed, HDACis themselves can be neurotoxic $(163,297)$, further cautioning against their unsurveyed use.

More specific epigenetic treatments are thus highly warranted (129). Ideally, compounds for the treatment of epigenetic brain disorders would be characterized by an efficient penetration of the blood-brain barrier, by a sufficient metabolic stability in the target tissue, and by a high, as of now not achieved, degree of selectivity (156).

\section{B. Future Directions}

To develop more potent and more selective epigenetic treatments against brain disorders, a better understanding of the epigenetic machinery is thus required. To achieve this, two main research approaches should be pursued. First, genetic models of various epigenetic com- 
TABLE 6. Investigated epigenetic "treatments" against neurodevelopmental, neuropsychiatric, and neurodegenerative disorders

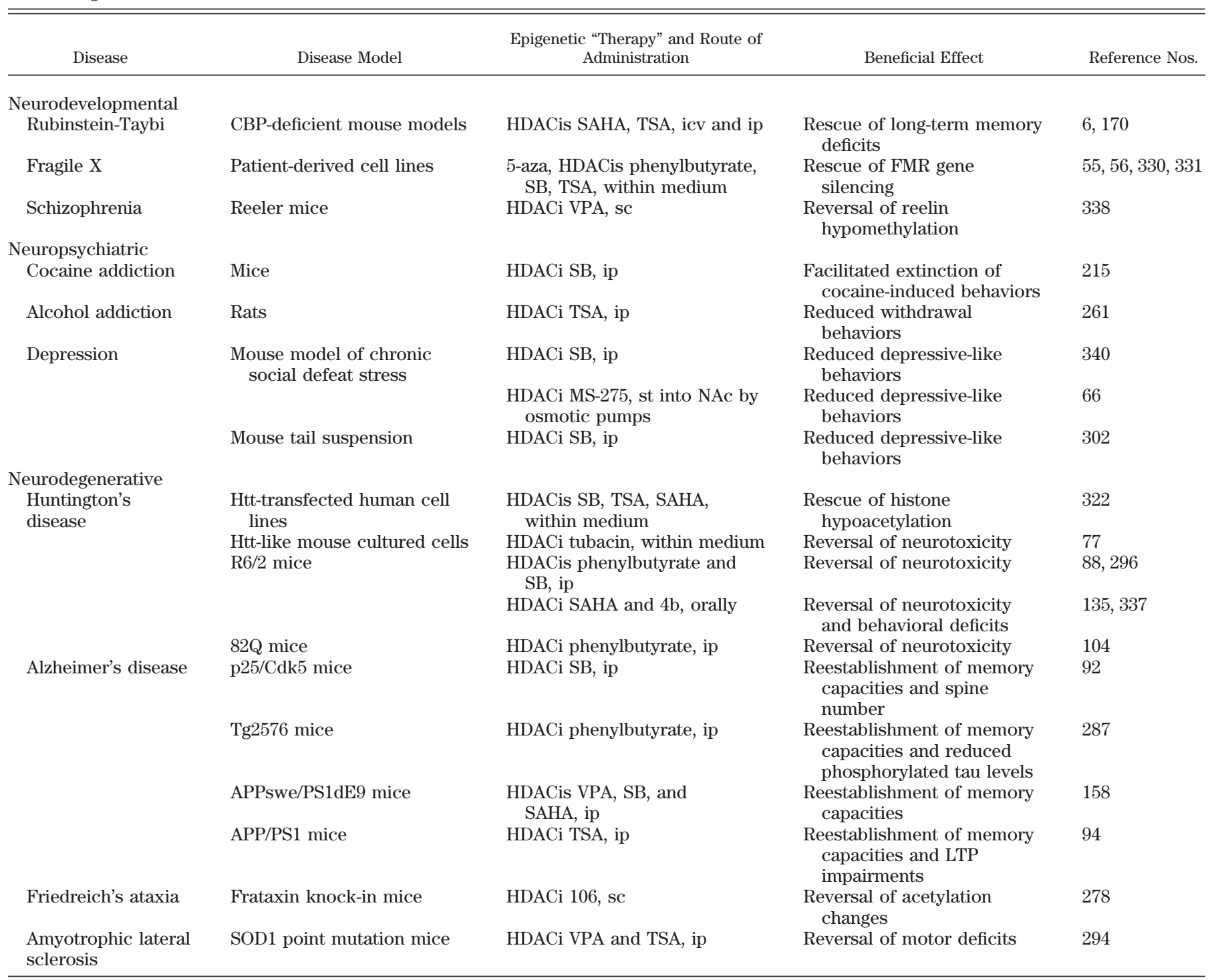

APP, amyloid precursor protein; CBP, CREB-binding protein; Cdk5, cyclin-dependent kinase 5; FMR, fragile X mental retardation; HDACi, HDAC inhibitor; Htt, huntingtin; icv, intracerebroventricular; ip, intraperitoneal; NAc, nucleus accumbens; PS1, presenilin 1; sc, subcutaneous; st, stereotaxical; SAHA, suberoylanilide acid; SOD1, superoxide dismutase 1; SB, sodium butyrate; TSA, trichostatin A; VPA, valproic acid; 5-aza, 5-aza-2-deoxycytidine.

ponents are invaluable tools to increase our understanding of epigenetic mechanisms at play in physiological brain functions. In particular, conditional loss-of-function mutants are invaluable in deciphering why a certain epigenetic mechanism is important during a particular stage of development or for a particular phenotype, but not in other circumstances. In combination with cell-type specific promoters, this constitutes a promising avenue to study epigenetic mechanisms in a time- and locationrestricted manner.

Second, epigenomic approaches at different time points and in different cell types should be highly informative to disentangle the complexity of the epigenetic regulatory network and to identify the individual loci affected in each disease. This can be addressed with chromatin immunoprecipitation techniques coupled with deep sequencing technology (ChIP-Seq). In analogy to stem cell research, where cells are already being epigenomically analyzed at different stages of their differentiation (e.g., Ref. 76), different developmental stages of the nervous system and of its cell types in response to specific environments will have to be studied this way, as each of them is predicted to have its unique epigenetic code. In conjunction with whole-genome gene expression profiles, the future of epigenetic research in the brain will hopefully give a clearer picture of how the brain reacts to 
a given environment by tissue- and cell-type specific epigenetic codes on a certain set of genes.

Lastly, it is tempting to speculate that epigenetic mechanisms, which by definition touch upon the most stable carrier of information over time, i.e., the chromatin, have the inherent potential to explain changes in behavior that are long-lasting. Indeed, findings that DNA methylation marks were still present in the brain several months after an episode of early life stress (360) or 1 mo after a learning event (236) point towards that direction. However, such stability of DNA methylation marks does not apply for histone modifications, which are of more transient nature and have, for instance in yeast, an overall half-life on the order of only minutes (155). It is likely that such short half-lives also characterize histone modifications in the brain. So, then, how could histone modifications explain long-lasting behavioral changes? One possibility is the extensive cross-talk between histone and DNA modifications, by which the former might serve as a mere trigger for the latter (which in many studies might simply not have been investigated), and that DNA methylation is the actual carrier of stable changes (see also Ref. 73 for a recent discussion of this scenario). Another option is that some histone modifications, hardly detectable by the current technology, do indeed persist, and thus leave a mark on the chromatin that can later be recognized and potentiated by context-specific coregulators and transcription factors. The future will certainly see more detailed mechanistic studies at higher resolution that address these fascinating questions.

In sum, epigenetic mechanisms in the nervous system, or "neuroepigenetics," constitute an exciting new field of research with the premise to not only better understand how plastic adaptive responses to the environment lead to stable gene expression and behavioral changes, but also to provide new therapeutic approaches for a broad variety of brain disorders. Yet more work is still required until we get there.

\section{ACKNOWLEDGMENTS}

We thank Dr. Alison Mungenast for critical reading of the manuscript.

Present address of D. Kim: Whitehead Institute for Biomedical Research, Massachusetts Institute of Technology, Cambridge, MA 02142.

Address for reprint requests and other correspondence: L.-H. Tsai, Massachusetts Institute of Technology, Bldg. 46, Rm. 4235, 77 Massachusetts Ave., Cambridge, MA 02139 (e-mail: lhtsai@mit.edu).

\section{GRANTS}

J. Gräff is a postdoctoral fellow sponsored by the Swiss National Science Foundation, and D. Kim is a postdoctoral associate at the Massachusetts Institute of Technology (MIT). M. M. Dobbin is in the graduate student program of the Depart- ment of Brain and Cognitive Sciences at MIT. L.-H. Tsai is an investigator of the Howard Hughes Medical Institute.

\section{DISCLOSURES}

No conflicts of interest, financial or otherwise, are declared by the authors.

\section{REFERENCES}

1. Abdolmaleky HM, Cheng KH, Faraone SV, Wilcox M, Glatt SJ, Gao F, Smith CL, Shafa R, Aeali B, Carnevale J, Pan H, Papageorgis P, Ponte JF, Sivaraman V, Tsuang MT, Thiagalingam S. Hypomethylation of MB-COMT promoter is a major risk factor for schizophrenia and bipolar disorder. Hum Mol Genet 15: 3132-3145, 2006.

2. Abel T, Zukin RS. Epigenetic targets of HDAC inhibition in neurodegenerative and psychiatric disorders. Curr Opin Pharmacol 8: 57-64, 2008.

3. Adachi M, Autry AE, Covington HE 3rd, Monteggia LM. MeCP2-mediated transcription repression in the basolateral amygdala may underlie heightened anxiety in a mouse model of Rett syndrome. J Neurosci 29: 4218-4227, 2009.

4. Adamec E, Vonsattel JP, Nixon RA. DNA strand breaks in Alzheimer's disease. Brain Res 849: 67-77, 1999.

5. Akhtar MW, Raingo J, Nelson ED, Montgomery RL, Olson EN, Kavalali ET, Monteggia LM. Histone deacetylases 1 and 2 form a developmental switch that controls excitatory synapse maturation and function. J Neurosci 29: 8288-8297, 2009.

6. Alarcon JM, Malleret G, Touzani K, Vronskaya S, Ishii S, Kandel ER, Barco A. Chromatin acetylation, memory, and LTP are impaired in $\mathrm{CBP}+/-$ mice: a model for the cognitive deficit in Rubinstein-Taybi syndrome and its amelioration. Neuron 42: 947959, 2004.

7. Alt SR, Turner JD, Klok MD, Meijer OC, Lakke EA, Derijk RH, Muller CP. Differential expression of glucocorticoid receptor transcripts in major depressive disorder is not epigenetically programmed. Psychoneuroendocrinology 35: 544-556, 2010.

8. Amir RE, Van den Veyver IB, Wan M, Tran CQ, Francke U, Zoghbi HY. Rett syndrome is caused by mutations in X-linked MECP2, encoding methyl-CpG-binding protein 2. Nat Genet 23: 185-188, 1999.

9. Andres ME, Burger C, Peral-Rubio MJ, Battaglioli E, Anderson ME, Grimes J, Dallman J, Ballas N, Mandel G. CoREST: a functional corepressor required for regulation of neural-specific gene expression. Proc Natl Acad Sci USA 96: 9873-9878, 1999.

10. Antun FT, Burnett GB, Cooper AJ, Daly RJ, Smythies JR, Zealley AK. The effects of L-methionine (without MAOI) in schizophrenia. J Psychiatr Res 8: 63-71, 1971.

11. Ashley CT, Sutcliffe JS, Kunst CB, Leiner HA, Eichler EE, Nelson DL, Warren ST. Human and murine FMR-1: alternative splicing and translational initiation downstream of the CGG-repeat. Nat Genet 4: 244-251, 1993.

12. Attia M, Rachez C, De Pauw A, Avner P, Rogner UC. Nap112 promotes histone acetylation activity during neuronal differentiation. Mol Cell Biol 27: 6093-6102, 2007.

13. Baeza N, Weller M, Yonekawa Y, Kleihues P, Ohgaki H. PTEN methylation and expression in glioblastomas. Acta Neuropathol 106: 479-485, 2003.

14. Bai S, Ghoshal K, Datta J, Majumder S, Yoon SO, Jacob ST. DNA methyltransferase $3 \mathrm{~b}$ regulates nerve growth factor-induced differentiation of PC12 cells by recruiting histone deacetylase 2 . Mol Cell Biol 25: 751-766, 2005.

15. Ballas N, Battaglioli E, Atouf F, Andres ME, Chenoweth J, Anderson ME, Burger C, Moniwa M, Davie JR, Bowers WJ, Federoff HJ, Rose DW, Rosenfeld MG, Brehm P, Mandel G. Regulation of neuronal traits by a novel transcriptional complex. Neuron 31: 353-365, 2001.

16. Ballas N, Grunseich C, Lu DD, Speh JC, Mandel G. REST and its corepressors mediate plasticity of neuronal gene chromatin throughout neurogenesis. Cell 121: 645-657, 2005. 
17. Ballas N, Mandel G. The many faces of REST oversee epigenetic programming of neuronal genes. Curr Opin Neurobiol 15: 500-506, 2005.

18. Barch DM, Smith E. The cognitive neuroscience of working memory: relevance to CNTRICS and schizophrenia. Biol Psychiatry 64: $11-17,2008$

19. Becker PB, Horz W. ATP-dependent nucleosome remodeling. Annu Rev Biochem 71: 247-273, 2002.

20. Belichenko PV, Wright EE, Belichenko NP, Masliah E, Li HH, Mobley WC, Francke U. Widespread changes in dendritic and axonal morphology in Mecp2-mutant mouse models of Rett syndrome: evidence for disruption of neuronal networks. $J$ Comp Neurol 514: 240-258, 2009.

21. Benn SC, Woolf CJ. Adult neuron survival strategies-slamming on the brakes. Nat Rev Neurosci 5: 686-700, 2004.

22. Berton O, McClung CA, Dileone RJ, Krishnan V, Renthal W, Russo SJ, Graham D, Tsankova NM, Bolanos CA, Rios M, Monteggia LM, Self DW, Nestler EJ. Essential role of BDNF in the mesolimbic dopamine pathway in social defeat stress. Science 311: 864-868, 2006.

23. Beydoun H, Saftlas AF. Physical and mental health outcomes of prenatal maternal stress in human and animal studies: a review of recent evidence. Paediatr Perinat Epidemiol 22: 438-466, 2008.

24. Bibb JA, Chen J, Taylor JR, Svenningsson P, Nishi A, Snyder GL, Yan Z, Sagawa ZK, Ouimet CC, Nairn AC, Nestler EJ, Greengard P. Effects of chronic exposure to cocaine are regulated by the neuronal protein Cdk5. Nature 410: 376-380, 2001.

25. Bilang-Bleuel A, Ulbricht S, Chandramohan Y, De Carli S, Droste SK, Reul JMHM. Psychological stress increases histone H3 phosphorylation in adult dentate gyrus granule neurons: involvement in a glucocorticoid receptor-dependent behavioural response. Eur J Neurosci 22: 1691-1700, 2005.

26. Bird A. DNA methylation patterns and epigenetic memory. Genes Dev 16: 6-21, 2002.

27. Bird A. Perceptions of epigenetics. Nature 447: 396-398, 2007.

28. Bliss TV, Collingridge GL. A synaptic model of memory: longterm potentiation in the hippocampus. Nature 361: 31-39, 1993.

29. Borrell-Pages M, Zala D, Humbert S, Saudou F. Huntington's disease: from huntingtin function and dysfunction to therapeutic strategies. Cell Mol Life Sci 63: 2642-2660, 2006.

30. Bortolotto ZA, Collingridge GL. Characterisation of LTP induced by the activation of glutamate metabotropic receptors in area CA1 of the hippocampus. Neuropharmacology 32: 1-9, 1993.

31. Bosch A, Suau P. Changes in core histone variant composition in differentiating neurons: the roles of differential turnover and synthesis rates. Eur J Cell Biol 68: 220-225, 1995.

32. Bourtchouladze R, Lidge R, Catapano R, Stanley J, Gossweiler S, Romashko D, Scott R, Tully T. A mouse model of Rubinstein-Taybi syndrome: defective long-term memory is ameliorated by inhibitors of phosphodiesterase 4. Proc Natl Acad Sci USA 100: 10518-10522, 2003.

33. Brami-Cherrier K, Valjent E, Herve D, Darragh J, Corvol JC, Pages C, Arthur SJ, Girault JA, Caboche J. Parsing molecular and behavioral effects of cocaine in mitogen- and stress-activated protein kinase-1-deficient mice. J Neurosci 25: 11444-11454, 2005.

34. Bredy TW, Barad M. The histone deacetylase inhibitor valproic acid enhances acquisition, extinction, and reconsolidation of conditioned fear. Learn Mem 15: 39-45, 2008.

35. Bredy TW, Wu H, Crego C, Zellhoefer J, Sun YE, Barad M. Histone modifications around individual BDNF gene promoters in prefrontal cortex are associated with extinction of conditioned fear. Learn Mem 14: 268-276, 2007.

36. Broide RS, Redwine JM, Aftahi N, Young W, Bloom FE, Winrow CJ. Distribution of histone deacetylases $1-11$ in the rat brain. J Mol Neurosci 31: 47-58, 2007.

37. Brownell JE, Allis CD. Special HATs for special occasions: linking histone acetylation to chromatin assembly and gene activation. Curr Opin Genet Dev 6: 176-184, 1996.

38. Burgold T, Spreafico F, De Santa F, Totaro MG, Prosperini E, Natoli G, Testa G. The histone H3 lysine 27-specific demethylase Jmjd3 is required for neural commitment. PLoS One 3: e3034, 2008.
39. Butler R, Bates GP. Histone deacetylase inhibitors as therapeutics for polyglutamine disorders. Nat Rev Neurosci 7: 784-796, 2006.

40. Cao X, Sudhof TC. A transcriptionally active complex of APP with Fe65 and histone acetyltransferase Tip60. Science 293: 115-120, 2001.

41. Cassel S, Carouge D, Gensburger C, Anglard P, Burgun C, Dietrich JB, Aunis D, Zwiller J. Fluoxetine and cocaine induce the epigenetic factors MeCP2 and MBD1 in adult rat brain. Mol Pharmacol 70: 487-492, 2006.

42. Castro LM, Gallant M, Niles LP. Novel targets for valproic acid: up-regulation of melatonin receptors and neurotrophic factors in C6 glioma cells. J Neurochem 95: 1227-1236, 2005.

43. Cedar H, Bergman Y. Linking DNA methylation and histone modification: patterns and paradigms. Nat Rev Genet 10: 295-304, 2009.

44. Chahrour M, Jung SY, Shaw C, Zhou X, Wong ST, Qin J, Zoghbi HY. MeCP2, a key contributor to neurological disease, activates and represses transcription. Science 320: 1224-1229, 2008.

45. Champagne FA, Francis DD, Mar A, Meaney MJ. Variations in maternal care in the rat as a mediating influence for the effects of environment on development. Physiol Behav 79: 359-371, 2003.

46. Chang Q, Khare G, Dani V, Nelson S, Jaenisch R. The disease progression of Mecp2 mutant mice is affected by the level of BDNF expression. Neuron 49: 341-348, 2006.

47. Chen G, Zeng WZ, Yuan PX, Huang LD, Jiang YM, Zhao ZH, Manji HK. The mood-stabilizing agents lithium and valproate robustly increase the levels of the neuroprotective protein bcl-2 in the CNS. J Neurochem 72: 879-882, 1999.

48. Chen PS, Wang CC, Bortner CD, Peng GS, Wu X, Pang H, Lu RB, Gean PW, Chuang DM, Hong JS. Valproic acid and other histone deacetylase inhibitors induce microglial apoptosis and attenuate lipopolysaccharide-induced dopaminergic neurotoxicity. Neuroscience 149: 203-212, 2007.

49. Chen RZ, Akbarian S, Tudor M, Jaenisch R. Deficiency of methyl-CpG binding protein-2 in CNS neurons results in a Rett-like phenotype in mice. Nat Genet 27: 327-331, 2001.

50. Chen Y, Sharma RP, Costa RH, Costa E, Grayson DR. On the epigenetic regulation of the human reelin promoter. Nucleic Acids Res 30: 2930-2939, 2002.

51. Chen YL, Law PY, Loh HH. NGF/PI3K signaling-mediated epigenetic regulation of delta opioid receptor gene expression. Biochem Biophys Res Commun 368: 755-760, 2008.

52. Chen ZF, Paquette AJ, Anderson DJ. NRSF/REST is required in vivo for repression of multiple neuronal target genes during embryogenesis. Nat Genet 20: 136-142, 1998.

53. Chertkow-Deutsher Y, Cohen H, Klein E, Ben-Shachar D. DNA methylation in vulnerability to post-traumatic stress in rats: evidence for the role of the post-synaptic density protein Dlgap2. Int $J$ Neuropsychopharmacol: 1-13, 2009.

54. Cheung I, Shulha HP, Jiang Y, Matevossian A, Wang J, Weng Z, Akbarian S. Developmental regulation and individual differences of neuronal H3K4me3 epigenomes in the prefrontal cortex. Proc Natl Acad Sci USA 107: 8824-8829.

55. Chiurazzi P, Pomponi MG, Pietrobono R, Bakker CE, Neri G, Oostra BA. Synergistic effect of histone hyperacetylation and DNA demethylation in the reactivation of the FMR1 gene. Hum Mol Genet 8: 2317-2323, 1999.

56. Chiurazzi P, Pomponi MG, Willemsen R, Oostra BA, Neri G. In vitro reactivation of the FMR1 gene involved in fragile $\mathrm{X}$ syndrome. Hum Mol Genet 7: 109-113, 1998.

57. Chong JA, Tapia-Ramirez J, Kim S, Toledo-Aral JJ, Zheng Y, Boutros MC, Altshuller YM, Frohman MA, Kraner SD, Mandel G. REST: a mammalian silencer protein that restricts sodium channel gene expression to neurons. Cell 80: 949-957, 1995.

58. Chwang WB, Arthur JS, Schumacher A, Sweatt JD. The nuclear kinase mitogen- and stress-activated protein kinase 1 regulates hippocampal chromatin remodeling in memory formation. $J$ Neurosci 27: 12732-12742, 2007.

59. Chwang WB, O'Riordan KJ, Levenson JM, Sweatt JD. ERK/ MAPK regulates hippocampal histone phosphorylation following contextual fear conditioning. Learning Memory 13: 322-328, 2006. 
60. Collins A, Hill LE, Chandramohan Y, Whitcomb D, Droste SK, Reul JM. Exercise improves cognitive responses to psychological stress through enhancement of epigenetic mechanisms and gene expression in the dentate gyrus. PLoS One 4: e4330, 2009.

61. Collins AL, Levenson JM, Vilaythong AP, Richman R, Armstrong DL, Noebels JL, Sweatt JD, Zoghbi HY. Mild overexpression of MeCP2 causes a progressive neurological disorder in mice. Hum Mol Genet 13: 2679-2689, 2004.

62. Copray S, Huynh JL, Sher F, Casaccia-Bonnefil P, Boddeke E. Epigenetic mechanisms facilitating oligodendrocyte development, maturation, and aging. Glia 57: 1579-1587, 2009.

63. Costa E, Chen Y, Davis J, Dong E, Noh JS, Tremolizzo L, Veldic M, Grayson DR, Guidotti A. REELIN and schizophrenia:: a disease at the interface of the genome and the epigenome. $\mathrm{Mol}$ Interv 2: 47-57, 2002.

64. Costa E, Chen Y, Dong E, Grayson DR, Kundakovic M, Maloku E, Ruzicka W, Satta R, Veldic M, Zhubi A, Guidotti A. GABAergic promoter hypermethylation as a model to study the neurochemistry of schizophrenia vulnerability. Expert Rev Neurother 9: 87-98, 2009.

65. Costello JF, Berger MS, Huang HS, Cavenee WK. Silencing of p16/CDKN2 expression in human gliomas by methylation and chromatin condensation. Cancer Res 56: 2405-2410, 1996.

66. Covington HE 3rd, Maze I, LaPlant QC, Vialou VF, Ohnishi YN, Berton O, Fass DM, Renthal W, Rush AJ 3rd, Wu EY, Ghose S, Krishnan V, Russo SJ, Tamminga C, Haggarty SJ, Nestler EJ. Antidepressant actions of histone deacetylase inhibitors. J Neurosci 29: 11451-11460, 2009.

67. Crick F. Neurobiology: memory and molecular turnover. Nature 312: 101, 1984.

68. Crosio C, Heitz E, Allis CD, Borrelli E, Sassone-Corsi P. Chromatin remodeling and neuronal response: multiple signaling pathways induce specific histone H3 modifications and early gene expression in hippocampal neurons. J Cell Sci 116: 4905-4914, 2003.

69. Cruz JC, Tseng HC, Goldman JA, Shih H, Tsai LH. Aberrant Cdk5 activation by 25 triggers pathological events leading to neurodegeneration and neurofibrillary tangles. Neuron 40: 471483, 2003.

70. Daniels WM, Fairbairn LR, van Tilburg G, McEvoy CR, Zigmond MJ, Russell VA, Stein DJ. Maternal separation alters nerve growth factor and corticosterone levels but not the DNA methylation status of the exon 1(7) glucocorticoid receptor promoter region. Metab Brain Dis 24: 615-627, 2009.

71. Darnaudery M, Maccari S. Epigenetic programming of the stress response in male and female rats by prenatal restraint stress. Brain Res Rev 57: 571-585, 2008.

72. Dash PK, Orsi SA, Moore AN. Histone deactylase inhibition combined with behavioral therapy enhances learning and memory following traumatic brain injury. Neuroscience 163: 1-8, 2009.

73. Day JJ, Sweatt JD. DNA methylation and memory formation. Nat Neurosci 13: 1319-1323, 2010.

74. Deng JV, Rodriguiz RM, Hutchinson AN, Kim IH, Wetsel WC, West AE. MeCP2 in the nucleus accumbens contributes to neural and behavioral responses to psychostimulants. Nat Neurosci 13: 1128-1136, 2010.

75. Dion MF, Altschuler SJ, Wu LF, Rando OJ. Genomic characterization reveals a simple histone $\mathrm{H} 4$ acetylation code. Proc Natl Acad Sci USA 102: 5501-5506, 2005.

76. Doi A, Park IH, Wen B, Murakami P, Aryee MJ, Irizarry R, Herb B, Ladd-Acosta C, Rho J, Loewer S, Miller J, Schlaeger T, Daley GQ, Feinberg AP. Differential methylation of tissue- and cancer-specific $\mathrm{CpG}$ island shores distinguishes human induced pluripotent stem cells, embryonic stem cells and fibroblasts. Nat Genet 41: 1350-1353, 2009.

77. Dompierre JP, Godin JD, Charrin BC, Cordelieres FP, King SJ, Humbert S, Saudou F. Histone deacetylase 6 inhibition compensates for the transport deficit in Huntington's disease by increasing tubulin acetylation. J Neurosci 27: 3571-3583, 2007.

78. Donmez G, Wang D, Cohen DE, Guarente L. SIRT1 suppresses beta-amyloid production by activating the alpha-secretase gene ADAM10. Cell 142: 320-332, 2010.
79. Eisen JA, Sweder KS, Hanawalt PC. Evolution of the SNF2 family of proteins: subfamilies with distinct sequences and functions. Nucleic Acids Res 23: 2715-2723, 1995.

80. Eleuteri S, Monti B, Brignani S, Contestabile A. Chronic dietary administration of valproic acid protects neurons of the rat nucleus basalis magnocellularis from ibotenic acid neurotoxicity. Neurotox Res 15: 127-132, 2009.

81. Fan G, Martinowich K, Chin MH, He F, Fouse SD, Hutnick L, Hattori D, Ge W, Shen Y, Wu H, ten Hoeve J, Shuai K, Sun YE. DNA methylation controls the timing of astrogliogenesis through regulation of JAK-STAT signaling. Development 132: 3345-3356, 2005.

82. Faraco G, Pancani T, Formentini L, Mascagni P, Fossati G, Leoni F, Moroni F, Chiarugi A. Pharmacological inhibition of histone deacetylases by suberoylanilide hydroxamic acid specifically alters gene expression and reduces ischemic injury in the mouse brain. Mol Pharmacol 70: 1876-1884, 2006.

83. Fatemi SH. Reelin glycoprotein: structure, biology and roles in health and disease. Mol Psychiatry 10: 251-257, 2005.

84. Fatemi SH, Folsom TD. The neurodevelopmental hypothesis of schizophrenia, revisited. Schizophr Bull 35: 528-548, 2009.

85. Federman N, Fustinana MS, Romano A. Histone acetylation is recruited in consolidation as a molecular feature of stronger memories. Learn Mem 16: 600-606, 2009.

86. Feng J, Zhou Y, Campbell SL, Le T, Li E, Sweatt JD, Silva AJ, Fan G. Dnmt1 and Dnmt3a maintain DNA methylation and regulate synaptic function in adult forebrain neurons. Nat Neurosci 13: 423-430, 2010.

87. Fernandez SM, Lewis MC, Pechenino AS, Harburger LL, Orr PT, Gresack JE, Schafe GE, Frick KM. Estradiol-induced enhancement of object memory consolidation involves hippocampal extracellular signal-regulated kinase activation and membranebound estrogen receptors. J Neurosci 28: 8660-8667, 2008.

88. Ferrante RJ, Kubilus JK, Lee J, Ryu H, Beesen A, Zucker B, Smith K, Kowall NW, Ratan RR, Luthi-Carter R, Hersch SM. Histone deacetylase inhibition by sodium butyrate chemotherapy ameliorates the neurodegenerative phenotype in Huntington's disease mice. J Neurosci 23: 9418-9427, 2003.

89. Ferrante RJ, Ryu H, Kubilus JK, D'Mello S, Sugars KL, Lee J, Lu P, Smith K, Browne S, Beal MF, Kristal BS, Stavrovskaya IG, Hewett S, Rubinsztein DC, Langley B, Ratan RR. Chemotherapy for the brain: the antitumor antibiotic mithramycin prolongs survival in a mouse model of Huntington's disease. J Neurosci 24: 10335-10342, 2004.

90. Fischer A, Sananbenesi F, Mungenast A, Tsai LH. Targeting the correct HDAC(s) to treat cognitive disorders. Trends Pharmacol Sci. In press.

91. Fischer A, Sananbenesi F, Pang PT, Lu B, Tsai LH. Opposing roles of transient and prolonged expression of p 25 in synaptic plasticity and hippocampus-dependent memory. Neuron 48: 825838, 2005.

92. Fischer A, Sananbenesi F, Wang XY, Dobbin M, Tsai LH. Recovery of learning and memory is associated with chromatin remodelling. Nature 447: 172-178, 2007.

93. Francis D, Diorio J, Liu D, Meaney MJ. Nongenomic transmission across generations of maternal behavior and stress responses in the rat. Science 286: 1155-1158, 1999.

94. Francis YI, Fa M, Ashraf H, Zhang H, Staniszewski A, Latchman DS, Arancio O. Dysregulation of histone acetylation in the APP/PS1 mouse model of Alzheimer's disease. J Alzheimers Dis 18: 131-139, 2009.

95. Franklin TB, Russig H, Weiss IC, Gräff J, Linder N, Michalon A, Vizi S, Mansuy IM. Epigenetic transmission of the impact of early stress across generations. Biol Psychiatry 68: 408-415, 2010.

96. Frey U, Matthies H, Reymann KG, Matthies H. The effect of dopaminergic D1 receptor blockade during tetanization on the expression of long-term potentiation in the rat CA1 region in vitro. Neurosci Lett 129: 111-114, 1991.

97. Fuchikami M, Morinobu S, Kurata A, Yamamoto S, Yamawaki S. Single immobilization stress differentially alters the expression profile of transcripts of the brain-derived neurotrophic factor (BDNF) gene and histone acetylation at its promoters in the rat hippocampus. Int J Neuropsychopharmacol 12: 73-82, 2009. 
98. Fukumoto T, Morinobu S, Okamoto Y, Kagaya A, Yamawaki S. Chronic lithium treatment increases the expression of brain-derived neurotrophic factor in the rat brain. Psychopharmacology 158: 100-106, 2001.

99. Fuso A, Seminara L, Cavallaro RA, D'Anselmi F, Scarpa S. $S$-adenosylmethionine/homocysteine cycle alterations modify DNA methylation status with consequent deregulation of PS1 and BACE and beta-amyloid production. Mol Cell Neurosci 28: 195-204, 2005.

100. Gage FH. Mammalian neural stem cells. Science 287: 1433-1438, 2000.

101. Gama-Sosa MA, Slagel VA, Trewyn RW, Oxenhandler R, Kuo KC, Gehrke CW, Ehrlich M. The 5-methylcytosine content of DNA from human tumors. Nucleic Acids Res 11: 6883-6894, 1983.

102. Garber KB, Visootsak J, Warren ST. Fragile X syndrome. Eur J Hum Genet 16: 666-672, 2008.

103. Garcia-Dominguez M, Reyes JC. SUMO association with repressor complexes, emerging routes for transcriptional control. Biochim Biophys Acta 1789: 451-459, 2009.

104. Gardian G, Browne SE, Choi DK, Klivenyi P, Gregorio J, Kubilus JK, Ryu H, Langley B, Ratan RR, Ferrante RJ, Beal MF. Neuroprotective effects of phenylbutyrate in the N171-82Q transgenic mouse model of Huntington's disease. J Biol Chem 280: $556-563,2005$.

105. Gaub P, Tedeschi A, Puttagunta R, Nguyen T, Schmandke A, Di Giovanni S. HDAC inhibition promotes neuronal outgrowth and counteracts growth cone collapse through CBP/p300 and P/CAF-dependent p53 acetylation. Cell Death Differ 17: 1392-1408, 2010.

106. Gaudet F, Hodgson JG, Eden A, Jackson-Grusby L, Dausman J, Gray JW, Leonhardt H, Jaenisch R. Induction of tumors in mice by genomic hypomethylation. Science 300: 489-492, 2003.

107. Gecz J, Gedeon AK, Sutherland GR, Mulley JC. Identification of the gene FMR2, associated with FRAXE mental retardation. Nat Genet 13: 105-108, 1996

108. Genoux D, Haditsch U, Knobloch M, Michalon A, Storm D, Mansuy IM. Protein phosphatase 1 is a molecular constraint on learning and memory. Nature 418: 970-975, 2002.

109. Gibbons R. Alpha thalassaemia-mental retardation, $\mathrm{X}$ linked. Orphanet J Rare Dis 1: 15, 2006.

110. Gibbons RJ, McDowell TL, Raman S, O'Rourke DM, Garrick D, Ayyub H, Higgs DR. Mutations in ATRX, encoding a SWI/SNFlike protein, cause diverse changes in the pattern of DNA methylation. Nat Genet 24: 368-371, 2000.

111. Gonzalez-Gomez P, Bello MJ, Arjona D, Lomas J, Alonso ME, De Campos JM, Vaquero J, Isla A, Gutierrez M, Rey JA. Promoter hypermethylation of multiple genes in astrocytic gliomas. Int J Oncol 22: 601-608, 2003.

112. Gottlicher M. Valproic acid: an old drug newly discovered as inhibitor of histone deacetylases. Ann Hematol 83 Suppl 1: S91S92, 2004.

113. Gräff J, Mansuy IM. Epigenetic codes in cognition and behaviour. Behav Brain Res 192: 70-87, 2008.

114. Graham DL, Edwards S, Bachtell RK, DiLeone RJ, Rios M, Self DW. Dynamic BDNF activity in nucleus accumbens with cocaine use increases self-administration and relapse. Nat Neurosci 10: 1029-1037, 2007.

115. Granger A, Abdullah I, Huebner F, Stout A, Wang T, Huebner T, Epstein JA, Gruber PJ. Histone deacetylase inhibition reduces myocardial ischemia-reperfusion injury in mice. FASEB J 22: 35493560, 2008.

116. Grant PA. A tale of histone modifications. Genome Biol 2: 3, 2001.

117. Gregg C, Zhang J, Butler JE, Haig D, Dulac C. Sex-specific parent-of-origin allelic expression in the mouse brain. Science 329: $682-685,2010$

118. Gregg C, Zhang J, Weissbourd B, Luo S, Schroth GP, Haig D, Dulac C. High-resolution analysis of parent-of-origin allelic expression in the mouse brain. Science 329: 643-648, 2010.

119. Grimm JW, Lu L, Hayashi T, Hope BT, Su TP, Shaham Y. Time-dependent increases in brain-derived neurotrophic factor protein levels within the mesolimbic dopamine system after withdrawal from cocaine: implications for incubation of cocaine craving. J Neurosci 23: 742-747, 2003.
120. Gu Y, Shen Y, Gibbs RA, Nelson DL. Identification of FMR2, a novel gene associated with the FRAXE CCG repeat and CpG island. Nat Genet 13: 109-113, 1996.

121. Guan JS, Haggarty SJ, Giacometti E, Dannenberg JH, Joseph N, Gao J, Nieland TJ, Zhou Y, Wang X, Mazitschek R, Bradner JE, DePinho RA, Jaenisch R, Tsai LH. HDAC2 negatively regulates memory formation and synaptic plasticity. Nature 459: 55-60, 2009.

122. Guan ZH, Giustetto M, Lomvardas S, Kim JH, Miniaci MC, Schwartz JH, Thanos D, Kandel ER. Integration of long-termmemory-related synaptic plasticity involves bidirectional regulation of gene expression and chromatin structure. Cell 111: 483-493, 2002.

123. Guidotti A, Auta J, Davis JM, Di-Giorgi-Gerevini V, Dwivedi Y, Grayson DR, Impagnatiello F, Pandey G, Pesold C, Sharma R, Uzunov D, Costa E. Decrease in reelin and glutamic acid decarboxylase67 (GAD67) expression in schizophrenia and bipolar disorder: a postmortem brain study. Arch Gen Psychiatry 57: 10611069, 2000.

124. Guidotti A, Ruzicka W, Grayson DR, Veldic M, Pinna G, Davis JM, Costa E. $S$-adenosyl methionine and DNA methyltransferase-1 mRNA overexpression in psychosis. Neuroreport 18: 57-60, 2007.

125. Gundersen BB, Blendy JA. Effects of the histone deacetylase inhibitor sodium butyrate in models of depression and anxiety. Neuropharmacology 57: 67-74, 2009.

126. Gupta S, Kim SY, Artis S, Molfese DL, Schumacher A, Sweatt JD, Paylor RE, Lubin FD. Histone methylation regulates memory formation. J Neurosci 30: 3589-3599, 2010.

127. Guy J, Hendrich B, Holmes M, Martin JE, Bird A. A mouse Mecp2-null mutation causes neurological symptoms that mimic Rett syndrome. Nat Genet 27: 322-326, 2001.

128. Haberland M, Montgomery RL, Olson EN. The many roles of histone deacetylases in development and physiology: implications for disease and therapy. Nat Rev Genet 10: 32-42, 2009.

129. Haggarty SJ, Clemons PA, Wong JC, Schreiber SL. Mapping chemical space using molecular descriptors and chemical genetics: deacetylase inhibitors. Comb Chem High Throughput Screen 7: 669-676, 2004.

130. Hatada I, Namihira M, Morita S, Kimura M, Horii T, Nakashima K. Astrocyte-specific genes are generally demethylated in neural precursor cells prior to astrocytic differentiation. PLoS One 3: e3189, 2008.

131. He Y, Sandoval J, Casaccia-Bonnefil P. Events at the transition between cell cycle exit and oligodendrocyte progenitor differentiation: the role of HDAC and YY1. Neuron Glia Biol 3: 221-231, 2007.

132. Hegi ME, Diserens AC, Gorlia T, Hamou MF, de Tribolet N, Weller M, Kros JM, Hainfellner JA, Mason W, Mariani L, Bromberg JE, Hau P, Mirimanoff RO, Cairncross JG, Janzer RC, Stupp R. MGMT gene silencing and benefit from temozolomide in glioblastoma. $N$ Engl J Med 352: 997-1003, 2005.

133. Herman D, Jenssen K, Burnett R, Soragni E, Perlman SL, Gottesfeld JM. Histone deacetylase inhibitors reverse gene silencing in Friedreich's ataxia. Nat Chem Biol 2: 551-558, 2006.

134. Heron M, Hoyert DL, Murphy SL, Xu J, Kochanek KD, TejadaVera B. Deaths: final data for 2006. Natl Vital Stat Rep 57: 1-134, 2009.

135. Hockly E, Richon VM, Woodman B, Smith DL, Zhou X, Rosa E, Sathasivam K, Ghazi-Noori S, Mahal A, Lowden PA, Steffan JS, Marsh JL, Thompson LM, Lewis CM, Marks PA, Bates GP. Suberoylanilide hydroxamic acid, a histone deacetylase inhibitor, ameliorates motor deficits in a mouse model of Huntington's disease. Proc Natl Acad Sci USA 100: 2041-2046, 2003.

136. Huang HS, Akbarian S. GAD1 mRNA expression and DNA methylation in prefrontal cortex of subjects with schizophrenia. PLoS ONE 2: e809, 2007.

137. Huang HY, Lin SZ, Chen WF, Li KW, Kuo JS, Wang MJ. Urocortin modulates dopaminergic neuronal survival via inhibition of glycogen synthase kinase-3beta and histone deacetylase. Neurobiol Aging 2009.

138. Huang Y, Doherty JJ, Dingledine R. Altered histone acetylation at glutamate receptor 2 and brain-derived neurotrophic factor 
genes is an early event triggered by status epilepticus. $J$ Neurosci 22: 8422-8428, 2002.

139. Huang Y, Myers SJ, Dingledine R. Transcriptional repression by REST: recruitment of Sin3A and histone deacetylase to neuronal genes. Nat Neurosci 2: 867-872, 1999.

140. Huerta PT, Lisman JE. Heightened synaptic plasticity of hippocampal CA1 neurons during a cholinergically induced rhythmic state. Nature 364: 723-725, 1993.

141. Hutnick LK, Golshani P, Namihira M, Xue Z, Matynia A, Yang XW, Silva AJ, Schweizer FE, Fan G. DNA hypomethylation restricted to the murine forebrain induces cortical degeneration and impairs postnatal neuronal maturation. Hum Mol Genet 18: 2875-2888, 2009.

142. Huuskonen J, Suuronen T, Nuutinen T, Kyrylenko S, Salminen A. Regulation of microglial inflammatory response by sodium butyrate and short-chain fatty acids. Br J Pharmacol 141: 874-880, 2004.

143. Hwang CK, Song KY, Kim CS, Choi HS, Guo XH, Law PY, Wei LN, Loh HH. Epigenetic programming of mu opioid receptor gene in mouse brain is regulated by MeCP2 and Brg1 chromatin remodeling factor. J Cell Mol Med 13: 3591-3615, 2009.

144. Im HI, Hollander JA, Bali P, Kenny PJ. MeCP2 controls BDNF expression and cocaine intake through homeostatic interactions with microRNA-212. Nat Neurosci 13: 1120-1127, 2010.

145. Impagnatiello F, Guidotti AR, Pesold C, Dwivedi Y, Caruncho H, Pisu MG, Uzunov DP, Smalheiser NR, Davis JM, Pandey GN, Pappas GD, Tueting P, Sharma RP, Costa E. A decrease of reelin expression as a putative vulnerability factor in schizophrenia. Proc Natl Acad Sci USA 95: 15718-15723, 1998.

146. Iwamoto K, Bundo M, Yamada K, Takao H, Iwayama-Shigeno Y, Yoshikawa T, Kato T. DNA methylation status of SOX10 correlates with its downregulation and oligodendrocyte dysfunction in schizophrenia. J Neurosci 25: 5376-5381, 2005.

147. Jaenisch R, Bird A. Epigenetic regulation of gene expression: how the genome integrates intrinsic and environmental signals. Nature Genet 33: 245-254, 2003.

148. Jakobsson J, Cordero MI, Bisaz R, Groner AC, Busskamp V, Bensadoun JC, Cammas F, Losson R, Mansuy IM, Sandi C, Trono D. KAP1-mediated epigenetic repression in the forebrain modulates behavioral vulnerability to stress. Neuron 60: 818-831, 2008.

149. Janssen C, Schmalbach S, Boeselt S, Sarlette A, Dengler R, Petri S. Differential histone deacetylase mRNA expression patterns in amyotrophic lateral sclerosis. J Neuropathol Exp Neurol 69: 573-581, 2010.

150. Jenuwein T, Allis CD. Translating the histone code. Science 293: 1074-1080, 2001.

151. Jessberger S, Nakashima K, Clemenson GD Jr, Mejia E, Mathews E, Ure K, Ogawa S, Sinton CM, Gage FH, Hsieh J. Epigenetic modulation of seizure-induced neurogenesis and cognitive decline. J Neurosci 27: 5967-5975, 2007.

152. Jost WH. Costs in the treatment of parkinsonism. J Neurol 247 Suppl 4: 31-33, 2000.

153. Kandel ER. The molecular biology of memory storage: a dialogue between genes and synapses. Science 294: 1030-1038, 2001.

154. Kangaspeska S, Stride B, Metivier R, Polycarpou-Schwarz M, Ibberson D, Carmouche RP, Benes V, Gannon F, Reid G. Transient cyclical methylation of promoter DNA. Nature 452: 112 115, 2008.

155. Katan-Khaykovich Y, Struhl K. Dynamics of global histone acetylation and deacetylation in vivo: rapid restoration of normal histone acetylation status upon removal of activators and repressors. Genes Dev 16: 743-752, 2002.

156. Kazantsev AG, Thompson LM. Therapeutic application of histone deacetylase inhibitors for central nervous system disorders. Nat Rev Drug Discov 7: 854-868, 2008.

157. Kernohan KD, Jiang Y, Tremblay DC, Bonvissuto AC, Eubanks JH, Mann MR, Berube NG. ATRX partners with cohesin and MeCP2 and contributes to developmental silencing of imprinted genes in the brain. Dev Cell 18: 191-202, 2010.

158. Kilgore M, Miller CA, Fass DM, Hennig KM, Haggarty SJ, Sweatt JD, Rumbaugh G. Inhibitors of class 1 histone deacety- lases reverse contextual memory deficits in a mouse model of Alzheimer's disease. Neuropsychopharmacology 35: 853-854, 2010.

159. Kim D, Frank CL, Dobbin MM, Tsunemoto RK, Tu W, Peng PL, Guan JS, Lee BH, Moy LY, Giusti P, Broodie N, Mazitschek R, Delalle I, Haggarty SJ, Neve RL, Lu Y, Tsai LH. Deregulation of HDAC1 by p25/Cdk5 in neurotoxicity. Neuron 60: 803-817, 2008.

160. Kim D, Nguyen MD, Dobbin MM, Fischer A, Sananbenesi F, Rodgers JT, Delalle I, Baur JA, Sui G, Armour SM, Puigserver P, Sinclair DA, Tsai LH. SIRT1 deacetylase protects against neurodegeneration in models for Alzheimer's disease and amyotrophic lateral sclerosis. EMBO J 26: 3169-3179, 2007.

161. Kim HJ, Leeds P, Chuang DM. The HDAC inhibitor, sodium butyrate, stimulates neurogenesis in the ischemic brain. J Neurochem 110: 1226-1240, 2009.

162. Kim HJ, Rowe M, Ren M, Hong JS, Chen PS, Chuang DM. Histone deacetylase inhibitors exhibit anti-inflammatory and neuroprotective effects in a rat permanent ischemic model of stroke: multiple mechanisms of action. J Pharmacol Exp Ther 321: 892901, 2007.

163. Kim HS, Kim EM, Kim NJ, Chang KA, Choi Y, Ahn KW, Lee JH, Kim S, Park CH, Suh YH. Inhibition of histone deacetylation enhances the neurotoxicity induced by the C-terminal fragments of amyloid precursor protein. J Neurosci Res 75: 117-124, 2004.

164. Kim J, Kim JD. In vivo YY1 knockdown effects on genomic imprinting. Hum Mol Genet 17: 391-401, 2008.

165. Kim JS, Shukla SD. Acute in vivo effect of ethanol (binge drinking) on histone $\mathrm{H} 3$ modifications in rat tissues. Alcohol Alcohol 41: 126-132, 2006.

166. Kim SY, Levenson JM, Korsmeyer S, Sweatt JD, Schumacher A. Developmental regulation of Eed complex composition governs a switch in global histone modification in brain. J Biol Chem 282: 9962-9972, 2007.

167. Klose RJ, Bird AP. Genomic DNA methylation: the mark and its mediators. Trends Biochem Sci 31: 89-97, 2006.

168. Klose RJ, Zhang Y. Regulation of histone methylation by demethylimination and demethylation. Nat Rev Mol Cell Biol 8: 307-318, 2007.

169. Kontopoulos E, Parvin JD, Feany MB. Alpha-synuclein acts in the nucleus to inhibit histone acetylation and promote neurotoxicity. Hum Mol Genet 15: 3012-3023, 2006.

170. Korzus E, Rosenfeld MG, Mayford M. CBP histone acetyltransferase activity is a critical component of memory consolidation. Neuron 42: 961-972, 2004.

171. Koshibu K, Graff J, Beullens M, Heitz FD, Berchtold D, Russig H, Farinelli M, Bollen M, Mansuy IM. Protein phosphatase 1 regulates the histone code for long-term memory. J Neurosci 29: 13079-13089, 2009.

172. Kouzarides T. Chromatin modifications and their function. Cell 128: 693-705, 2007.

173. Kriaucionis S, Heintz N. The nuclear DNA base 5-hydroxymethylcytosine is present in Purkinje neurons and the brain. Science 324: 929-930, 2009.

174. Kular RK, Cvetanovic M, Siferd S, Kini AR, Opal P. Neuronal differentiation is regulated by leucine-rich acidic nuclear protein (LANP), a member of the inhibitor of histone acetyltransferase complex. J Biol Chem 284: 7783-7792, 2009.

175. Kumar A, Choi KH, Renthal W, Tsankova NM, Theobald DEH, Truong HT, Russo SJ, LaPlant Q, Sasaki TS, Whistler KN, Neve RL, Self DW, Nestler EJ. Chromatin remodeling is a key mechanism underlying cocaine-induced plasticity in striatum. Neuron 48: 303-314, 2005.

176. Kundakovic M, Chen Y, Guidotti A, Grayson DR. The reelin and GAD67 promoters are activated by epigenetic drugs that facilitate the disruption of local repressor complexes. Mol Pharmacol 75: 342-354, 2009.

177. Laird PW. The power and the promise of DNA methylation markers. Nature Rev Cancer 3: 253-266, 2003.

178. Langley B, D'Annibale MA, Suh K, Ayoub I, Tolhurst A, Bas$\tan$ B, Yang L, Ko B, Fisher M, Cho S, Beal MF, Ratan RR. Pulse inhibition of histone deacetylases induces complete resistance to oxidative death in cortical neurons without toxicity and reveals a role for cytoplasmic p21(waf1/cip1) in cell cycle-independent neuroprotection. J Neurosci 28: 163-176, 2008. 
179. LaPlant Q, Vialou V, Covington HE, 3rd Dumitriu D, Feng J, Warren BL, Maze I, Dietz DM, Watts EL, Iniguez SD, Koo JW, Mouzon E, Renthal W, Hollis F, Wang H, Noonan MA, Ren Y, Eisch AJ, Bolanos CA, Kabbaj M, Xiao G, Neve RL, Hurd YL, Oosting RS, Fan G, Morrison JH, Nestler EJ. Dnmt3a regulates emotional behavior and spine plasticity in the nucleus accumbens. Nat Neurosci 13: 1137-1143, 2010.

180. Larimore JL, Chapleau CA, Kudo S, Theibert A, Percy AK, Pozzo-Miller L. BDNF overexpression in hippocampal neurons prevents dendritic atrophy caused by Rett-associated MECP2 mutations. Neurobiol Dis 34: 199-211, 2009.

181. Latham JA, Dent SY. Cross-regulation of histone modifications. Nat Struct Mol Biol 14: 1017-1024, 2007.

182. Lattal KM, Barrett RM, Wood MA. Systemic or intrahippocampal delivery of histone deacetylase inhibitors facilitates fear extinction. Behav Neurosci 121: 1125-1131, 2007.

183. Lee MG, Wynder C, Bochar DA, Hakimi MA, Cooch N, Shiekhattar R. Functional interplay between histone demethylase and deacetylase enzymes. Mol Cell Biol 26: 6395-6402, 2006.

184. Lee MG, Wynder C, Schmidt DM, McCafferty DG, Shiekhattar R. Histone H3 lysine 4 demethylation is a target of nonselective antidepressive medications. Chem Biol 13: 563-567, 2006.

185. Leng Y, Chuang DM. Endogenous alpha-synuclein is induced by valproic acid through histone deacetylase inhibition and participates in neuroprotection against glutamate-induced excitotoxicity. J Neurosci 26: 7502-7512, 2006.

186. Leng Y, Liang MH, Ren M, Marinova Z, Leeds P, Chuang DM. Synergistic neuroprotective effects of lithium and valproic acid or other histone deacetylase inhibitors in neurons: roles of glycogen synthase kinase-3 inhibition. J Neurosci 28: 2576-2588, 2008.

187. Levenson JM, O'Riordan KJ, Brown KD, Trinh MA, Molfese DL, Sweatt JD. Regulation of histone acetylation during memory formation in the hippocampus. $J$ Biol Chem 279: 40545-40559, 2004.

188. Levenson JM, Roth TL, Lubin FD, Miller CA, Huang IC, Desai P, Malone LM, Sweatt JD. Evidence that DNA (cytosine-5) methyltransferase regulates synaptic plasticity in the hippocampus. $J$ Biol Chem 281: 15763-15773, 2006.

189. Levenson JM, Sweatt JD. Epigenetic mechanisms in memory formation. Nat Rev Neurosci 6: 108-118, 2005.

190. Levenson JM, Sweatt JD. Epigenetic mechanisms: a common theme in vertebrate and invertebrate memory formation. Cell Mol Life Sci 63: 1009-1016, 2006.

191. Levine AA, Guan Z, Barco A, Xu S, Kandel ER, Schwartz JH. CREB-binding protein controls response to cocaine by acetylating histones at the fosB promoter in the mouse striatum. Proc Natl Acad Sci USA 102: 19186-19191, 2005.

192. Li B, Carey M, Workman JL. The role of chromatin during transcription. Cell 128: 707-719, 2007.

193. Li E. Chromatin modification and epigenetic reprogramming in mammalian development. Nature Rev Genet 3: 662-673, 2002.

194. Li J, Guo Y, Schroeder FA, Youngs RM, Schmidt TW, Ferris C, Konradi C, Akbarian S. Dopamine D2-like antagonists induce chromatin remodeling in striatal neurons through cyclic AMP-protein kinase A and NMDA receptor signaling. $J$ Neurochem 90: 1117-1131, 2004.

195. Li L, Suzuki T, Mori N, Greengard P. Identification of a functional silencer element involved in neuron-specific expression of the synapsin I gene. Proc Natl Acad Sci USA 90: 1460-1464, 1993.

196. Li X, Barkho BZ, Luo Y, Smrt RD, Santistevan NJ, Liu C, Kuwabara T, Gage FH, Zhao X. Epigenetic regulation of the stem cell mitogen Fgf-2 by Mbd1 in adult neural stem/progenitor cells. $J$ Biol Chem 283: 27644-27652, 2008.

197. Lim DA, Huang YC, Swigut T, Mirick AL, Garcia-Verdugo JM, Wysocka J, Ernst P. and Alvarez-Buylla A. Chromatin remodelling factor Mll1 is essential for neurogenesis from postnatal neural stem cells. Nature 458: 529-533, 2009.

198. Liu A, Han YR, Li J, Sun D, Ouyang M, Plummer MR, CasacciaBonnefil P. The glial or neuronal fate choice of oligodendrocyte progenitors is modulated by their ability to acquire an epigenetic memory. J Neurosci 27: 7339-7343, 2007.

199. Liu D, Diorio J, Tannenbaum B, Caldji C, Francis D, Freedman A, Sharma S, Pearson D, Plotsky PM, Meaney MJ. Mater- nal care, hippocampal glucocorticoid receptors, and hypothalamicpituitary-adrenal responses to stress. Science 277: 1659-1662, 1997.

200. Liu DX, Nath N, Chellappan SP, Greene LA. Regulation of neuron survival and death by $\mathrm{p} 130$ and associated chromatin modifiers. Genes Dev 19: 719-732, 2005.

201. Lorente A, Mueller W, Urdangarin E, Lazcoz P, Lass U, von Deimling A, Castresana JS. RASSF1A, BLU, NORE1A, PTEN and MGMT expression and promoter methylation in gliomas and glioma cell lines and evidence of deregulated expression of de novo DNMTs. Brain Pathol 19: 279-292, 2009.

202. Louis DN. Molecular pathology of malignant gliomas. Annu Rev Pathol 1: 97-117, 2006.

203. Loury R, Sassone-Corsi P. Histone phosphorylation: how to proceed. Methods 31: 40-48, 2003.

204. Lu T, Pan Y, Kao SY, Li C, Kohane I, Chan J, Yankner BA. Gene regulation and DNA damage in the ageing human brain. Nature 429: 883-891, 2004.

205. Lubin FD, Roth TL, Sweatt JD. Epigenetic regulation of BDNF gene transcription in the consolidation of fear memory. J Neurosci 28: 10576-10586, 2008.

206. Lubin FD, Sweatt JD. The IkappaB kinase regulates chromatin structure during reconsolidation of conditioned fear memories. Neuron 55: 942-957, 2007.

207. Lucio-Eterovic AK, Cortez MA, Valera ET, Motta FJ, Queiroz RG, Machado HR, Carlotti CG Jr, Neder L, Scrideli CA, Tone LG. Differential expression of 12 histone deacetylase (HDAC) genes in astrocytomas and normal brain tissue: class II and IV are hypoexpressed in glioblastomas. BMC Cancer 8: 243, 2008.

208. Luger K, Mader AW, Richmond RK, Sargent DF, Richmond TJ. Crystal structure of the nucleosome core particle at $2.8 \mathrm{~A}$ resolution. Nature 389: 251-260, 1997.

209. Lunyak VV, Burgess R, Prefontaine GG, Nelson C, Sze SH, Chenoweth J, Schwartz P, Pevzner PA, Glass C, Mandel G, Rosenfeld MG. Corepressor-dependent silencing of chromosomal regions encoding neuronal genes. Science 298: 1747-1752, 2002.

210. Lupien SJ, McEwen BS, Gunnar MR, Heim C. Effects of stress throughout the lifespan on the brain, behaviour and cognition. Nat Rev Neurosci 10: 434-445, 2009.

211. Lutter M, Krishnan V, Russo SJ, Jung S, McClung CA, Nestler EJ. Orexin signaling mediates the antidepressant-like effect of calorie restriction. $J$ Neurosci 28: 3071-3075, 2008.

212. Lyssiotis CA, Walker J, Wu C, Kondo T, Schultz PG, Wu X. Inhibition of histone deacetylase activity induces developmental plasticity in oligodendrocyte precursor cells. Proc Natl Acad Sci USA 104: 14982-14987, 2007.

213. Ma DK, Jang MH, Guo JU, Kitabatake Y, Chang ML, PowAnpongkul N, Flavell RA, Lu B, Ming GL, Song H. Neuronal activity-induced Gadd45b promotes epigenetic DNA demethylation and adult neurogenesis. Science 323: 1074-1077, 2009.

214. Majdzadeh N, Wang L, Morrison BE, Bassel-Duby R, Olson EN, D'Mello SR. HDAC4 inhibits cell-cycle progression and protects neurons from cell death. Dev Neurobiol 68: 1076-1092, 2008.

215. Malvaez M, Sanchis-Segura C, Vo D, Lattal KM, Wood MA. Modulation of chromatin modification facilitates extinction of cocaine-induced conditioned place preference. Biol Psychiatry 67: $36-43,2010$.

216. Marambaud P, Wen PH, Dutt A, Shioi J, Takashima A, Siman R, Robakis NK. A CBP binding transcriptional repressor produced by the PS1/epsilon-cleavage of N-cadherin is inhibited by PS1 FAD mutations. Cell 114: 635-645, 2003.

217. Marin-Husstege M, Muggironi M, Liu A, Casaccia-Bonnefil P. Histone deacetylase activity is necessary for oligodendrocyte lineage progression. J Neurosci 22: 10333-10345, 2002.

218. Marinova Z, Ren M, Wendland JR, Leng Y, Liang MH, Yasuda S, Leeds P, Chuang DM. Valproic acid induces functional heatshock protein 70 via Class I histone deacetylase inhibition in cortical neurons: a potential role of Sp1 acetylation. J Neurochem 111: 976-987, 2009.

219. Marques Pereira P, Schneider A, Pannetier S, Heron D, Hanauer A. Coffin-Lowry syndrome. Eur J Hum Genet 18: 627633, 2010. 
220. Martinowich K, Hattori D, Wu H, Fouse S, He F, Hu Y, Fan G, Sun YE. DNA methylation-related chromatin remodeling in activity-dependent BDNF gene regulation. Science 302: 890-893, 2003.

221. Matijevic T, Knezevic J, Slavica M, Pavelic J. Rett syndrome: from the gene to the disease. Eur Neurol 61: 3-10, 2009.

222. Matzke MA, Birchler JA. RNAi-mediated pathways in the nucleus. Nat Rev Genet 6: 24-35, 2005.

223. Maue RA, Kraner SD, Goodman RH, Mandel G. Neuron-specific expression of the rat brain type II sodium channel gene is directed by upstream regulatory elements. Neuron 4: 223-231, 1990.

224. Maze I, Covington HE 3rd, Dietz DM, LaPlant Q, Renthal W, Russo SJ, Mechanic M, Mouzon E, Neve RL, Haggarty SJ, Ren Y, Sampath SC, Hurd YL, Greengard P, Tarakhovsky A, Schaefer A, Nestler EJ. Essential role of the histone methyltransferase G9a in cocaine-induced plasticity. Science 327: 213-216, 2010.

225. McCarthy MM, Auger AP, Bale TL, De Vries GJ, Dunn GA, Forger NG, Murray EK, Nugent BM, Schwarz JM, Wilson ME. The epigenetics of sex differences in the brain. J Neurosci 29: 12815-12823, 2009.

226. McClung CA, Nestler EJ. Regulation of gene expression and cocaine reward by CREB and DeltaFosB. Nat Neurosci 6: 1208$1215,2003$.

227. McClung CA, Ulery PG, Perrotti LI, Zachariou V, Berton O, Nestler EJ. DeltaFosB: a molecular switch for long-term adaptation in the brain. Brain Res 132: 146-154, 2004.

228. McGowan PO, Sasaki A, D'Alessio AC, Dymov S, Labonte B, Szyf M, Turecki G, Meaney MJ. Epigenetic regulation of the glucocorticoid receptor in human brain associates with childhood abuse. Nat Neurosci 12: 342-348, 2009.

229. Meaney MJ. Maternal care, gene expression, and the transmission of individual differences in stress reactivity across generations. Annu Rev Neurosci 24: 1161-1192, 2001.

230. Mehedint MG, Niculescu MD, Craciunescu CN, Zeisel SH. Choline deficiency alters global histone methylation and epigenetic marking at the Re1 site of the calbindin 1 gene. FASEB $J 2009$.

231. Meisel A, Harms C, Yildirim F, Bosel J, Kronenberg G, Harms U, Fink KB, Endres M. Inhibition of histone deacetylation protects wild-type but not gelsolin-deficient neurons from oxygen/ glucose deprivation. J Neurochem 98: 1019-1031, 2006.

232. Melnikov AA, Gartenhaus RB, Levenson AS, Motchoulskaia NA, Levenson VV. MSRE-PCR for analysis of gene-specific DNA methylation. Nucleic Acids Res 33: E93, 2005.

233. Merienne K, Jacquot S, Pannetier S, Zeniou M, Bankier A, Gecz J, Mandel JL, Mulley J, Sassone-Corsi P, Hanauer A. A missense mutation in RPS6KA3 (RSK2) responsible for non-specific mental retardation. Nat Genet 22: 13-14, 1999.

234. Metivier R, Gallais R, Tiffoche C, Le Peron C, Jurkowska RZ, Carmouche RP, Ibberson D, Barath P, Demay F, Reid G, Benes V, Jeltsch A, Gannon F, Salbert G. Cyclical DNA methylation of a transcriptionally active promoter. Nature 452 : 45-50, 2008.

235. Miller CA, Campbell SL, Sweatt JD. DNA methylation and histone acetylation work in concert to regulate memory formation and synaptic plasticity. Neurobiol Learn Mem 89: 599-603, 2008.

236. Miller CA, Gavin CF, White JA, Parrish RR, Honasoge A, Yancey CR, Rivera IM, Rubio MD, Rumbaugh G, Sweatt JD. Cortical DNA methylation maintains remote memory. Nat Neurosci 13: 664-666, 2010.

237. Miller CA, Sweatt JD. Covalent modification of DNA regulates memory formation. Neuron 53: 857-869, 2007.

238. Moonat S, Starkman BG, Sakharkar A, Pandey SC. Neuroscience of alcoholism: molecular and cellular mechanisms. Cell Mol Life Sci 60: 73-88, 2010.

239. Moore DJ, West AB, Dawson VL, Dawson TM. Molecular pathophysiology of Parkinson's disease. Annu Rev Neurosci 28: 57-87, 2005.

240. Moore T, Haig D. Genomic imprinting in mammalian development: a parental tug-of-war. Trends Genet 7: 45-49, 1991.

241. Mori N, Schoenherr C, Vandenbergh DJ, Anderson DJ. A common silencer element in the SCG10 and type II $\mathrm{Na}^{+}$channel genes binds a factor present in nonneuronal cells but not in neuronal cells. Neuron 9: 45-54, 1992.
242. Morris RG, Garrud P, Rawlins JN, O'Keefe J. Place navigation impaired in rats with hippocampal lesions. Nature 297: 681-683, 1982.

243. Morrison BE, Majdzadeh N, Zhang X, Lyles A, Bassel-Duby R, Olson EN, D'Mello SR. Neuroprotection by histone deacetylaserelated protein. Mol Cell Biol 26: 3550-3564, 2006.

244. Mueller BR, Bale TL. Sex-specific programming of offspring emotionality after stress early in pregnancy. J Neurosci 28: 9055-9065, 2008.

245. Murgatroyd C, Patchev AV, Wu Y, Micale V, Bockmuhl Y, Fischer D, Holsboer F, Wotjak CT, Almeida OF, Spengler D. Dynamic DNA methylation programs persistent adverse effects of early-life stress. Nat Neurosci 12: 1559-1566, 2009.

246. Nader K. Memory traces unbound. Trends Neurosci 26: 65-72, 2003.

247. Nader K, Hardt O. A single standard for memory: the case for reconsolidation. Nat Rev Neurosci 10: 224-234, 2009.

248. Nagarajan RP, Costello JF. Epigenetic mechanisms in glioblastoma multiforme. Semin Cancer Biol 19: 188-197, 2009.

249. Naidu S, Kaufmann WE, Abrams MT, Pearlson GD, Lanham DC, Fredericksen KA, Barker PB, Horska A, Golay X, Mori S, Wong DF, Yablonski M, Moser HW, Johnston MV. Neuroimaging studies in Rett syndrome. Brain Dev 23 Suppl 1: S62-S71, 2001.

250. Namihira M, Kohyama J, Abematsu M, Nakashima K. Epigenetic mechanisms regulating fate specification of neural stem cells. Philos Trans R Soc Lond B Biol Sci 363: 2099-2109, 2008.

251. Naruse Y, Aoki T, Kojima T, Mori N. Neural restrictive silencer factor recruits $\mathrm{mSin} 3$ and histone deacetylase complex to repress neuron-specific target genes. Proc Natl Acad Sci USA 96: 1369113696, 1999.

252. Nathan D, Ingvarsdottir K, Sterner DE, Bylebyl GR, Dokmanovic M, Dorsey LA, Whelan KA, Krsmanovic M, Lane WS, Meluh PB, Johnson ES, Berger SL. Histone sumoylation is a negative regulator in Saccharomyces cerevisiae and shows dynamic interplay with positive-acting histone modifications. Genes Dev 20: 966-976, 2006.

253. Nelson ED, Kavalali ET, Monteggia LM. Activity-dependent suppression of miniature neurotransmission through the regulation of DNA methylation. $J$ Neurosci 28: 395-406, 2008.

254. Nott A, Watson PM, Robinson JD, Crepaldi L, Riccio A. $S$ nitrosylation of histone deacetylase 2 induces chromatin remodelling in neurons. Nature 455: 411-415, 2008.

255. Nucifora FC Jr, Sasaki M, Peters MF, Huang H, Cooper JK, Yamada M, Takahashi H, Tsuji S, Troncoso J, Dawson VL, Dawson TM, Ross CA. Interference by huntingtin and atrophin-1 with cbp-mediated transcription leading to cellular toxicity. Science 291: 2423-2428, 2001.

256. Oberlander TF, Weinberg J, Papsdorf M, Grunau R, Misri S, Devlin AM. Prenatal exposure to maternal depression, neonatal methylation of human glucocorticoid receptor gene (NR3C1) and infant cortisol stress responses. Epigenetics 3: 97-106, 2008.

257. Ohgaki H, Kleihues P. Population-based studies on incidence, survival rates, and genetic alterations in astrocytic and oligodendroglial gliomas. J Neuropathol Exp Neurol 64: 479-489, 2005.

258. Oike Y, Hata A, Mamiya T, Kaname T, Noda Y, Suzuki M, Yasue H, Nabeshima T, Araki K, Yamamura K. Truncated CBP protein leads to classical Rubinstein-Taybi syndrome phenotypes in mice: implications for a dominant-negative mechanism. Hum Mol Genet 8: 387-396, 1999.

259. Oliveira AMM, Wood MA, McDonough CB. Transgenic mice expressing an inhibitory truncated form of p300 exhibit long-term memory deficits. Learn Mem 14: 564-572, 2007.

260. Outeiro TF, Kontopoulos E, Altmann SM, Kufareva I, Strathearn KE, Amore AM, Volk CB, Maxwell MM, Rochet JC, McLean PJ, Young AB, Abagyan R, Feany MB, Hyman BT, Kazantsev AG. Sirtuin 2 inhibitors rescue alpha-synuclein-mediated toxicity in models of Parkinson's disease. Science 317: 516519, 2007.

261. Pandey SC, Ugale R, Zhang H, Tang L, Prakash A. Brain chromatin remodeling: a novel mechanism of alcoholism. J Neurosci 28: 3729-3737, 2008. 
262. Pandolfo M, Pastore A. The pathogenesis of Friedreich ataxia and the structure and function of frataxin. J Neurol 256 Suppl 1: 9-17, 2009.

263. Panteleeva I, Rouaux C, Larmet Y, Boutillier S, Loeffler JP, Boutillier AL. HDAC-3 participates in the repression of e2f-dependent gene transcription in primary differentiated neurons. Ann NY Acad Sci 1030: 656-660, 2004.

264. Paquette AJ, Perez SE, Anderson DJ. Constitutive expression of the neuron-restrictive silencer factor (NRSF)/REST in differentiating neurons disrupts neuronal gene expression and causes axon pathfinding errors in vivo. Proc Natl Acad Sci USA 97: 1231812323, 2000.

265. Park SW, He Y, Ha SG, Loh HH, Wei LN. Epigenetic regulation of kappa opioid receptor gene in neuronal differentiation. Neuroscience 151: 1034-1041, 2008.

266. Parsons DW, Jones S, Zhang X, Lin JC, Leary RJ, Angenendt P, Mankoo P, Carter H, Siu IM, Gallia GL, Olivi A, McLendon R, Rasheed BA, Keir S, Nikolskaya T, Nikolsky Y, Busam DA, Tekleab H, Diaz LA Jr, Hartigan J, Smith DR, Strausberg RL, Marie SK, Shinjo SM, Yan H, Riggins GJ, Bigner DD, Karchin R, Papadopoulos N, Parmigiani G, Vogelstein B, Velculescu VE, Kinzler KW. An integrated genomic analysis of human glioblastoma multiforme. Science 321: 1807-1812, 2008.

267. Pascual M, Boix J, Felipo V, Guerri C. Repeated alcohol administration during adolescence causes changes in the mesolimbic dopaminergic and glutamatergic systems and promotes alcohol intake in the adult rat. $J$ Neurochem 108: 920-931, 2009.

268. Peleg S, Sananbenesi F, Zovoilis A, Burkhardt S, BahariJavan S, Agis-Balboa RC, Cota P, Wittnam JL, Gogol-Doering A, Opitz L, Salinas-Riester G, Dettenhofer M, Kang H, Farinelli L, Chen W, Fischer A. Altered histone acetylation is associated with age-dependent memory impairment in mice. Science 328: 753-756, 2010.

269. Penner MR, Roth TL, Barnes CA, Sweatt JD. An epigenetic hypothesis of aging-related cognitive dysfunction. Front Aging Neurosci 2: 9, 2010

270. Penner MR, Roth TL, Chawla MK, Hoang LT, Roth ED, Lubin FD, Sweatt JD, Worley PF, Barnes CA. Age-related changes in Arc transcription and DNA methylation within the hippocampus. Neurobiol Aging. In press.

271. Peters AH, Schubeler D. Methylation of histones: playing memory with DNA. Curr Opin Cell Biol 17: 230-238, 2005.

272. Petrij F, Giles RH, Dauwerse HG, Saris JJ, Hennekam RC, Masuno M, Tommerup N, van Ommen GJ, Goodman RH, Peters DJ, Breuning MH. Rubinstein-Taybi syndrome caused by mutations in the transcriptional co-activator CBP. Nature 376: 348-351, 1995

273. Pittenger C, Kandel ER. In search of general mechanisms for long-lasting plasticity: Aplysia and the hippocampus. Philos Trans $R$ Soc Lond B Biol Sci 358: 757-763, 2003.

274. Poulter MO, Du L, Weaver IC, Palkovits M, Faludi G, Merali Z, Szyf M, Anisman H. GABA A receptor promoter hypermethylation in suicide brain: implications for the involvement of epigenetic processes. Biol Psychiatry 64: 645-652, 2008.

275. Pusarla RH, Bhargava P. Histones in functional diversification. Core histone variants. FEBS J 272: 5149-5168, 2005.

276. Putignano E, Lonetti G, Cancedda L, Ratto G, Costa M, Maffei L, Pizzorusso T. Developmental downregulation of histone posttranslational modifications regulates visual cortical plasticity. Neuron 53: 747-759, 2007.

277. Qi X, Hosoi T, Okuma Y, Kaneko M, Nomura Y. Sodium 4-phenylbutyrate protects against cerebral ischemic injury. Mol Pharmacol 66: 899-908, 2004

278. Rai M, Soragni E, Jenssen K, Burnett R, Herman D, Coppola G, Geschwind DH, Gottesfeld JM, Pandolfo M. HDAC inhibitors correct frataxin deficiency in a Friedreich ataxia mouse model. PLoS One 3: e1958, 2008.

279. Ramsahoye BH, Biniszkiewicz D, Lyko F, Clark V, Bird AP, Jaenisch R. Non-CpG methylation is prevalent in embryonic stem cells and may be mediated by DNA methyltransferase 3a. Proc Natl Acad Sci USA 97: 5237-5242, 2000.

280. Regier DA, Narrow WE, Rae DS, Manderscheid RW, Locke BZ, Goodwin FK. The de facto US mental and addictive disorders service system. Epidemiologic catchment area prospective 1-year prevalence rates of disorders and services. Arch Gen Psychiatry 50: 85-94, 1993.

281. Reik W, Walter J. Genomic imprinting: parental influence on the genome. Nat Rev Genet 2: 21-32, 2001.

282. Ren M, Leng Y, Jeong M, Leeds PR, Chuang DM. Valproic acid reduces brain damage induced by transient focal cerebral ischemia in rats: potential roles of histone deacetylase inhibition and heat shock protein induction. J Neurochem 89: 1358-1367, 2004.

283. Renthal W, Carle TL, Maze I, Covington HE 3rd, Truong HT, Alibhai I, Kumar A, Montgomery RL, Olson EN, Nestler EJ. Delta FosB mediates epigenetic desensitization of the c-fos gene after chronic amphetamine exposure. J Neurosci 28: 7344-7349, 2008.

284. Renthal W, Kumar A, Xiao G, Wilkinson M, Covington HE 3rd, Maze I, Sikder D, Robison AJ, LaPlant Q, Dietz DM, Russo SJ, Vialou V, Chakravarty S, Kodadek TJ, Stack A, Kabbaj M, Nestler EJ. Genome-wide analysis of chromatin regulation by cocaine reveals a role for sirtuins. Neuron 62: 335-348, 2009.

285. Renthal W, Maze I, Krishnan V, Covington HE 3rd, Xiao G, Kumar A, Russo SJ, Graham A, Tsankova N, Kippin TE, Kerstetter KA, Neve RL, Haggarty SJ, McKinsey TA, Bassel-Duby R, Olson EN, Nestler EJ. Histone deacetylase 5 epigenetically controls behavioral adaptations to chronic emotional stimuli. Neuron 56: 517-529, 2007.

286. Reul JM, Hesketh SA, Collins A, Mecinas MG. Epigenetic mechanisms in the dentate gyrus act as a molecular switch in hippocampus-associated memory formation. Epigenetics 4: 434439, 2009.

287. Ricobaraza A, Cuadrado-Tejedor M, Perez-Mediavilla A, Frechilla D, Del Rio J, Garcia-Osta A. Phenylbutyrate ameliorates cognitive deficit and reduces tau pathology in an Alzheimer's disease mouse model. Neuropsychopharmacology 34: 1721-1732, 2009.

288. Rivieccio MA, Brochier C, Willis DE, Walker BA, D'Annibale MA, McLaughlin K, Siddiq A, Kozikowski AP, Jaffrey SR, Twiss JL, Ratan RR, Langley B. HDAC6 is a target for protection and regeneration following injury in the nervous system. Proc Natl Acad Sci USA 106: 19599-19604, 2009.

289. Robertson KD, Wolffe AP. DNA methylation in health and disease. Nat Rev Genet 1: 11-19, 2000.

290. Roopra A, Sharling L, Wood IC, Briggs T, Bachfischer U, Paquette AJ, Buckley NJ. Transcriptional repression by neuronrestrictive silencer factor is mediated via the Sin3-histone deacetylase complex. Mol Cell Biol 20: 2147-2157, 2000.

291. Rosenfeld MG, Lunyak VV, Glass CK. Sensors and signals: a coactivator/corepressor/epigenetic code for integrating signal-dependent programs of transcriptional response. Genes Dev 20: 14051428, 2006

292. Roth TL, Lubin FD, Funk AJ, Sweatt JD. Lasting epigenetic influence of early-life adversity on the BDNF gene. Biol Psychiatry 65: 760-769, 2009.

293. Rouaux C, Jokic N, Mbebi C, Boutillier S, Loeffler JP, Boutillier AL. Critical loss of CBP/p300 histone acetylase activity by caspase-6 during neurodegeneration. EMBO J 22: 6537-6549, 2003.

294. Rouaux C, Panteleeva I, Rene F, Gonzalez de Aguilar JL, Echaniz-Laguna A, Dupuis L, Menger Y, Boutillier AL, Loeffler JP. Sodium valproate exerts neuroprotective effects in vivo through CREB-binding protein-dependent mechanisms but does not improve survival in an amyotrophic lateral sclerosis mouse model. J Neurosci 27: 5535-5545, 2007.

295. Russo VEA, Martienssen RA, Riggs AD. (Editors). Epigenetic Mechanisms of Gene Regulation. Cold Spring Harbor, NY: Cold Spring Harbor Laboratory Press, 1996.

296. Sadri-Vakili G, Bouzou B, Benn CL, Kim MO, Chawla P, Overland RP, Glajch KE, Xia E, Qiu Z, Hersch SM, Clark TW, Yohrling GJ, Cha JH. Histones associated with downregulated genes are hypo-acetylated in Huntington's disease models. Hum Mol Genet 16: 1293-1306, 2007.

297. Salminen A, Tapiola T, Korhonen P, Suuronen T. Neuronal apoptosis induced by histone deacetylase inhibitors. Brain Res 61 : 203-206, 1998. 
298. Sanchis-Segura C, Lopez-Atalaya JP, Barco A. Selective boosting of transcriptional and behavioral responses to drugs of abuse by histone deacetylase inhibition. Neuropsychopharmacology 34 : 2642-2654, 2009.

299. Saura CA, Choi SY, Beglopoulos V, Malkani S, Zhang D, Shankaranarayana Rao BS, Chattarji S, Kelleher RJ 3rd, Kandel ER, Duff K, Kirkwood A, Shen J. Loss of presenilin function causes impairments of memory and synaptic plasticity followed by age-dependent neurodegeneration. Neuron 42: 23-36, 2004.

300. Scarpa S, Fuso A, D'Anselmi F, Cavallaro RA. Presenilin 1 gene silencing by $S$-adenosylmethionine: a treatment for Alzheimer disease? FEBS Lett 541: 145-148, 2003.

301. Schaefer A, Sampath SC, Intrator A, Min A, Gertler TS, Surmeier DJ, Tarakhovsky A, Greengard P. Control of cognition and adaptive behavior by the GLP/G9a epigenetic suppressor complex. Neuron 64: 678-691, 2009.

302. Schroeder FA, Lin CL, Crusio WE, Akbarian S. Antidepressantlike effects of the histone deacetylase inhibitor, sodium butyrate, in the mouse. Biol Psychiatry 62: 55-64, 2007.

303. Schwartzbaum JA, Fisher JL, Aldape KD, Wrensch M. Epidemiology and molecular pathology of glioma. Nat Clin Pract Neurol 2: 494-503, 2006.

304. Seckl JR. Glucocorticoids, developmental "programming" and the risk of affective dysfunction. Prog Brain Res 167: 17-34, 2008.

305. Seckl JR, Meaney MJ. Glucocorticoid "programming” and PTSD risk. Ann NY Acad Sci 1071: 351-378, 2006.

306. Sener RN. Rubinstein-Taybi syndrome: cranial MR imaging findings. Comput Med Imaging Graph 19: 417-418, 1995.

307. Shahbazian M, Young J, Yuva-Paylor L, Spencer C, Antalffy B, Noebels J, Armstrong D, Paylor R, Zoghbi H. Mice with truncated MeCP2 recapitulate many Rett syndrome features and display hyperacetylation of histone H3. Neuron 35: 243-254, 2002.

308. Sharma RP, Grayson DR, Gavin DP. Histone deactylase 1 expression is increased in the prefrontal cortex of schizophrenia subjects: analysis of the National Brain Databank microarray collection. Schizophr Res 98: 111-117, 2008.

309. Shen S, Li J, Casaccia-Bonnefil P. Histone modifications affect timing of oligodendrocyte progenitor differentiation in the developing rat brain. J Cell Biol 169: 577-589, 2005.

310. Shen S, Liu A, Li J, Wolubah C, Casaccia-Bonnefil P. Epigenetic memory loss in aging oligodendrocytes in the corpus callosum. Neurobiol Aging 29: 452-463, 2008.

311. Shiio Y, Eisenman RN. Histone sumoylation is associated with transcriptional repression. Proc Natl Acad Sci USA 100: 1322513230, 2003

312. Shilatifard A. Chromatin modifications by methylation and ubiquitination: implications in the regulation of gene expression. Annu Rev Biochem 75: 243-269, 2006.

313. Shimizu T, Kagawa T, Wada T, Muroyama Y, Takada S, Ikenaka K. Wnt signaling controls the timing of oligodendrocyte development in the spinal cord. Dev Biol 282: 397-410, 2005.

314. Siebzehnrubl FA, Buslei R, Eyupoglu IY, Seufert S, Hahnen E, Blumcke I. Histone deacetylase inhibitors increase neuronal differentiation in adult forebrain precursor cells. Exp Brain Res 176: 672-678, 2007

315. Sikorska M, Sandhu JK, Deb-Rinker P, Jezierski A, Leblanc J, Charlebois C, Ribecco-Lutkiewicz M, Bani-Yaghoub $\mathbf{M}$ Walker PR. Epigenetic modifications of SOX2 enhancers, SRR1 and SRR2, correlate with in vitro neural differentiation. $J$ Neurosci Res 86: 1680-1693, 2008.

316. Sinn DI, Kim SJ, Chu K, Jung KH, Lee ST, Song EC, Kim JM, Park DK, Kun Lee S, Kim M, Roh JK. Valproic acid-mediated neuroprotection in intracerebral hemorrhage via histone deacetylase inhibition and transcriptional activation. Neurobiol Dis 26: 464-472, 2007.

317. Slack JM. Conrad Hal Waddington: the last Renaissance biologist? Nat Rev Genet 3: 889-895, 2002.

318. Smart RD, Eaves-Egenes J, Barkho BZ, Santistevan NJ, Zhao C, Aimone JB, Gage FH, Zhao X. Mecp2 deficiency leads to delayed maturation and altered gene expression in hippocampal neurons. Neurobiol Dis 27: 77-89, 2007.

319. Soloaga A, Thomson S, Wiggin GR, Rampersaud N, Dyson MH, Hazzalin CA, Mahadevan LC, Arthur JS. MSK2 and MSK1 me- diate the mitogen- and stress-induced phosphorylation of histone H3 and HMG-14. EMBO J 22: 2788-2797, 2003.

320. Stack EC, Del Signore SJ, Luthi-Carter R, Soh BY, Goldstein DR, Matson S, Goodrich S, Markey AL, Cormier K, Hagerty SW, Smith K, Ryu H, Ferrante RJ. Modulation of nucleosome dynamics in Huntington's disease. Hum Mol Genet 16: 1164-1175, 2007.

321. Stefanko DP, Barrett RM, Ly AR, Reolon GK, Wood MA. Modulation of long-term memory for object recognition via HDAC inhibition. Proc Natl Acad Sci USA 106: 9447-9452, 2009.

322. Steffan JS, Bodai L, Pallos J, Poelman M, McCampbell A, Apostol BL, Kazantsev A, Schmidt E, Zhu YZ, Greenwald M, Kurokawa R, Housman DE, Jackson GR, Marsh JL, Thompson LM. Histone deacetylase inhibitors arrest polyglutamine-dependent neurodegeneration in Drosophila. Nature 413: 739-743, 2001.

323. Steffan JS, Kazantsev A, Spasic-Boskovic O, Greenwald M, Zhu YZ, Gohler H, Wanker EE, Bates GP, Housman DE, Thompson LM. The Huntington's disease protein interacts with p53 and CREB-binding protein and represses transcription. Proc Natl Acad Sci USA 97: 6763-6768, 2000.

324. Sun Y, Nadal-Vicens M, Misono S, Lin MZ, Zubiaga A, Hua X, Fan G, Greenberg ME. Neurogenin promotes neurogenesis and inhibits glial differentiation by independent mechanisms. Cell 104: 365-376, 2001.

325. Suzuki MM, Bird A. DNA methylation landscapes: provocative insights from epigenomics. Nat Rev Genet 9: 465-476, 2008.

326. Swank MW, Sweatt JD. Increased histone acetyltransferase and lysine acetyltransferase activity and biphasic activation of the ERK/ RSK cascade in insular cortex during novel taste learning. $J \mathrm{Neu}$ rosci 21: 3383-3391, 2001.

327. Sweatt JD. Experience-dependent epigenetic modifications in the central nervous system. Biol Psychiatry 65: 191-197, 2009.

328. Sweatt JD. The neuronal MAP kinase cascade: a biochemical signal integration system subserving synaptic plasticity and memory. J Neurochem 76: 1-10, 2001.

329. Szyf M. The early life environment and the epigenome. Biochim Biophys Acta 1790: 878-885, 2009.

330. Tabolacci E, Moscato U, Zalfa F, Bagni C, Chiurazzi P, Neri G. Epigenetic analysis reveals a euchromatic configuration in the FMR1 unmethylated full mutations. Eur J Hum Genet 16: 14871498, 2008.

331. Tabolacci E, Pietrobono R, Moscato U, Oostra BA, Chiurazzi P, Neri G. Differential epigenetic modifications in the FMR1 gene of the fragile $\mathrm{X}$ syndrome after reactivating pharmacological treatments. Eur J Hum Genet 13: 641-648, 2005.

332. Takizawa T, Nakashima K, Namihira M, Ochiai W, Uemura A, Yanagisawa M, Fujita N, Nakao M, Taga T. DNA methylation is a critical cell-intrinsic determinant of astrocyte differentiation in the fetal brain. Dev Cell 1: 749-758, 2001.

333. Talbert PB, Henikoff S. Histone variants: ancient wrap artists of the epigenome. Nat Rev Mol Cell Biol 11: 264-275.

334. Taplick J, Kurtev V, Kroboth K, Posch M, Lechner T, Seiser C. Homo-oligomerisation and nuclear localisation of mouse histone deacetylase 1. J Mol Biol 308: 27-38, 2001.

335. Taverna SD, Li H, Ruthenburg AJ, Allis CD, Patel DJ. How chromatin-binding modules interpret histone modifications: lessons from professional pocket pickers. Nat Struct Mol Biol 14: 1025-1040, 2007

336. Temple S. The development of neural stem cells. Nature 414 112-117, 2001

337. Thomas EA, Coppola G, Desplats PA, Tang B, Soragni E, Burnett R, Gao F, Fitzgerald KM, Borok JF, Herman D, Geschwind DH, Gottesfeld JM. The HDAC inhibitor $4 \mathrm{~b}$ ameliorates the disease phenotype and transcriptional abnormalities in Huntington's disease transgenic mice. Proc Natl Acad Sci USA 105: 15564-15569, 2008.

338. Tremolizzo L, Carboni G, Ruzicka WB, Mitchell CP, Sugaya I, Tueting P, Sharma R, Grayson DR, Costa E, Guidotti A. An epigenetic mouse model for molecular and behavioral neuropathologies related to schizophrenia vulnerability. Proc Natl Acad Sci USA 99: 17095-17100, 2002. 
339. Tsankova N, Renthal W, Kumar A, Nestler EJ. Epigenetic regulation in psychiatric disorders. Nature Rev Neurosci 8: 355$367,2007$.

340. Tsankova NM, Berton O, Renthal W, Kumar A, Neve RL, Nestler EJ. Sustained hippocampal chromatin regulation in a mouse model of depression and antidepressant action. Nature Neurosci 9: 519-525, 2006.

341. Tsankova NM, Kumar A, Nestler EJ. Histone modifications at gene promoter regions in rat hippocampus after acute and chronic electroconvulsive seizures. J Neurosci 24: 5603-5610, 2004.

342. Turner BM. Cellular memory and the histone code. Cell 111: 285-291, 2002.

343. Turner BM. Defining an epigenetic code. Nat Cell Biol 9: 2-6, 2007.

344. Turner BM. Memorable transcription. Nat Cell Biol 5: 390-393, 2003.

345. Tweedie-Cullen RY, Reck JM, Mansuy IM. Comprehensive mapping of post-translational modifications on synaptic, nuclear, histone proteins in the adult mouse brain. J Proteome Res 8: 49664982, 2009

346. Urdinguio RG, Lopez-Serra L, Lopez-Nieva P, Alaminos M, Diaz-Uriarte R, Fernandez AF, Esteller M. Mecp2-null mice provide new neuronal targets for Rett syndrome. PLOS ONE 3: e3669, 2008

347. Van Vliet J, Oates NA, Whitelaw E. Epigenetic mechanisms in the context of complex diseases. Cell Mol Life Sci 64: 1531-1538, 2007.

348. Vecsey CG, Hawk JD, Lattal KM, Stein JM, Fabian SA, Attner MA, Cabrera SM, McDonough CB, Brindle PK, Abel T, Wood MA. Histone deacetylase inhibitors enhance memory and synaptic plasticity via CREB:CBP-dependent transcriptional activation. $J$ Neurosci 27: 6128-6140, 2007.

349. Veldic M, Guidotti A, Maloku E, Davis JM, Costa E. In psychosis, cortical interneurons overexpress DNA-methyltransferase 1. Proc Natl Acad Sci USA 102: 2152-2157, 2005.

350. Waddington CH. Canalization of development and the inheritance of acquired characters. Nature 150: 563-565, 1942.

351. Waddington CH. Organisers and Genes. Cambridge, UK: Cambridge Univ. Press, 1940.

352. Waddington CH. The Strategy of the Genes. London: Geo Allen \& Unwin, 1957.

353. Wang L, Lv Z, Hu Z, Sheng J, Hui B, Sun J, Ma L. Chronic cocaine-induced $\mathrm{H} 3$ acetylation and transcriptional activation of CaMKIIalpha in the nucleus accumbens is critical for motivation for drug reinforcement. Neuropsychopharmacology 35: 913-928, 2010.

354. Wang SC, Oelze B, Schumacher A. Age-specific epigenetic drift in late-onset Alzheimer's disease. PLoS ONE 3: e2698, 2008.

355. Wang $\mathbf{Y}$, Wang $\mathbf{X}$, Liu L. HDAC inhibitor trichostatin A-inhibited survival of dopaminergic neuronal cells. Neurosci Lett 467: 212 216, 2009.

356. Wang Z, Zang C, Cui K, Schones DE, Barski A, Peng W, Zhao K. Genome-wide mapping of HATs and HDACs reveals distinct functions in active and inactive genes. Cell 138: 1019-1031, 2009.

357. Weake VM, Workman JL. Histone ubiquitination: triggering gene activity. Mol Cell 29: 653-663, 2008.

358. Weaver IC, D'Alessio AC, Brown SE, Hellstrom IC, Dymov S, Sharma S, Szyf M, Meaney MJ. The transcription factor nerve growth factor-inducible protein a mediates epigenetic program- ming: altering epigenetic marks by immediate-early genes. $\mathrm{J} \mathrm{Neu}$ rosci 27: 1756-1768, 2007.

359. Weaver IC, Meaney MJ, Szyf M. Maternal care effects on the hippocampal transcriptome and anxiety-mediated behaviors in the offspring that are reversible in adulthood. Proc Natl Acad Sci USA 103: 3480-3485, 2006.

360. Weaver ICG, Cervoni N, Champagne FA, D'Alessio AC, Sharma S, Seckl JR, Dymov S, Szyf M, Meaney MJ. Epigenetic programming by maternal behavior. Nature Neurosci 7: 847-854, 2004.

361. Weaver ICG, Champagne FA, Brown SE, Dymov S, Sharma S, Meaney MJ, Szyf M. Reversal of maternal programming of stress responses in adult offspring through methyl supplementation: altering epigenetic marking later in life. J Neurosci 25: 11045-11054, 2005.

362. Weber M, Hellmann I, Stadler MB, Ramos L, Paabo S, Rebhan M, Schubeler D. Distribution, silencing potential and evolutionary impact of promoter DNA methylation in the human genome. Nat Genet 39: 457-466, 2007.

363. Whitlock JR, Heynen AJ, Shuler MG, Bear MF. Learning induces long-term potentiation in the hippocampus. Science 313: 1093-1097, 2006

364. Wilkinson LS, Davies W, Isles AR. Genomic imprinting effects on brain development and function. Nat Rev Neurosci 8: 832-843, 2007.

365. Wood MA, Kaplan MP, Park A, Blanchard EJ, Oliveira AM, Lombardi TL, Abel T. Transgenic mice expressing a truncated form of CREB-binding protein (CBP) exhibit deficits in hippocampal synaptic plasticity and memory storage. Learn Mem 12: 111119, 2005.

366. Wu J, Basha MR, Brock B, Cox DP, Cardozo-Pelaez F, McPherson CA, Harry J, Rice DC, Maloney B, Chen D, Lahiri DK, Zawia NH. Alzheimer's disease (AD)-like pathology in aged monkeys after infantile exposure to environmental metal lead $(\mathrm{Pb})$ : evidence for a developmental origin and environmental link for $\mathrm{AD}$. J Neurosci 28: 3-9, 2008.

367. Ye F, Chen Y, Hoang T, Montgomery RL, Zhao XH, Bu H, Hu T, Taketo MM, van Es JH, Clevers H, Hsieh J, Bassel-Duby R, Olson EN, Lu QR. HDAC1 and HDAC2 regulate oligodendrocyte differentiation by disrupting the beta-catenin-TCF interaction. Nat Neurosci 12: 829-838, 2009.

368. Yeh SH, Lin CH, Gean PW. Acetylation of nuclear factor-kappa B in rat amygdala improves long-term but not short-term retention of fear memory. Mol Pharmacol 65: 1286-1292, 2004.

369. Zhao X, Ueba T, Christie BR, Barkho B, McConnell MJ, Nakashima K, Lein ES, Eadie BD, Willhoite AR, Muotri AR, Summers RG, Chun J, Lee KF, Gage FH. Mice lacking methyl$\mathrm{CpG}$ binding protein 1 have deficits in adult neurogenesis and hippocampal function. Proc Natl Acad Sci USA 100: 6777-6782, 2003.

370. Zhao Z, Fan L, Frick KM. Epigenetic alterations regulate estradiol-induced enhancement of memory consolidation. Proc Natl Acad Sci USA 107: 5605-5610, 2010.

371. Zhou Z, Hong EJ, Cohen S, Zhao WN, Ho HY, Schmidt L, Chen WG, Lin Y, Savner E, Griffith EC, Hu L, Steen JA, Weitz CJ, Greenberg ME. Brain-specific phosphorylation of MeCP2 regulates activity-dependent Bdnf transcription, dendritic growth, and spine maturation. Neuron 52: 255-269, 2006.

372. Zhu JK. Active DNA demethylation mediated by DNA glycosylases. Annu Rev Genet 43: 143-166, 2009. 